Paulino José Soares de Souza Jr.

Análise cladística da família Marginellidae (Mollusca, Gastropoda) baseada em morfologia comparada.

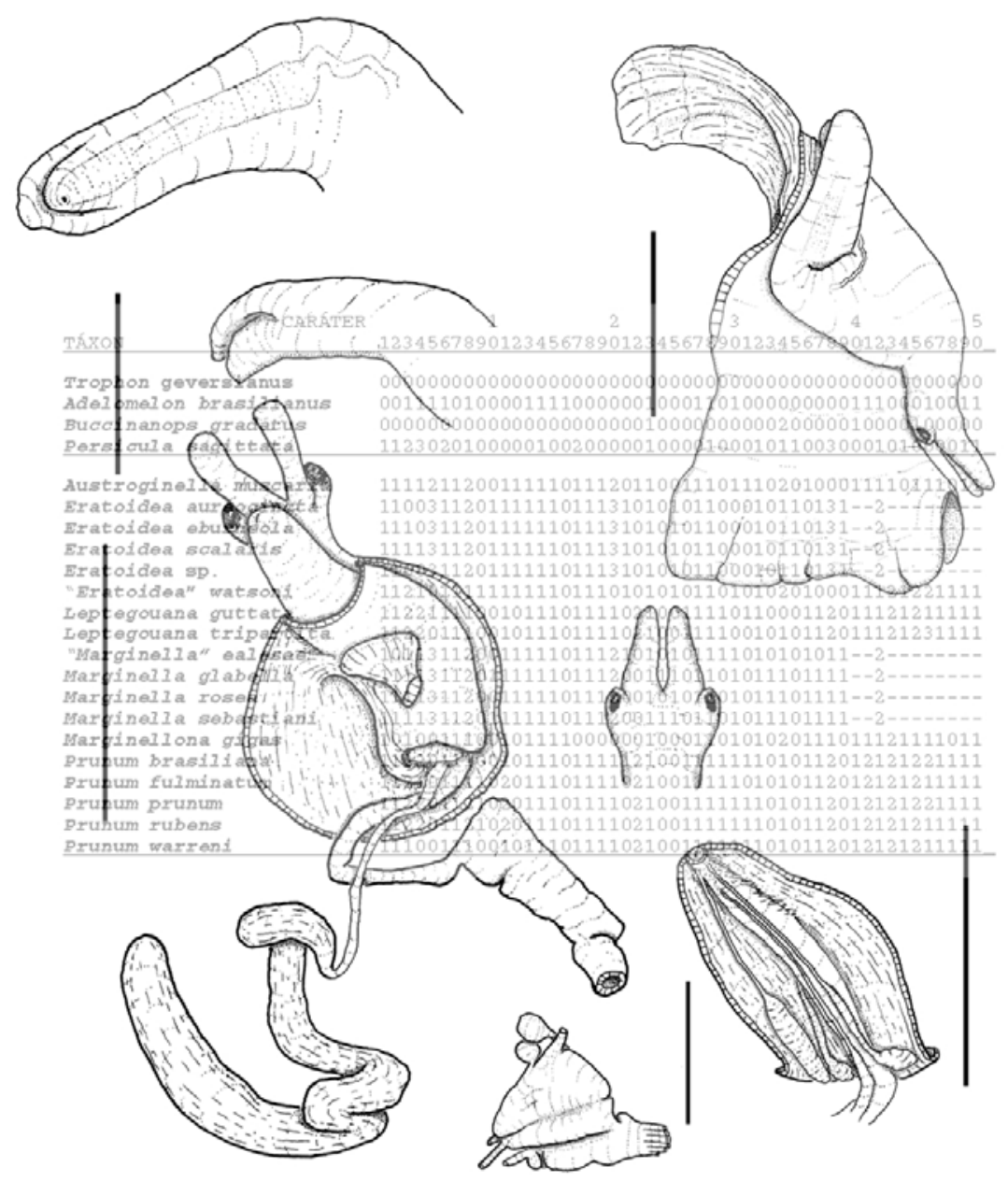

São Paulo 
Paulino José Soares de Souza Jr.

\section{Análise cladística da família Marginellidae (Mollusca, Gastropoda) baseada em morfologia comparada.}

Tese apresentada ao Instituto de Biociências da Universidade de São Paulo, para a obtenção de Título de Doutor em Ciências, na Área de Zoologia.

Orientador(a): Luiz R. L. de Simone

São Paulo 


\section{Ficha Catalográfica}

Souza, Paulino José Soares, Jr.

Análise cladística da família Marginellidae

(Mollusca, Gastropoda) baseada em morfologia comparada

$$
\mathrm{x}+129 \mathrm{pp} \text {. }
$$

Tese (Doutorado) - Instituto de Biociências da Universidade de São Paulo. Departamento de Zoologia.

1. Palavra- Mollusca 2. Análise cladística 3. Anatomia I. Universidade de São Paulo. Instituto de Biociências. Departamento de Zoologia.

\section{Comissão Julgadora:}


Dedico esta tese à memória do meu tio, Almirante José Gerardo Theófilo Albano de Aratanha, que me iniciou no mundo dos moluscos. 
"Da natureza, existe em nossas mentes, um desejo insaciável de conhecer a verdade"

Cícero, Tusculanarum Disputationum:1.2.44 


\section{Sumário}

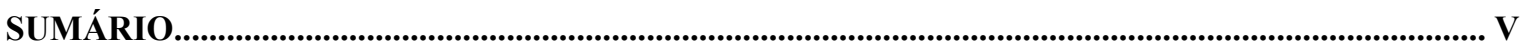

AGRADECIMENTOS ....................................................................................................................

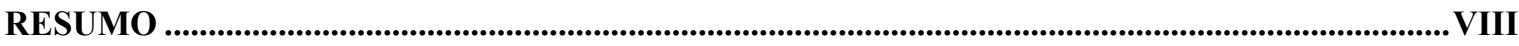

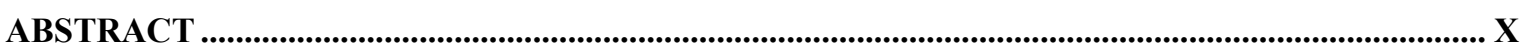

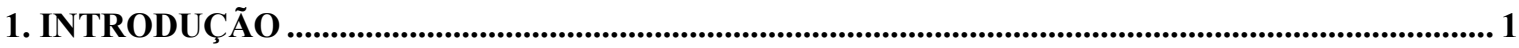

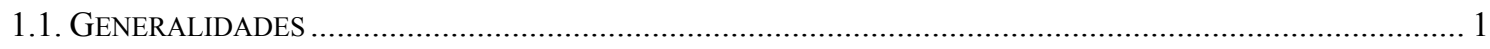

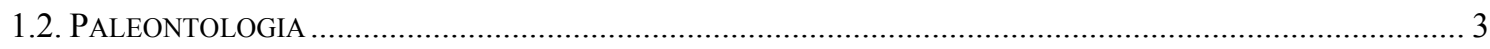

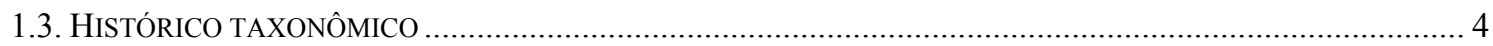

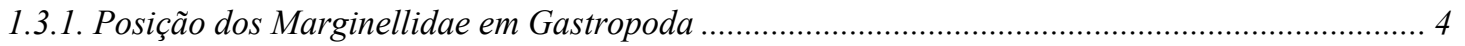

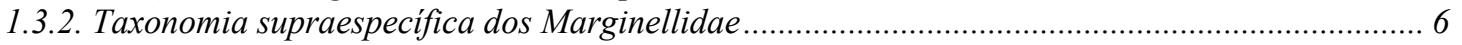

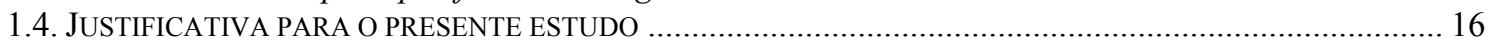

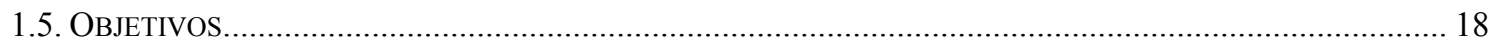

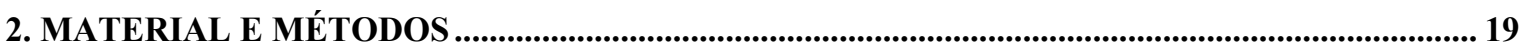

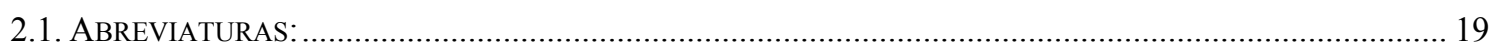

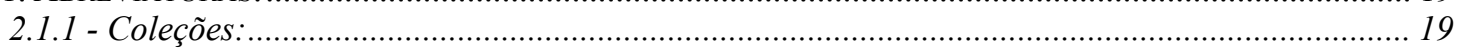

2.1.2 - Anatomia:

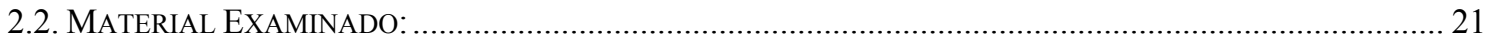

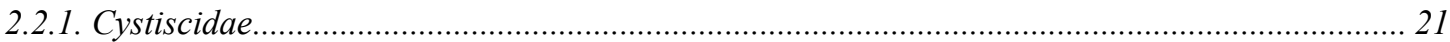

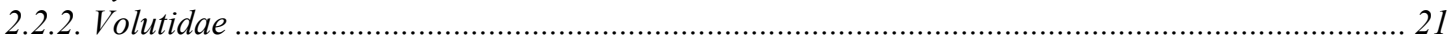

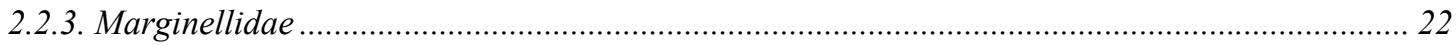

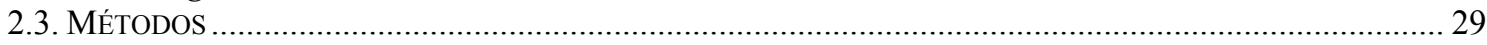

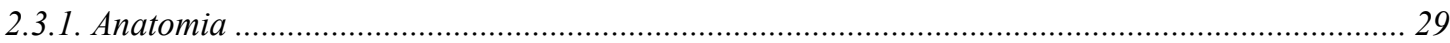

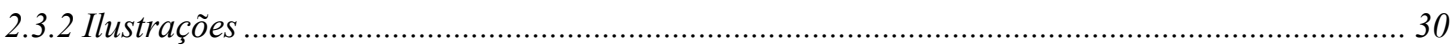

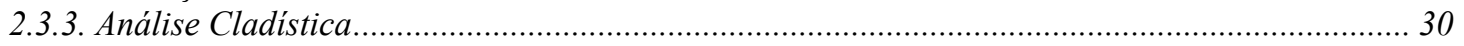

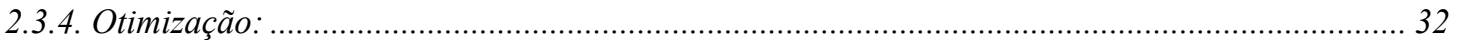

2.3.5. Programas de computador auxiliares na análise cladística: .................................................... 32

3. RESULTADOS ...................................................................................................................................... 33

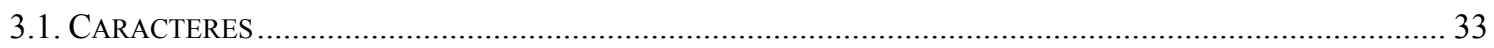

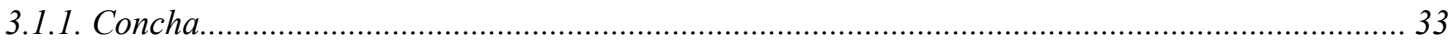

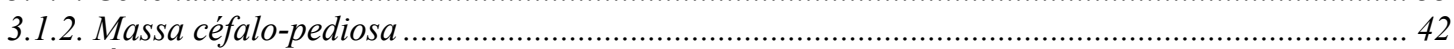

3.1.3. Órgãos do manto e sistemas circulatório e excretor............................................................ 48

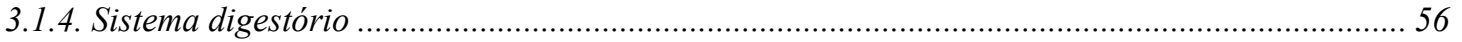

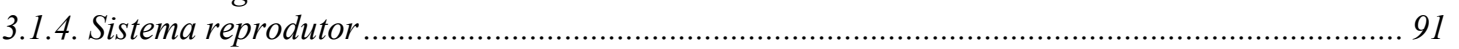

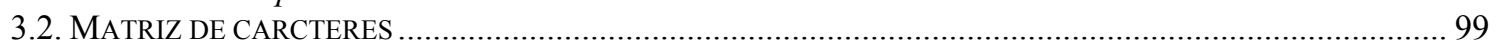

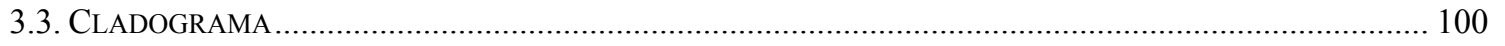

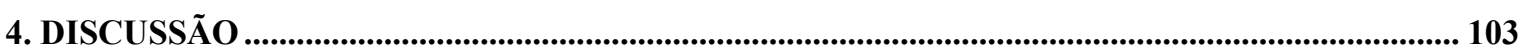

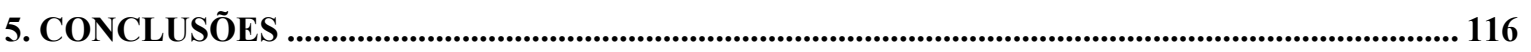

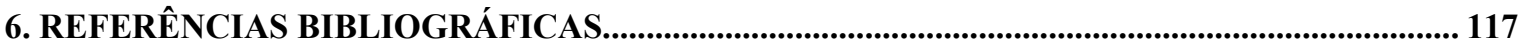




\section{Agradecimentos}

Meu caminho até a conclusão desta tese foi longo, e não teria chegado ao fim dele não fora o auxílio de meus orientadores: Dr. Nélson Papavero, que aceitou me orientar no início do projeto; Prof. Dr. Mario C. C. de Pinna, por ter dado a chance de reiniciar o caminho, quando eu não acreditava mais que ainda era possível; e Prof. Dr. Luiz Ricardo L. Simone, que além de ter me ensinado tudo que sei sobre anatomia de moluscos, sempre me brindou com sua amizade e apoio, e cuja obstinação e zelo científicos, só posso aspirar. Também, gostaria de agradecer ao Dr. José Luiz de Moreira Leme, por me receber na Seção de Malacologia do Museu de Zoologia da USP.

Sou muito grato ao Dr. Gary A. Coovert e à sua esposa Holly K. Coovert, por me receberam pra uma agradabilíssima e produtiva estada em sua residência e por me cederam, além de várias cópias de artigos consultados, originais de toda a série Marginella Marginallia.

Às bibliotecárias do MZUSP, Teresa Beatriz Nunes Guimarães, Cláudia Alves de Melo, Janete da Rocha, Carmina Lupo, meus por todo auxílio bibliográfico, sempre prestado com boa vontade e simpatia, tão raras nos dias de hoje. E um agradecimento muito especial à Dione Seripierri, pela minuciosa revisão da lista bibliográfica.

Minha longa estada em São Paulo teria sido muito mais solitária sem meus amigos e colegas do MZUSP, em especial Carlo Magenta da Cunha (que também me conseguiu lotes de Eratoidea scalaris), Cibele Bragagnolo, Gilson Iak Ximenes, Carlos Augusto Figueiredo e Flávio C. C. de Lima. Devo um agradecimento especial a Cristiano Moreira que sempre me auxiliou com meus minhas dúvidas em relação aos softwares de análise filogenética, mesmo quando seu próprio tempo era escasso. Ao amigo e co-fundador do CML Eric P. Gonçalves, sou profundamente grato por participar em, praticamente, todos 
os aspectos desta tese, até o último minuto! Agradeço, especialmente, ao meu amigo Antônio Cornetta (Black Hawk Computers), não só pela companhia como também pela consultoria em assuntos de informática.

A José Coltro, minha sincera gratidão, por facilitar minha na coleta de material no sul da Bahia, onde coletei os exemplares de Prunum fulminatum e por ter cedido o tão precioso lote de Marginellona gigas estudado aqui, um espécime raro que ajudou muito nas conclusões desta tese.

Aos curadores que cederam a maior parte dos espécimes aqui estudados: Dr. Miroslaw G. Harasewych (Smithsonian Museum), Dr. Winston Ponder e Sr. Ian Locke, (Australian Museum), Dra. Nancy Voss (Marine Laboratory, Rosenstiel School of Marine and Atmospheric Sciences, University of Miami), Dr. Ricardo Silva Absalão (Instituto de Biologia da Universidade Federal do Rio de Janeiro), Dr. Boris Sirenko (Instituto Zoológico da Academia Russa de Ciência).

A Fundação de Amparo à Pesquisa do Estado de São Paulo, pelo apoio material e financeiro, sem o qual essa tese não seria possível.

E finalmente à família que fez tudo, pelo que passei, valer a pena. À minha esposa Luciana Botelho, à minha filha do coração Catarina Botelho Catta Preta, à minha mãe Maria Luiza da Justa Soares de Souza, meu pai Paulino José Soares de Souza e minha irmã, Luciana da Justa de Faria. A todos, sou muito grato, pois nunca faltou apoio e nas horas mais difíceis sempre recebi mais do que se pode pedir a qualquer um. 


\section{Resumo}

Neste trabalho se realiza uma análise cladística da família Marginellidae. Para tanto foram estudadas 18 espécies, pertencentes a família, e quatro, pertencentes a superfamília Muricoidea, como grupo externo. Através da dissecção e análise morfológica comparativa, foram levantados 93 caracteres, sendo 12 coquiliológicos e 81 da morfologia das partes moles

A análise da matriz resultou em 4 árvores igualmente parcimoniosas (237 passos, IC: 0,55, IR: 0,79). Foi feita, então, uma análise de ponderação sucessiva na qual foram obtidas 3 árvores igualmente parcimoniosas (982 passos, IC: 0,75, IR: 0,9), o consenso estrito destas foi utilizado nas discussões.

A patir desta árvore conclui-se que:

Marginellidae é um grupo monofilético distinto de Cystiscidae, que tem uma posição mais basal dentro dos Muricoidea, mas com muitos caracteres homoplásticos em relação à Marginellidae.

Volutidae é o grupo irmão de Marginellidae.

Austroginellini foi definido por COOVERT \& COOVERT (1995) a partir de uma plesiomorfia interna, sugerindo que não é uma grupo monofilético.

A perda da válvula de Leiblein ocorreu independentemente em Prunini e Marginellini.

Prunini forma um grupo monofilético definido pelo ceco esofágico e por diversas modificações coquiliológicas e anatômicas decorrentes da lateralização;

Prunum forma um grupo monofilético definido pela fusão posterior da cartilagem odontofórica. 
Leptegouana forma um grupo monofilético definido pelo encurtamento do m8 e redução da cavidade renal.

Marginellini forma um grupo monofilético definido pelas perdas do odontóforo e do tubo oral.

Marginella forma um gênero monofilético diagnosticável pela abertura da glândula de Leiblein logo a frente do anel nervoso, válvula de Leiblein vestigial e pela probóscide muito musculosa.

Eratoidea forma um gênero monofilético diagnosticável pelas seguintes características: sifão anal delgado; pênis com papila ejaculatória; abertura da glândula de Leiblein próxima a boca; e glândulas salivares tubulares localizadas dentro da probóscide. 


\section{Abstract}

In the present study a cladistic analysis of the family Marginellidae is carried out. A sample consiting of 18 marginellid species and 4 muricoideans, as out group, was examined. Dissection and comparative morphological analysis of this sample rendered 93 characters, 12 conchological characters and 81 derived from the soft parts morphology.

The matrix analysis resulted in four equally parsimonious trees (237 steps, IC: 0,55, IR: 0,79). A successive weighting analysis was then carried out that resulted in three equally parsimonious trees (982 steps, IC: 0,75 , IR: 0,9), and their strict consesus was chosen for the discussions.

From the resulting three we conclude that:

Marginellidae is a monophyletic group suported by 17 syanpomorphies.

Cystiscidae is distinct from Marginellidae, but share many homoplastic characters with it.

Volutidae is sister group to Marginellidae.

Autroginellini as defined by COOVERT \& COOVERT (1995) is supported by a in-group plesiomorphy, suggesting it is not a monophyletic grouping.

The loss of the valve of Leiblein occurred independently in Prunini and Marginellini.

Prunini is a is a monophyletic group defined by the esophageal pouch, and several anatomical and conchological modifications that occurred due to the lateralization of the animal.

Prunum is a monophyletic group defined by the posterior fusion of the odontophoric cartilage. 
Leptegouana is a monophyletic group defined by the shortening of $\mathrm{m} 8$ and renal cavity.

Marginellini is a monophyletic group defined by the loss of the odontophore and the oral tube.

Marginella is a monophyletic genus diagnosed by the opening of the gland of Leiblein right infront the nerve ring, by the vestigial valve of Leiblein, and but the muscular proboscis.

Eratoidea is a is a monophyletic genus diagnosed by the elongated anal siphon, by the presence of an ejaculatory papilla on the penis, by the opening of the gland of Leiblein close to the mouth, and by tubular salivary glands located inside the proboscis. 


\section{Introdução}

\subsection{Generalidades}

A família Marginellidae é composta por gastrópodes de pequeno a médio porte (3 $\mathrm{mm}$ - $150 \mathrm{~mm}$ de comprimento da concha) que habitam, preferencialmente, os mares tropicais e temperados do todo o mundo, sendo também conhecidas duas espécies antárticas ["Marginella” ealesae Powell, 1958 e M. hyalina Thiele, 1912 (DELL, 1990)] e duas dulciaquícolas [Rivomarginella eletrum (Reeve, 1865) e R. morrisoni Brandt, 1968], do sudeste asiático. A maioria das espécies observadas está associada ao sedimento no entorno de rochas, recifes coralinos e bancos de algas calcárias (FRETTER, 1976; COOVERT, 1987; GOFAS \& FERNANDES, 1988, 1992, 1994; GOFAS, 1989; observação pessoal). Batimetricamente, a maioria das espécies vive nas zonas médiolitoral e sublitoral, mas são conhecidas algumas espécies na região batial (e.g., Volvarina pontesi Rios \& Leal, 1993; V. hennequini Boyer, 2000). Os poucos registros para a região abissal são de conchas mortas (CLARKE, 1962).

$\mathrm{Na}$ maioria das espécies observadas, o hábito alimentar é carnívoro, como em grande parte dos Muricoidea (sensu PONDER, 1973), apresentando uma variedade de relações tróficas. Foram observados representantes predadores [Leptegouana guttata (Dillwyn, 1817): poliquetos; P. labiatum (Kiener, 1841): bivalves; Bullata lilacina (Sowerby, 1846): microgastrópodes (observação pessoal); Austorginella johnstoni (Petterd, 1884) e A. muscaria (Lamarck, 1822): bivalves (PONDER \& TAYLOR, 1992); Rivomarginella electrum (Reeve, 1865): oligoquetas], necrófagos [Volvarina taeniolata Mörch, 1860: crustáceos mortos in vitro (FRETTER,1976)] e parasitos [Hydroginella caledonica (Jousseaume, 1877): peixes (BOUCHET, 1989)]. Há um único registro de herbivoria, in vitro, para Prunum apicinum (Menke, 1828) (BAUGH, 1990), que também foi observado como predador (D’ASARO, 1970, RAEIHLE, 1965) e necrófago (WINNER, 1983). 
Os marginelídeos, como a maioria dos Caenogastropoda, são dióicos e dotados de órgãos para cópula (Fig. 1, 2, 3, 4). Os ovos ficam encerrados dentro de cápsulas rígidas e bentônicas (Fig. 6), em algumas espécies de Marginella estas cápsulas são fixadas em algas, pedras, conchas de moluscos etc. (GOFAS \& FERNANDES, 1988), aparentemente, por uma glândula aderente presente na parte anterior ventral do pé das fêmeas COOVERT (1986c) (Fig. 5). O desenvolvimento a partir desses ovos, observado em quatro gêneros, é direto (COOVERT, 1986c) e PENCHASZADEH \& RINCON (1996) observaram a total supressão do estágio larvar véliger em Prunum prunum (Gmelin, 1791).
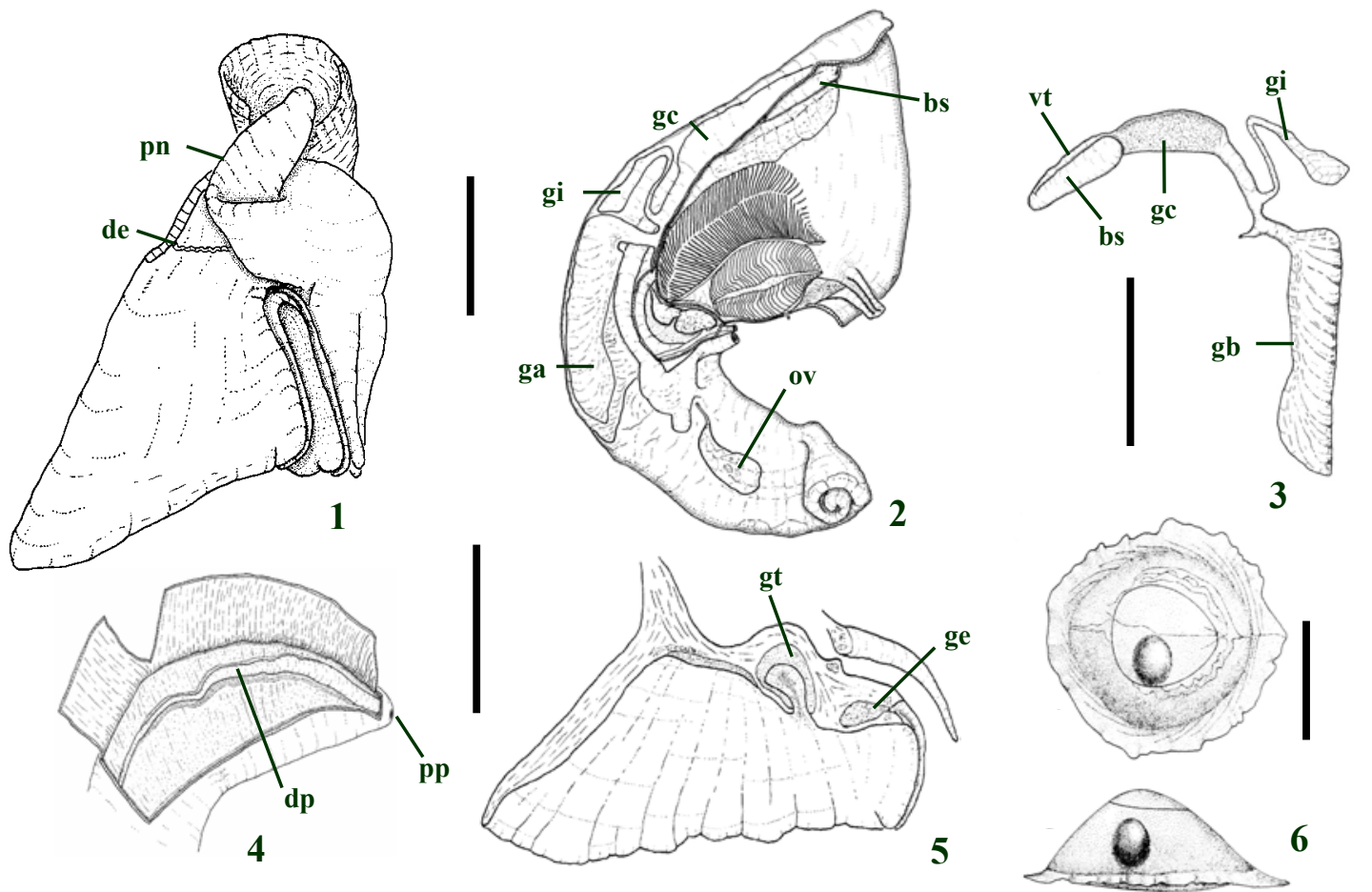

Figura 1 - 5. Aspectos Reprodutivos dos Marginellidae. 1- Massa céfalo-pediosa de um macho de Eratoidea watsoni (Dall, 1927); 2- Massa pálio-visceral de E. watsoni; 3- oviduto palial, vista dorsal;4- Detalhe do pênis de E. watsoni com parede ventral aberta, mostrando duto peniano; 5- Corte longitudinal do pé de uma fêmea de E. watsoni, mostrando glândula aderente; 5- Cápsula ovígera de Prunum prunum (modificado de PENCHASZADEH \& RINCON, 1996). bc - bursa copulatrix; dp - duto peniano; ed - espermoduto; ga - glândula de albúmen; ge - glândula pediosa; gi glândula ingestória ; gp - glândula da cápsula; gt - glândula aderente; oo - ovário; pf- poro genital feminino pm - poro genital masculino. Barra de escala: $2 \mathrm{~mm}$. [dá uma aumentada nos números das figs.]

Atualmente, são conhecidas 555 espécies nominais recentes de Marginellidae, distribuídas em 21 gêneros (COOVERT \& COOVERT, 1995; ZOOLOGICAL RECORDS, 1995 - 2006). 


\subsection{Paleontologia}

No registro fóssil, TRACEY et al. (1993) citam a ocorrência dos Marginellidae no Paleoceno inferior (Daniano 65 - 61 m.a.), baseando-se em Gibberula sp., mas esse gênero atualmente está classificado dentro da família Cystiscidae. A ocorrência da família no Cretáceo (Maestrichtiano, Cretáceo superior 70- 64.9 m.a.) está baseada em Myobarbum laevigatum Sohl, 1963, que foi originalmente descrito na família Volutidae e realocado em Marginellidae por PONDER (1973), mas que difere bastante do demais Marginellidae em sua estrutura columelar.

Espécies fósseis, que, inequivocamente, pertencem à família Marginellidae, aparecem no Eoceno médio (Figs. 7-10), revelando-se um grupo muito diversificado, presente em diversas bacias do mundo (e.g. COSSMANN, 1899: Paris, EAMES, 1952: Paquistão, LASERON, 1957: Austrália). Certas espécies paleogênicas apresentam-se bastante distintas das formas neogênicas (e.g. Euryentome Cossmann 1899 e Stazzania sensu COSSMANN, 1899), sendo caracterizadas por ter uma grande variação da estrutura pilar. Outras espécies apresentam grande semelhança conquiliológica com espécies recentes, tendo sido alocadas em gêneros recentes (e.g., Volvarina Hinds, 1844, Marginella Lamarck, 1799). Adicionalmente, gêneros baseados em espécies paleogênicas foram utilizados para espécies recentes (e.g. Dentimargo Cossmann, 1899: ROTH, 1973). Há ainda espécies que, por apresentarem características conquiliológicas intermediárias, dificilmente podem ser alocar dentro de quaisquer grupos.

A partir do Mioceno (Figs. 11-14), encontramos registro fóssil da maioria dos gêneros recentes (e.g., MAURY, 1925: América do Sul, DALL 1892: América do Norte; COTTON, 1949: Austrália; SACCO, 1890: Europa). 

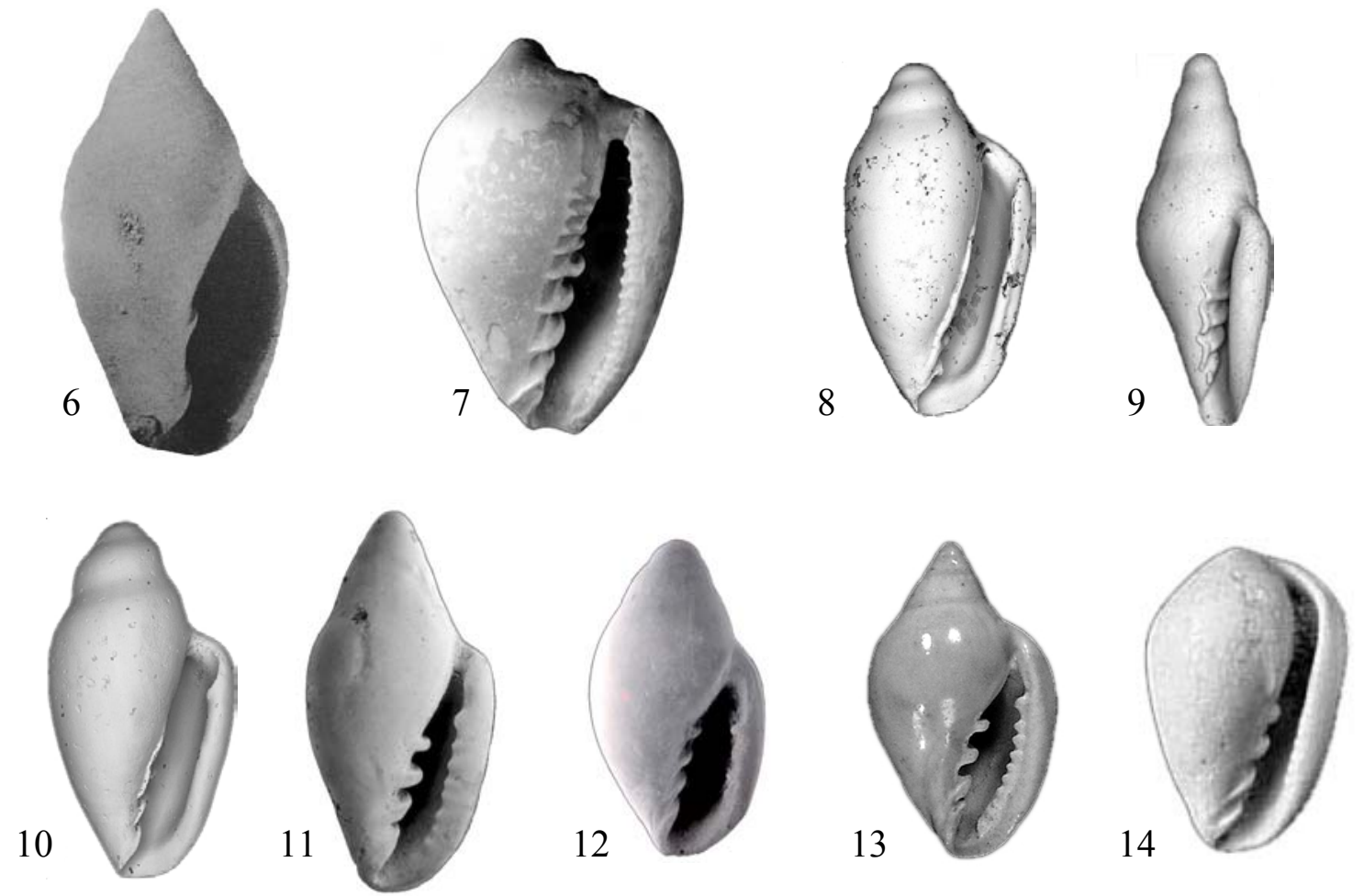

Figuras 6-14. Registro fóssil de Marginellidae 6- Myobarbum laevigatum, comprimento 18,5 mm, Cretáceo superior, EUA ; 7- Euryentome anatina (I. Lea, 1833), comprimento 7,8 mm, Eoceno médio, EUA; 8- Stazzania canaliculata Le Renard \& van Nieulande, 1985, comprimento 4,9 mm, Eoceno superior, França; 9- Stazzania stenostoma angulata Le Renard \& van Nieulande, 1985, comprimento 4.7mm, Eoceno superior, França; 10- Stazzania vandenbergae van Nieulande, 1981, comprimento $5.3 \mathrm{~mm}$, Eoceno médio, França; 11- Eratoidea sp. 1, comprimento $5.6 \mathrm{~mm}$, Oligoceno, EUA; 12- Eratoidea sp.2, comprimento $3.8 \mathrm{~mm}$, Mioceno superior, EUA; 13Eratoidea vadosa (Gardner, 1938), comprimento 4,9 mm, Mioceno médio, EUA; 14- Prunum apicinum (Menke, 1828), comprimento 10,5 mm, Plioceno, EUA.

\subsection{Histórico taxonômico}

\subsubsection{Posição dos Marginellidae em Gastropoda}

A relação dos Marginellidae com as demais famílias dos gastrópodes prosobrânquios nunca foi alvo de estudos aprofundados. Durante os séculos XVIII e XIX muito se especulou sobre a classificação dos Gastropoda, mas os Marginellidae sempre estiveram associados aos Volutidae, ora como gênero ou subfamília (e.g., LAMARK, 
1799; SWAINSON, 1840), ora como família próxima (e.g. FLEMING, 1828; HINDS, 1844).

THIELE (1929-1931) propôs uma classificação que foi utilizada pelos autores durante a maior parte do século XX. Segundo esta, os Marginellidae pertenciam à Ordem Stenoglossa (= Neogastropoda Wenz, 1938), superfamília (stirp) Volutoidea (Volutacea sic.).

PONDER (1973), baseando-se em caracteres anatômicos e radulares, propôs uma classificação para os Neogastropoda (= Stenoglossa sensu Thiele), dividindo a ordem em três superfamílias: Conoidea, Cancellarioidea e Muricoidea. Nessa classificação, adotada no presente estudo, os Marginellidae foram incluídos dentro dos Muricoidea. O autor também afirma, com base em algumas características anatômicas, que os Marginellidae teriam um ancestral comum com os Volutomitridae. Essa posição foi seguida pela classificação de VAUGHT (1988) e o estudo de KANTOR (1996).

RIEDEL (2000) utilizou-se de dados moleculares para fazer uma análise cladística dos Caenogastropoda "superiores". Para tal, ele utilizou duas bases (18S mtDNA e 16s rDNA), que foram analisadas separadamente e, posteriormente, reunidas numa árvore de consenso. Essa árvore gerou uma topologia bastante heterodoxa para os Marginellidae, que ficaram próximos à base do grupo estudado e separados dos demais Neogastropoda. No entanto, no mesmo trabalho, o autor também propõe um filograma intuitivo, baseado em dados morfológicos, no qual os Neogastropoda aparecem como um grupo monofilético divididos em 4 grupos (Buccinina, Turrina, Volutina , Muricina). Já dentro de Volutina, Marginellidae aparece como grupo irmão de Volutidae.

Outros estudos filogenéticos modernos, que utilizaram dados morfológicos e/ou moleculares (e.g., PONDER \& LINDBERG, 1996; HARASEWYCH et al., 1997), não incluíram Marginellidae entre os espécimes estudados. 


\subsubsection{Taxonomia supraespecífica dos Marginellidae}

A taxonomia supraespecífica interna dos Marginellidae tem sido motivo de discussões por quase 200 anos. Durante a maior parte desse tempo, o gênero Marginella foi utilizado para agrupar a maior parte das espécies, enquanto algumas outras foram distribuídas em subfamílias, gêneros e subgêneros, cuja definição, quando feita, utilizava caracteres conquiliológicos como base. A seguir são listadas, em ordem cronológica, os trabalhos mais importantes da história taxonômica interna dos Marginellidae.

LINNÉ (1758) descreveu as primeiras espécies de Marginellidae ainda no gênero Voluta Linnaeus, 1758 (gênero tipo da família Volutidae Rafinesque, 1815). As descrições são imprecisas, o que dificultou algumas identificações posteriores.

LAMARCK (1799) criou o gênero Marginella na família Volutidae, considerando Marginella glabella (Linnaeus, 1758) como seu único representante, sendo esta a espécietipo do gênero, por monotipia.

SCHUMACHER (1817) utilizou Marginella e criou os gêneros Persicula e Hyalina, utilizando características da espira para defini-los.

FLEMING (1828) retirou o gênero Marginella da família Volutidae e criou a família Marginellidae, sem, no entanto, ter dado descrição ou diagnose.

KIENER (1834, 1841), em sua iconografia, arranjou as espécies de marginelídeos em quatro grupos morfológicos, baseando-se na escultura e forma da concha, sem, no entanto, propor qualquer status taxonômico para eles e utilizando apenas o gênero Marginella.

SWAINSON (1840), no Treatise on Malacology, considerou Marginellidae como uma subfamília de Volutidae e a dividiu em cinco gêneros: Marginella, Persicola 
(Persicula redigido errado), Volutella, Gibberula e Glabella, sendo os últimos três de sua autoria.

HINDS (1844) propôs a divisão da família nas seções Phaenospira e Cryptospira, de sua autoria, e descreveu Volvarina como um subgênero de Phaenospira. Em inúmeros trabalhos de autores posteriores, Cryptospira e Volvarina foram considerados como gênero ou subgênero de Marginella, enquanto que Phaenospira foi citado como sinônimo.

SOWERBY (1846) considerou todas as espécies, que revisou e descreveu nesse trabalho, como pertencentes ao gênero Marginella, ignorando por completo todos os outros gêneros já descritos.

GRAY (1847) estabeleceu as espécies-tipo para todos os gêneros publicados de Marginellidae, a qual ele ainda considerava como subfamília de Volutidae. Nesse trabalho, admitiu três gêneros válidos: Porcellana Adanson, $1757^{1}$, Hyalina e Persicula.

PETIT (1851) propôs três grupos morfológicos dentro de Marginellidae, mas não nomeou nenhum deles e referiu todas as espécies estudadas a Marginella.

GRAY (1857) criou a subfamília Porcellaninae dentro de Volutidae e considerou válidos os gêneros Porcellana, Persicula. Ele descreveu ainda Closia e seu subgênero Rabicea.

ADAMS \& ADAMS (1858) organizaram a família com os gêneros e subgêneros Erato Risso, 1826; Marginella: Marginella s.s., Glabella, Prunum Herrmannsen, 1852, Volutella e Cryptospira; Persicula: Persicula s.s. e Gibberula; Pachybathron Gaskoin, 1853; Volvaria Lamarck, $1801^{2}$.

\footnotetext{
${ }^{1}$ De acordo com o Artigo 3 do Código Internacional de Nomenclatura Zoologica (ICNZ, 1999) este gênero não pode ser considerado válido, pois foi criado antes de 1758, mas é válido como Porcellana Gray, 1847.

${ }^{2}$ Volvaria Lamarck, 1801, espécie-tipo por monotipia, Volvaria bulloides Lamarck, 1801, é um opistobrânquio fóssil do Eoceno da Bacia de Paris, que foi por muitas vezes mal utilizado para abrigar alguns marginelídeos segundo LAMARCK, 1822: 362-364.
} 
STIMPSON (1865) descreveu Cystiscus e criou a família Cystiscidae.

REDFIELD (1870) listou as espécies conhecidas (fósseis e recentes) de Marginellidae e considerou válidos os gêneros Erato, Marginella e Volvaria.

JOUSSEAUME (1875) descreveu os seguintes gêneros: Egouena, Serrata, Granula, Bullata, Balanetta e Canalispira; e ainda considerou Marginella, Volvarina, Cryptospira, Gibberula, Persicula, Volvaria e Erato.

WEINKAUFF (1879) revisou as espécies utilizando apenas Marginella. No entanto, no apêndice, propôs o esboço de uma nova classificação, na qual descreveu o gênero Eratoidea baseando-se na espira baixa característica de Marginella margarita Kiener, 1834, cuja concha se assemelha às de Erato.

TRYON (1883) utilizou os gêneros Erato e Marginella, este último com várias seções e divisões.

FISCHER (1887), em seu Manuel de Conchyliologie, classificou os Marginellidae nos gêneros e subgêneros Marginella - Marginella s.s. (dividido em quatro seções: Marginella s.s., Faba, Eratoidea e Serrata), Volutella, Balanetta, Closia, Volvarina (este dividido em duas seções: Volvarina s.s., Neovolvarina), Canalispira e Cryptospira; Persicula - Persicula s.s. e Gibberula; e Pachybathron (apesar de não estar certo quanto à sua posição sistemática).

SACCO (1890) revisou as espécies do Terciário da Itália, descreveu as seções subgenéricas Simplicoglabella, Denticuloglabella, Stazzania e utilizou o subgênero Cryptospira.

COSSMANN (1899) em seu Éssais de Paléoconchologie Comparé propôs uma classificação para as espécies de Marginellidae, descrevendo Dentimargo como uma seção do subgênero Stazzania, e Euryentome como seção do subgênero Cryptospira. 
TOMLIN $(1917,1918)$ listou todas as espécies recentes e fósseis, incluindo as sinônimas, fornecendo informações sobre a localização dos tipos e localidades-tipo, mas não teceu considerações sobre a taxonomia supra-específica.

THIELE (1929) propôs a seguinte classificação: gênero Persicula, subgêneros Persicula s.s. (seções Persicula s.s. e Rabicea), Gibberula e Gibberulina; gênero Marginella, subgêneros Canalispira, Cryptospira, Glabella, Closia (seções Closia s.s., Bullata), Hyalina (seções Hyalina s.s., Volvarina e Serrata), Marginella s.s. (seções Marginella s.s., Eratoidea e Faba); gênero Marginellona.

WENZ (1943) propôs uma classificação dividindo a família em 10 gêneros e 21 subgêneros, na seguinte ordem: Persicula - Persicula s.s. e Rabicea; Gibberula; Gibberulina: Gibberulina s.s., Extra Jousseaume, 1894 e Marginellopsis; Canalispira; Cryptospira - Cryptospira s.s. e Euryentome; Prunum - Prunum s.s. e Leptogouana; Closia: Closia s.s. e Bullata; Hyalina - Hyalina s.s., Balanetta, Volvarina e Serrata; Marginella - Marginella s.s., Eratoidea, Stazzania, Dentimargo, Glabella e Hiwia Marwick, 1931; Marginellona Martens, 1904.

LASERON (1957) revisou as espécies recentes e fósseis de marginelídeos da Austrália e descreveu 30 gêneros novos, considerados endêmicos desse continente e/ou do oceano Pacífico.

BARNARD (1962) descreveu o gênero Diluculum e afirmou que os gêneros deveriam ser baseados em caracteres anatômicos, além dos conquiliológicos, mas ressaltou as dificuldades na obtenção de material com partes moles de todos os gêneros.

COAN (1965) fez um histórico da taxonomia da família e propôs uma importante reclassificação, subdividindo a família em três subfamílias -- Marginellinae, Cystiscinae e 
Marginelloninae (esta de sua autoria) --, baseadas em caracteres da morfologia externa, radulares e biogeográficos.

ROTH (1973) utilizou, pela primeira vez, o gênero Dentimargo para uma espécie recente, baseando-se na dentição do lábio externo da abertura e na forma bicônica da concha.

GÖTTING (1974) ressaltou a importância da distribuição biogeográfica para o entendimento da evolução da família e tentou relacionar os gêneros às bacias oceânicas.

COAN \& ROTH (1976) discutiram a validade do gênero Hyalina e o separaram definitivamente de Volvarina baseando-se na ausência de rádula em Hyalina.

COOVERT (1986 - 1999) editou Marginella Marginalia, Dayton, o primeiro e único periódico dedicado ao estudo da família. Nessa revista, ele listou todos os gêneros já descritos, redescreveu vários gêneros e espécies, estabeleceu padrões radulares e de morfologia externa, e publicou revisões bibliográficas e uma lista praticamente completa da literatura sobre Marginellidae entre 1758 e 1986.

COOVERT \& COOVERT (1995), reunindo todos os dados conquiliológicos, radulares e anatômicos disponíveis e levantando novos, fizeram a maior e mais abrangente revisão do grupo. Nessa análise, foi verificado que na "família" havia dois grupos bem distintos e filogeneticamente disjuntos, portanto ela foi dividida em Marginellidae e Cystiscidae. Eles propuseram filogenias intuitivas, isto é, sem utilizar uma metodologia cladística ortodoxa. Subdividiram as famílias em grupos (subfamílias e tribos) monofiléticos, apesar de muitos desses grupos estarem baseados, ao que parece, em plesiomorfias. O presente estudo utiliza esta classificação como ponto de partida para as discussões, um resumo é apresentado aqui. 
Família Marginellidae Fleming, 1828

Subfamília Marginelloninae Coan, 1965

Gênero Afrivoluta Tomlin, 1947

Afrivoluta Tomlin, 1947: 244

Espécie tipo: Afrivoluta pringlei Tomlin, 1947, DO

Gênero Marginellona Martens, 1904

Marginella (Marginellona) Martens, 1904: 108

Sigaluta Rehder, 1967: 182 - 183 (espécie tipo: Sigaluta pratasensis Rehder, 1967 = Marginellona gigas Martens, 1904, DO)

Espécie tipo: Marginella (Marginellona) gigas Martens, 1904, M

Subfamília Marginellinae Fleming, 1828

Gênero Myobarbum Sohl, 1963

Myobarbum Sohl, 1963: 750-751

Espécie Tipo: Myobarbum laevigatum Sohl, 1963, DO

\section{Tribo Austroginellini Coovert \& Coovert, 1995}

Gênero Conuginella Laseron, 1957 (fóssil)

Conuginella Laseron, 1957: 288

Espécie tipo: Marginella inermis Tate, 1878 (fóssil), DO

\section{Gênero Serrata Jousseaume, 1875}

Serrata Jousseame, 1875: 167, 230

Haloginella Laseron, 1957: 284 (espécie-tipo: Marginella mustelina (Angas, 1871) = Hyalina (Volvarina) mustelina Angas, 1871; DO)

Exiginella Laseron, 1957: 289 (fóssil; espécie tipo: Marginella winteri Tate, 1878; DO)

Espécie tipo: Marginella serrata Gaskoin, 1849, T

Gênero Serrataginella Coovert \& Coovert, 1995

Serrataginella Coovert \& Coovert, 1995: 82

Espécie-tipo: Marginella spryi Clover, 1974, DO. 


\section{Gênero Stromboginella Laseron, 1957 (fóssil)}

Stromboginella Laseron, 1957: 289

Espécie tipo: Marginella crassidens Chapman \& Crespin, 1928, OD

\section{Gênero Hydroginella Laseron, 1957}

Hydroginella Laseron, 1957: 284

Neptoginella Laseron, 1957: 283 (espécie-tipo: Neptoginella fascicula Laseron, 1957, DO)

Pillarginella Gabriel, 1962: 197 (espécie-tipo: Marginella columnaria Hedley \& May, 1908)

Espécie tipo: Marginella crassidens Chapman \& Crespin, 1928, OD

\section{Gênero Mioginella Laseron, 1957 (fóssil)}

Mioginella Laseron, 1957: 287

Espécie-tipo: Marginella regula Cotton, 1949

\section{Gênero Protoginella Laseron, 1957}

Protoginella Laseron, 1957: 285

Espécie-tipo: Marginella lavigata Brazier, 1877 = Marginella (Prunum) lavigata Brazier, 1877, DO

\section{Gênero Nudifaba Eames, 1952 (fóssil)}

Marginella, subg. Nudifaba Eames, 1952: 122

Espécie-tipo: Marginella (N.) rakhiensis Eames, 1952, DO

\section{Genus Alaginella Laseron, 1957}

Alaginella Laseron, 1957: 286

Carinaginella Laseron, 1957: 286 (espécie-tipo: Marginella carinata Smith, 1891; DO)

Cassoginella Laseron, 1957: 287 (fóssil, espécie-tipo: Marginella palla Cotton, 1949, DO)

Triginella Laseron, 1957: 280-281 (espécie-tipo: Marginella malina Hedley, 1915, DO)

\section{Gênero Hiwia Marwick, 1931 (fóssil)}

Marginella, subg. Hiwia Marwick, 1931: 129

Espécie-tipo: Marginella (Hiwia) amplificata Marwick, 1931 


\section{Gênero Austroginella Laseron, 1957}

Austroginella Laseron, 1957: 285

Plicaginella Laseron, 1957:285 (espécie-tipo: Marginella formicula Lamarck, 1822, DO)

Espécie-tipo: Marginella muscaria Lamarck, 1822, DO

\section{Gênero Mesoginella Laseron, 1957}

Mesoginella Laseron, 1957: 282

Deviginella Laseron, 1957: 283-284 (espécie-tipo: Marginella brachia Watson, 1886 = Marginella (Glabella) brachia Watson, 1886, DO)

Hianoginella Laseron, 1957: 288 (fóssil, espécie-tipo: Marginella physa Cotton, 1949, DO)

Sinuginella Laseron, 1957: 282 (espécie-tipo: Marginella inconspicua Sowerby, 1846, DO)

Spiroginella Laseron, 1957: 283 (espécie-tipo: Marginella leia Cotton, 1944 = Marginella turbinata Sowerby, 1846, DO)

Urniginella Laseron, 1957: 287 (fóssil, espécie-tipo: Marginella cassidiformis Tate, 1878, DO)

Espécie-tipo: Marginella turbinata Sowerby, 1846, DO

\section{Gênero Closia, Gray 1857}

Closia, Gray 1857: 36

Espécie-tipo: Closia sarda (Kiener, 1834) = Marginella sarda Kiener, 1834, M

\section{Gênero Ovaginella Laseron, 1957}

Ovaginella Laseron, 1957: 280

Espécie-tipo: Marginella ovulum Sowerby, 1846, OD

\section{Gênero Balanetta Jousseaume, 1875}

Balanetta Jousseaume, 1875: 168, 269

Espécie-tipo: Balanetta baylei Jousseaume, 1875, M 
Tribo Prunini Coovert \& Coovert, 1995

\section{Gênero Volvarina Hinds, 1844}

Marginella sectio Volvarina, 1844: 75

Espécie-tipo: Marginella (Volvarina) nítida, Hinds, 1844 = Volvarina mitrella (Risso, 1826); DS: Redfield, 1870:221.

\section{Gênero Prunum Herrmannsen, 1852}

Prunum Herrmannsen, 1852: 113

Volutella subg. Microspira Conrad, 1868:66

(fóssil, espécie-tipo: Volutella (Microspira) oviformis Conrad, 1868, M)

Egouena Jousseaume, 1875: 167, 192 (espécie-tipo: Egouena egouen Jousseaume, $1875=$ Marginella amygdala Kiener, 1841; T)

Porcellanella Tryon, 1882: 16, non White in MacGilvray, 1852

(espécie-tipo: Prunum bella Conrad, 1868)

Porcellanella Conrad, 1863: 564, nomen nudum

Marginella subg. Volvarina, section Leptegouana Woodring, 1928: 237-238

(espécie-tipo: Voluta guttata Dilwyn, 1817, DO)

Espécie-tipo: Voluta prunum Gmelin, 1791; M

\section{Gênero Bullata Jousseaume, 1875}

Bullata Jousseaume, 1875: 167, 250

Marginella subg. Volutella Swainson, 1830: 2 (1) "Marginella" P1.I

(espécie-tipo: Voluta bullata Born, 1778, DS: Coovert \& Coovert, 1995)

Gibberulina Monterosato, 1884: 139 (emenda inválida)

Espécie tipo: Bullata bullata (Born, 1778) = Voluta bullata Born, 1778, T

\section{Gênero Rivomarginella Brandt, 1968}

Rivomarginella Brandt, 1968: 275

Espécie-tipo: Rivomarginella morrisoni Brandt, 1968, OD

\section{Gênero Cryptospira Hinds, 1844}

Marginella sectio Cryptospira Hinds, 1844: 76

Espécie-tipo: Marginella (Cryptospira) tricincta, Hinds, 1844, DS: Gray, 1847: 142 


\section{Gênero Hyalina Schumacher 1817}

Hyalina Schumacher 1817: 234

Marginella subg. Volvarina sectio Neovolvaria Fischer, 1883: 602

(espécie-tipo: Marginella pallida $($ Linnaeus, 1767$)=$ Bulla pallida Linnaeus, 1758

Espécie-tipo: Hyalina pellucida Schumacher, 1817 = Bulla pallida Linnaeus, 1758

\section{Tribo Marginellini Fleming, 1828}

\section{Gênero Stazzania Sacco, 1890 (fóssil)}

Marginella subg. Stazzania Sacco 1890: 138

Espécie tipo: Marginella (Stazzania) emarginata Sismonda, $1847=$ Marginella emarginata Sismonda, 1847

\section{Gênero Dentimargo Cossmann, 1899}

Marginella subg. Marginella sectio Dentimargo Cossmann, 1899: 90

Volvarinella Habe, 1951: 101-102 (espécie tipo: Volvarinella makiyamai Habe, 1951, DO)

Marginella subg. Eburnospira Olsson \& Harbison, 1953: 201-202 (espécie tipo Marginella eburneola Conrad, 1834, fóssil, OD)

Espécie-tipo: Marginella dentifera Lamack, 1803, OD

\section{Gênero Eratoidea Weinkauff, 1879}

Marginella sectio Marginella gruppe Eratoidea Weinkauff, 1879: 140

Espécie-tipo: Marginella margarita Kiener, 1834, DS: Cossmann, 1899: 87

\section{Gênero Simplicoglabella Sacco, 1890 (fóssil)}

Marginella subg. Glabella sectio Simplicoglabella, Sacco 1890b: 21

Espécie-tipo: Marginella (Glabella) taurinensis Michelotti, 1847 (fóssil, DS, Eames, 1952: 119)

\section{Gênero Marginella Lamarck, 1799}

Marginella Lamarck, 1799: 70

Cucumis Deshayes, 1830: 34

Porcellana Gray, 1847: 142 (non Lamarck, 1801) [espécie-tipo Marginella glabella (Linné, 1758), OD]

Pseudomarginella Maltzan, 1880: 108 in pars \{espécie-tipo Pseudomarginella adansoni, Maltzan, 1880 [= in pars Marginella glabella (Linné, 1758), M\}

Espécie-Tipo: Voluta glabella Linnaeus, 1758, M 


\section{Gênero Glabella Swainson, 1840}

Glabella Swainson, 1840: 133, 324

Marginella sectio Phaenospira Hinds, 1844:72 [espécie-tipo: Marginella noduta Hinds, 1844 (sic.) = Marginella nodata Hinds, 1844; DS Gray, 1847]

Marginella (Marginella) sectio Faba Fischer, 1883:602 [espécie-tipo: Marginella faba (Linnaeus, 1758), M]

Espécie-tipo: Voluta faba Linnaeus, 1758, DS Gray, 1847: 142

\subsection{Justificativa para o presente estudo}

A classificação de COOVERT \& COOVERT (1995), separando Cysticidae de Marginellidae, não foi amplamente discutida posteriormente. Alguns autores a ignoraram (e.g. RIEDL, 2000), enquanto outros a aceitaram parcialmente (e.g. PONDER, 1998), mas, em ambos os casos, Cystiscidae foi mantida como subfamília de Marginellidae, mantendo uma classificação mais semelhante à de COAN (1965), nenhum deles, no entanto, justificaram suas decisões. Por outro lado, vários outros autores que trataram da taxonomia alfa (e.g. COSSIGNANI, 2001; ESPINOSA \& ORTEA, 2000; WAKEFIELD \& MCCLEERY, 2005) seguiram a classificação de COOVERT \& COOVERT (1995).

Ao nível de gênero, alguns grupos ainda apresentam dificuldades em sua identificação (e.g. Volvarina / Prunum; Dentimargo / Eratoidea), estes gêneros possuem morfologia conquiliológica muito semelhante que levam muitas vezes a decisões arbitrárias, quanto à alocação das espécies (GOFAS 1989; GOFAS \& FERNADES 1992; SOUZA, 1992 e 1997, BOYER), e em um estudo paleontológico (NEHM, 2001) Prunum e Volvarina foram considerados como um único ramo ("the Prunum + Volvarina clade"), dada a dificuldade em separar os dois gêneros.

O trabalho de COOVERT \& COOVERT (1995) resolveu muitas das questões existentes sobre a classificação dos Marginellidae, organizando o conhecimento disperso que havia sobre a família. No entanto, boa parte de sua classificação e filogenia foi baseada em uma visão intuitiva da distribuição de caracteres conquiliológicos, radulares e 
os poucos caracteres morfológicos de que dispunha (COOVERT \& COOVERT, 1995: 102), sem uma análise cladística hennigiana.

Por outro lado, após o advento da metodologia cladística, sua aplicação em Mollusca, de um modo geral, iniciou-se tardia e timidamente, se comparada com a de outros grupos zoológicos. Os primeiros trabalhos datam do final da década de 1970 (WALLER, 1978) seguidos de alguns trabalhos que analisaram pequenos conjuntos de dados no início da década de 1980 (e.g. DAVIS \& GREER, 1980; MEIR-BROOK, 1983) que ainda utilizaram a metodologia manual para a construção de suas árvores. A partir dos meados desta mesma década, mais trabalhos começam a surgir (e.g. DAVIS et al., 1984; HOUBRICK, 1988; LINDBERG, 1988; BIELER, 1988) já utilizando auxílio de programas computacionais. Alguns trabalhos (HASZPRUNAR, 1985 a, b, 1988; SALVINI-PLAWEN \& HASZPRUNAR, 1987) utilizaram em parte a metodologia cladística, ao tentar estabelecer sinapomorfias, para cada táxon, no entanto os filogramas e classificações resultantes eram feitos de maneira intuitiva e em um dos trabalhos (HASZPRUNAR, 1988) foi proposta uma nova maneira de se derivar classificações a partir do cladograma, chamada "clado-evolucionária" (ver BIELER, 1990 para uma discussão detalhada).

Na década de 1990 mais trabalhos foram publicados, sendo alguns destes com bases em dados moleculares, e outros com bases de dados morfológicos, pouco extensas que produziram resultados com baixa resolução e ou controversos (e.g. IVANOV \& PAVLINOV, 1991; BIELER \& MIKKELSEN, 1992; STEINER, 1992; TILLIER et al.; 1992; MIKKELSEN, 1993; VOIGHT, 1993; HERSHLER, 1994; DAVIS et al., 1994; TILLIER et al., 1994; ROSENBERG et al., 1994; WINNPENNINCKX et al., 1994, 1996). No entanto, PONDER \& LINDBERG (1997), fizeram uma ampliação de outro trabalho (PONDER \& LINDBERG, 1995) reuniram uma grande base dados com 117 caracteres, levantados principalmente a partir da bibliografia, e 40 terminais para testar a hipótese de HASZPRUNAR (1988), utilizando metodologia cladística ortodoxa, apresentando importantes avanços na classificação dos Gastropoda. 
A partir do início deste século alguns trabalhos cladísticos foram realizados com análises morfológicas mais detalhadas das partes moles em Gastropoda (e.g. SIMONE 2001, 2002, STRONG, 2002) e estes demonstraram que as partes moles são uma riquíssima fonte de dados comparativos, resultando em análises bem resolvidas. Enquanto que, em Marginellidae, até o momento, só há uma análise cladística (SOUZA \& COOVERT, 2001), mas que abrange somente um gênero e utiliza apenas caracteres conquiliológicos. RIEDL (2000), incluiu em sua filogenia molecular de "Caenogastropoda superiores" ("höheren" Caenogastropoda) incluiu 2 representantes de Marginellidae (sensu COAN, $1965=$ Marginellidae + Cystiscidae), a topologia resultante foi bastante questionável, considerando as demais classificações de Muricoidea (e.g. KANTOR, 1988; SIMONE, 2000; STRONG, 2002) e pouco auxiliou na resolução interna do grupo e nem era esse o escopo do trabalho, dada a pequena amostra examinada. Dado este cenário, justifica-se um estudo morfológico mais detalhado da família e, a partir deste, organizar uma base de dados, da qual se possa produzir uma classificação da família a partir de uma análise cladística.

\subsection{Objetivos}

1) Realizar um estudo filogenético - cladístico - em uma amostra heterogênea de Marginellinade, com base em um estudo de morfologia detalhado.

2) Aplicar o conhecimento gerado pela análise filogenética na taxonomia do grupo.

3) Criar uma base de dados morfológicos para embasar uma futura revisão de Marginellidae. 


\section{Material e Métodos}

\subsection{Abreviaturas:}

\subsection{1 - Coleções:}

AMS: Australian Museum, Sidney

IBUFRJ: Instituto de Biologia / Universidade Federal do Rio de Janeiro, Rio de Janeiro.

MZUSP: Museu de Zoologia da Universidade de São Paulo, São Paulo.

UMML: Marine Laboratory, Rosenstiel School of Marine and Atmospheric Sciences /

University of Miami, Miami.

USNM: National Museum of Natural History, Washington D.C..

ZIN: Instituto Zoológico da Academia Russa de Ciências, São Petersburgo.

\subsection{2 - Anatomia:}

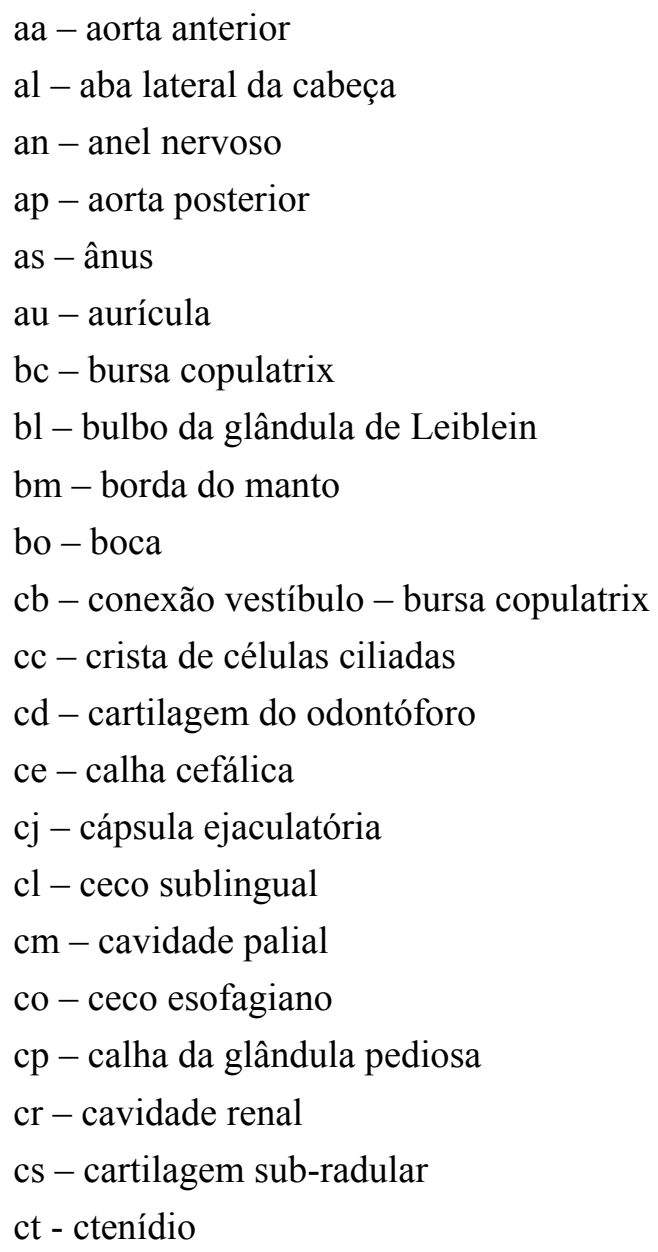

cv - Ponte da válvula de Leiblein em calha $\mathrm{dc}$ - duto da glândula salivar acessória de - divertículo do estômago $\mathrm{dg}$ - duto da glândula digestiva dl - duto da glândula de Leiblein $\mathrm{dp}$ - duto peniano ds - duto da glândula salivar ed - espermoduto es - estômago ev - envoltório ventral do odontóforo ga - glândula de albúmen gb - gânglio bucal gc - glândula salivar acessória gd - glândula anal gg - glândula digestiva gh - glândula hipobranquial gi - glândula ingestória gl - glândula de Leiblein gn - glândula nefridial gp - glândula da cápsula gs - glândula salivar gv - glândulas da vesícula seminal 


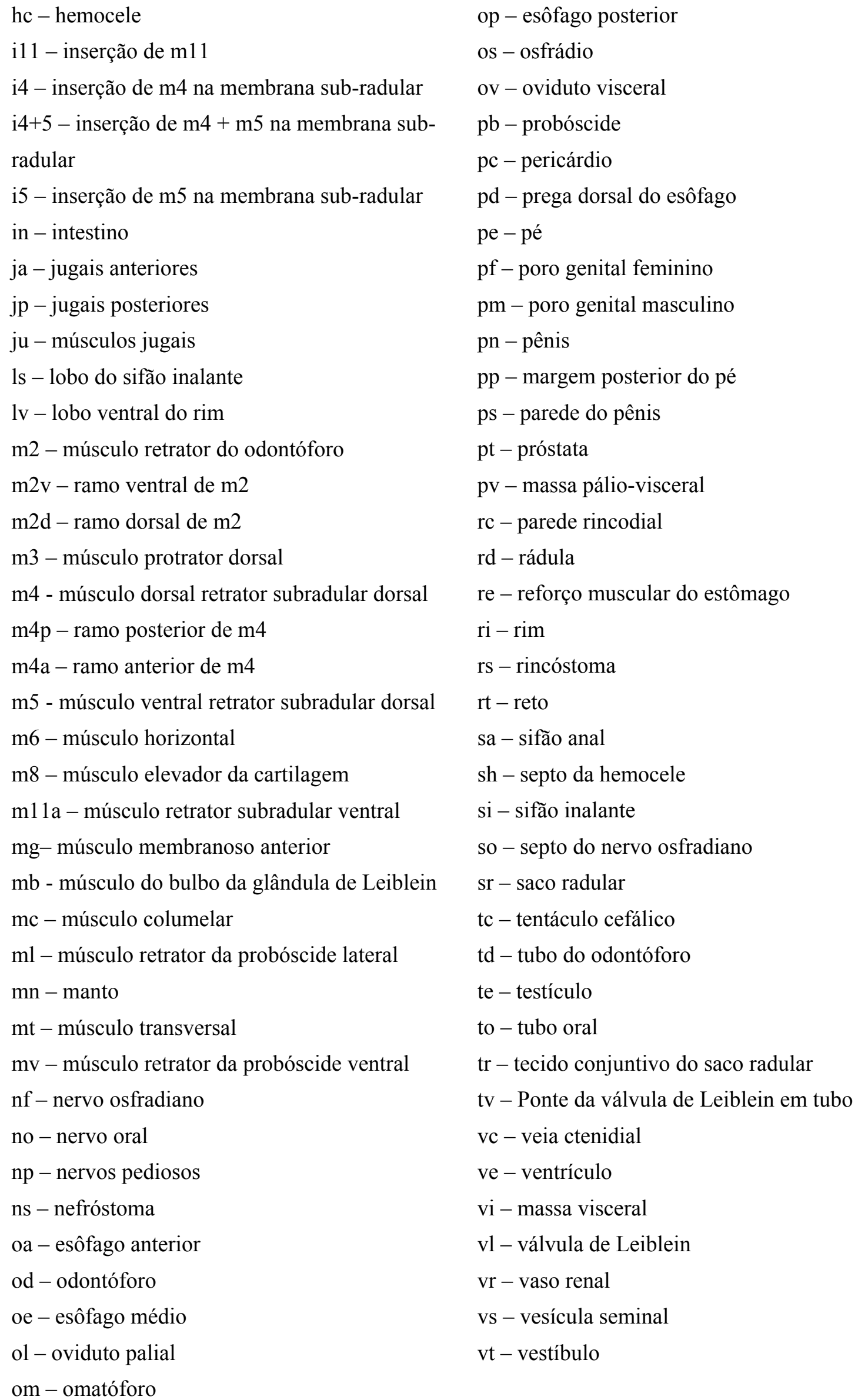




\subsection{Material Examinado:}

Os dados morfológicos levantados para o presente estudo foram, em sua maioria, levantados a partir do estudo morfológico direto do material, exceção feita a Trophon geversianus, cujos dados anatômicos foram levantados a partir de estudo não publicado de L. R. SIMONE (comunicação pessoal) e de HARASEWYCH (1984). A taxonomia das espécies seguiu (HARASEWYCH, 1984; PONDER \& TAYLOR, 1992; COSSIGNANI, 2006; ROSENBERG, 2006) a sinonimia primária específica pode ser encontrada nestas referências, se não estiver aqui esplicitada. A taxonomia genérica seguiu COOVERT \& COOVERT (1995) e resultados obtidos na presente análise cladística (ver discussão).

\subsubsection{Cystiscidae}

\section{Persicula sagittata (Hinds, 1844)}

MZUSP 31079: 43 espécimes (comprimento da concha: 6-9 $\mathrm{mm}$ ), Buraco do Inferno, Ilha Rata, Arquipélago de Fernando de Noronha, Pernambuco, 10 m, 07/1999, col. P. J. S. de Souza Jr \& L. R. Simone.

\subsubsection{Volutidae}

\section{Adelomelon brasilianus (Lamarck, 1811)}

MZUSP 31079: 4 espécimes (comprimento da concha: 138-161mm), ao largo de Mar del Plata, Argentina, 15-25 m, 03/2001, col. M. Cledón. 


\subsubsection{Marginellidae}

\subsubsection{Marginelloninae}

\section{Marginellona gigas Martens, 1904}

MZUSP 64952: 1 espécime inteiro (comprimento da concha: $78 \mathrm{~mm}$ ) e um fragmento das partes moles, ao largo de Kaohsiung, Taiwan, 2006, col. barco de pesca.

ZIN 45513: 1 espécime (comprimento da concha: $37 \mathrm{~mm}$ ), ao largo de Phan Ly, Vietnam, Mar da China, 700m, ix.1984, col. R.V. Odessey; ZIN 56353: 1 espécime (comprimento da concha: $68 \mathrm{~mm}$ ), ao largo de Phan Ly, Vietnam, Mar da China, 12801000m, 09/1984, col. R.V. Odessey;

\subsubsection{Austroginellini}

Austroginella muscaria (Lamarck, 1822)

AMS C383554: 21 espécimes (comprimento da concha: 12-14 mm), Praia de Boydtown, Baía Twofold, New South Wales, Autrália, intertidal, 05/1978, col. C. J. Murray.

\subsubsection{Marginellini}

\section{Eratoidea aureocincta (Stearns, 1872)}

IBUFRJ 6552: 6 espécimes (comprimento da concha: 4,1-4,5 mm, em Tampa Bay, Flórida, EUA, 0,6 m, vii.1991, col. R. Lipe. 


\section{Eratoidea eburneola (Conrad, 1834)}

MZUSP 323053: 28 espécimes (comprimento da concha: 3,6-7,1 mm), Long Key, Bight, Florida Keys, E.U.A., 1 m, 04/1998, col. M. Guimarães.

\section{Eratoidea scalaris (Jousseaume, 1875)}

MZUSP 19415: 2 espécimes, ao largo de Cabo Frio, Rio de Janeiro, Brasil, (22º 39’ S, 041³3’ W), 52 m, 01/1979; MZUSP 19618: 2 espécimes, ao largo de Santos, São Paulo, Brasil, 32 m, 04/1979; MZUSP 27770: 18 espécimes, ao largo de Itapemirim, Espírito Santo ( $21^{\circ} 15^{\prime} \mathrm{S}, 040^{\circ}$ 50’ W), Brasil., 19 m, 09/1970.

\section{Eratoidea sp.}

USNM 849799: 2 espécimes (comprimento da concha: $3,7 \mathrm{~mm} ; 4.1 \mathrm{~mm}$ ); , ao largo da Carolina do Sul, E.U.A., (32²9’36” N, 079 42’30” W), 17 m, 04/1981; USNM 849800: 1 espécime (comprimento da concha: $3.9 \mathrm{~mm}$ ), ao largo da Carolina do Sul, E.U.A. (32 29’ 36” N, 079 42’30” W), 26 m, 07/1981; USNM 849802: 3 espécimes (comprimento da concha: 3,5 mm; 4,0 mm; 3,9 mm), ao largo de Georgia, E.U.A. ( $31^{\circ} 41^{\text {' }}$ 06” N, 080 20'48” W), 26 m, 05/1981; USNM 849804: 2 espécimes (comprimento da concha: $3.8 \mathrm{~mm}$; $3.9 \mathrm{~mm}$ ), ao largo da Carolina do Norte, E.U.A. (34 $24^{\prime}$ 12” N, $076^{\circ} 35^{\prime}$ 48 "W), $18 \mathrm{~m}, 10 / 1981$ 


\section{Marginella glabella (Linnaeus, 1758)}

MZUSP 28805: 1 espécime (comprimento da concha: $28 \mathrm{~mm}$ ), Baia de Etoile, Nouadhibou, Mauritânia, 3-4 m, 1996, col E. Rólan.; MZUSP 50062: 3 espécimes (comprimento da concha: 29-34 mm), ao largo do Cabo Barba, Saara Ocidental, 58 m, col Catelhe \& A, Benite.

\section{Marginella desjardinii Marche-Marchard, 1957}

UMML 30.10859: 4 espécimes (comprimento da concha: 39 - $46 \mathrm{~mm}$ ), P-254, $05^{\circ}$ 05’ N, 004º 05' W, 85 m, 05/1965, col. R.V. Pillsbury. UMML 30.10891: 3 (comprimento da concha: 36-40 mm) espécimes, P-45, $03^{\circ} 51^{\prime} \mathrm{N}, 007^{\circ} 10^{\prime} \mathrm{E}, 161 \mathrm{~m}, 05 / 1965$, col. R.V. Pillsbury.

\section{Marginella rosea (Linnaeus, 1758)}

USMN 881220: 18 espécimens, False Bay, Cabo da Boa Esperança, África do Sul, 15-20 m, 10/1985. W. R. Liltved col.

\section{“Marginella” ealesae Powell, 1958}

USNM 886437: 4 espécimes (comprimento da concha: 15-22 $\mathrm{mm}$ ), Ilha de

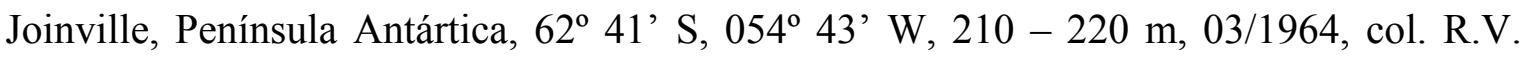
Eltanin. 


\subsubsection{Prunini}

“Eratoidea” watsoni (Dall, 1927)

Marginella watsoni Dall, 1881: 71

Marginella (Marginella) fernandinae Dall, 1927: 43-44

Marginella (Marginella) canilla Dall, 1927: 44

UMML 30.6021: 4 espécimes (comprimento da concha: $9-12 \mathrm{~mm}$ ), $25^{\circ} 31^{\prime} \mathrm{N}$, 079 31' W, 842 m, 08/1964, col. R.V. G-3 57. UMML 30.10424: 1 espécime, $21^{\circ} 17^{\text {`N }}$, 086 13 'W, 03/1967, 434 m, col. R.V. P-587. UMML 30.10885: 8 espécimes (comprimento da concha: 8-10 mm), $27^{\circ} 32^{\prime} \mathrm{N}, 079^{\circ} 22^{\prime} \mathrm{W}, 572 \mathrm{~m}, 07 / 1968$, col. R.V. Gerda. UMML 30.10886: 1 espécime (comprimento da concha: $9.5 \mathrm{~mm}$ ), $26^{\circ} 33^{`} \mathrm{~N}, 079^{\circ}$ 23’W, 635 m, 04/1964, col. R.V. Gerda. UMML 30.10887: 13 espécimes (comprimento da concha: 9,5 - $11 \mathrm{~mm}$ ), $23^{\circ} 34^{\prime} \mathrm{N}, 079^{\circ} 16^{\prime} \mathrm{W}, 520 \mathrm{~m}, 06 / 1968$, col. R.V. Gerda.

\section{Leptegouana tripartita (Cossignani, 2006).}

MZUSP 32405: 3 espécimes (comprimento da concha: 9,6-10,7 mm), ao largo de Rio do Fogo, Rio Grande do Norte, 15-20 m, 12/1998, col. A. Bodart.

\section{Leptegouana guttata (Dilwyn, 1817)}

IBUFRJ 5676: 2 espécimes (comprimento da concha: $17 \mathrm{~mm}, 27 \mathrm{~mm}$ ), Ilha de Cozumel, Quintana Roo, Mexico, 2 - 5 m, 02/1994, col. P. J. S. de Souza Jr. 
Prunum brasilianum (Boyer, 2000).

MZUSP 34359: 13 espécimes (comprimento da concha: 6,3 mm-8,7 mm), Praia do Gaibu, Cabo, Pernambuco, inter-mareal, 22/07/2001, col. P. J. S. de Souza Jr \& L. R. Simone.

\section{Prunum fulminatum (Kiener, 1841)}

MZUSP 32312: 7 espécimes (comprimento da concha: 15 - $19 \mathrm{~mm}$ ), Pedra da Lixa, Parcel de Paredes, Alcobaça, Bahia, Brasil, 1-5 m, 04/2000, col. P. J. S. de Souza Jr \& E. P. Gonçalves.

\section{Prunum prunum (Dilwyn, 1817)}

MZUSP 37440: 5 espécimes (comprimento da concha: 19-31 mm), laguna del Morro Chocopata, Venzuela, 1-2 m, 1999, col. P. Penchaszadeh.

\section{Prunum rubens (Martens, 1881)}

MZUSP 32962: 6 espécimes (comprimento da concha: $16-21 \mathrm{~mm}$ ), ao largo de Cabo Frio, Rio de Janeiro, Brasil, 80 - 140 m, 05/1998, col. barco de pesca.

\section{Prunum warreni (Marrat, 1876)}

USNM 881929: 56 espécimes (comprimento da concha: 13 - $19 \mathrm{~mm}$ ), ao largo da

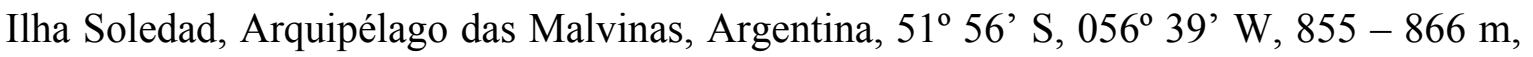
03/1963, col. USC. 


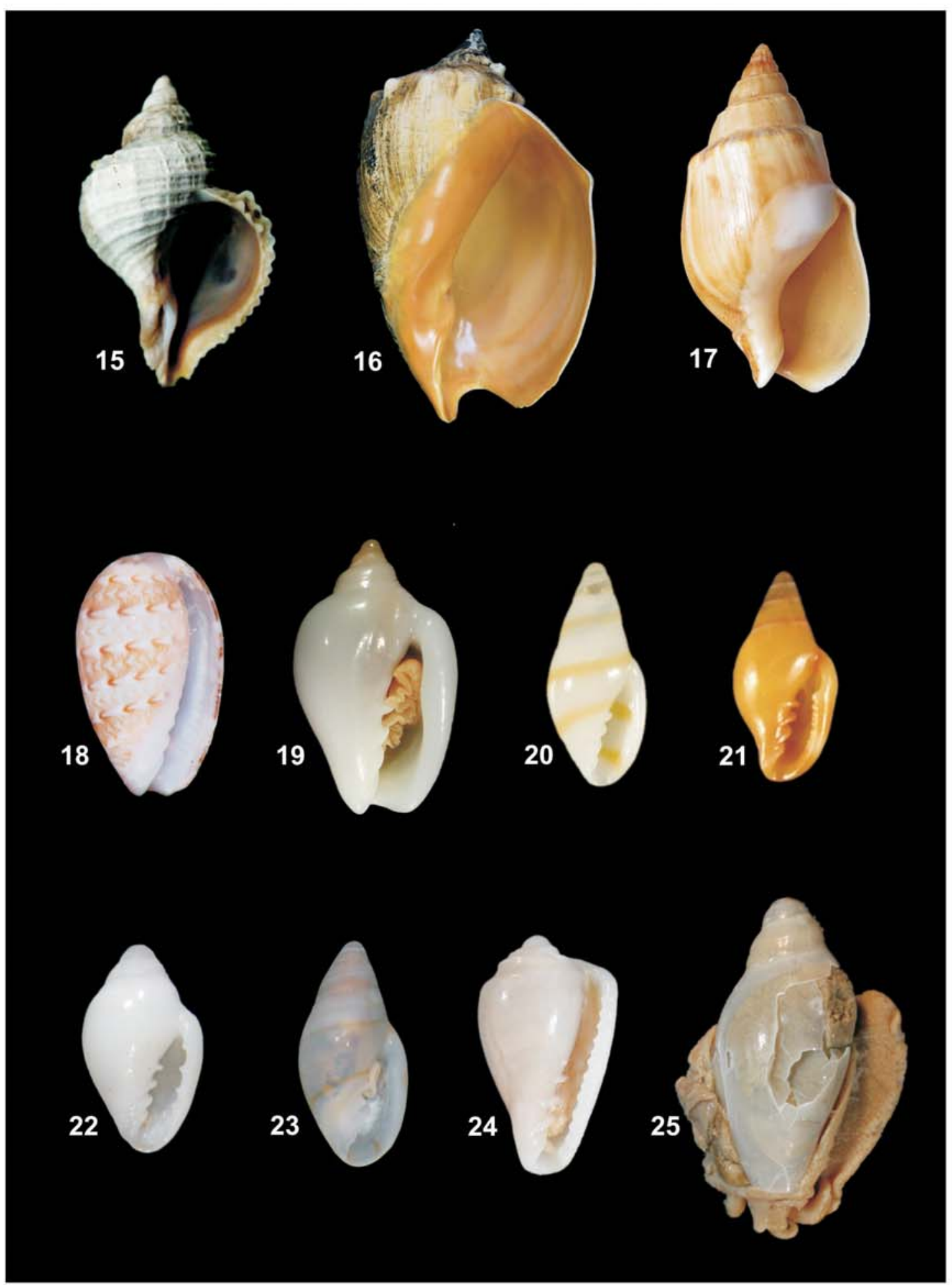

Figuras 15 - 25 Espécies estudadas, parte 1.

15. Trophon gervesianus, MZUSP 52643, comprimento $33 \mathrm{~mm}$;

16. Adelomelon brasilianus, MZUSP 31079, comprimento $161 \mathrm{~mm}$;

17. Buccinanops gradatus, MZUSP 73305, comprimento $41 \mathrm{~mm}$;

18. Persicula sagittata; MZUSP 31079 , comprimento $7,8 \mathrm{~mm}$;

19. Austroginella muscaria, AMS C383554, comprimento $13,2 \mathrm{~mm}$;

20. Eratoidea aureocincta, IBUFRJ 6552, comprimento $4,7 \mathrm{~mm}$;

21. Eratoidea eburneola, coleção particular (foto Marcus Coltro), comprimento 5,8 mm;

22. Eratoidea scalaris, MZUSP 66896, comprimento 4,3 mm;

23. Eratoidea sp., USNM 849802, comprimento 3,9 mm;

24. "Eratoidea" watsoni, UMML 10.10887, comprimento $10,3 \mathrm{~mm}$;

25. "Marginella" ealesae USNM 886437, comprimento da concha $22 \mathrm{~mm}$. 


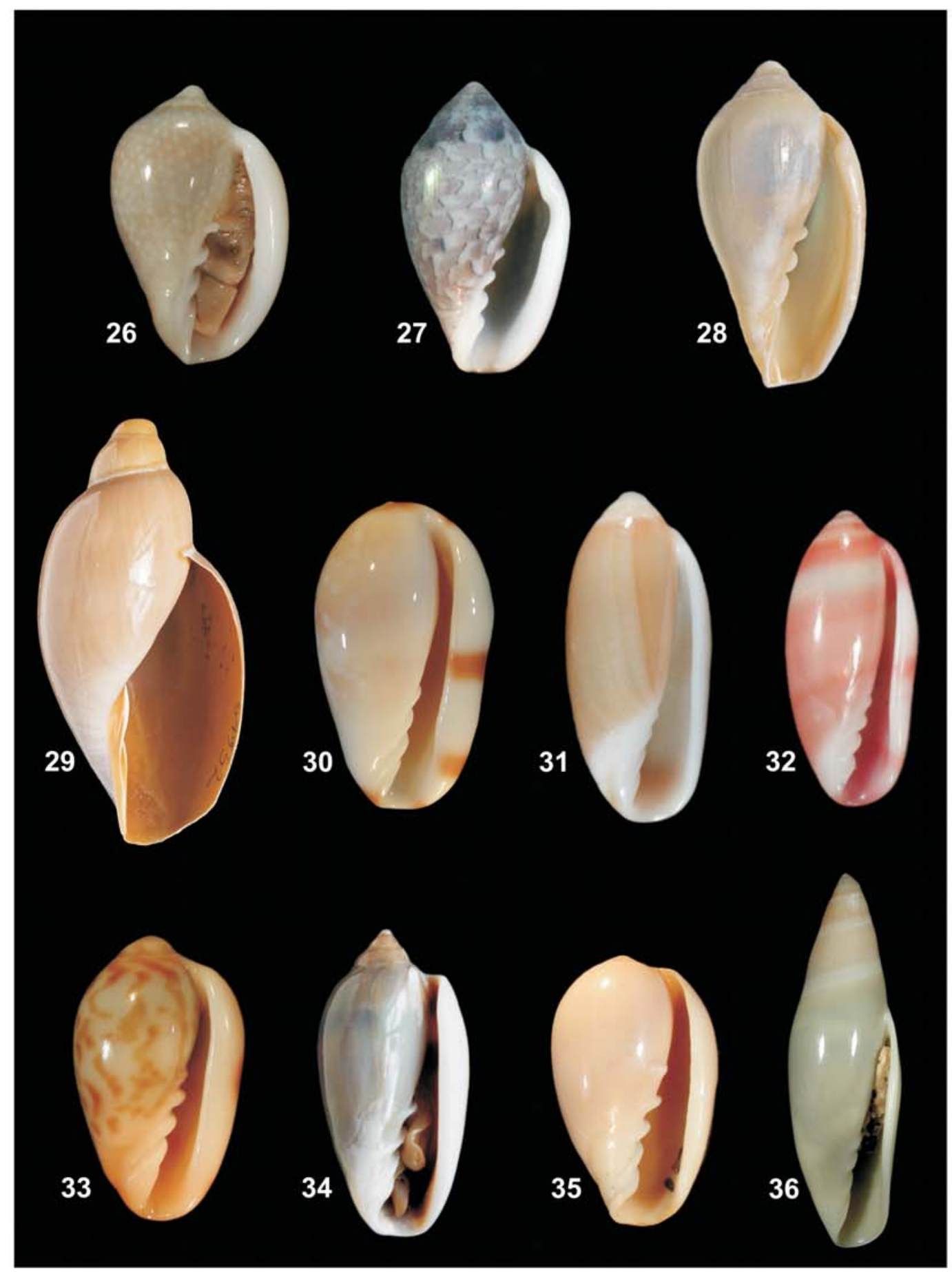

Figuras 26 - 36 Espécies estudadas, parte 2.

26. Marginella glabella, MZUSP 50062, comprimento $29 \mathrm{~mm}$; 27. Marginella rosea, USMN 881220 , comprimento $27 \mathrm{~mm}$;

28. Marginella sebastiani, UMML 30;10891, comprimento $30 \mathrm{~mm}$;

29. Marginellona gigas; MZUSP 64952, comprimento $71 \mathrm{~mm}$;

30. Leptegouena guttata, IBUFRJ 5676, comprimento $27 \mathrm{~mm}$;

31. Leptegouena tripartita, MZUSP 32405, comprimento 10,7 mm;

32. Prunum brasilianum, MZUSP 34359, comprimento 5,8 mm;

33. Prunum fulminatum, MZUSP 32312, comprimento $17 \mathrm{~mm}$;

34. Prunum prunum, MZUSP 37440, comprimento $29 \mathrm{~mm}$;

35. Prunum rubens ., MZUSP 32962, comprimento $17 \mathrm{~mm}$;

36. Prunum warreni, USNM 881929, comprimento $19 \mathrm{~mm}$; 


\subsection{Métodos}

\subsubsection{Anatomia}

Para se realizar o estudo anatômico dos espécimes, as partes moles eram extraídas de suas conchas. As partes moles dos marginelídeos são geralmente de difícil extração, devido a interdigitação dos lobos do músculo columelar com as plicas columelares, especialmente em animais fixados, onde já ocorreu uma desidratação do músculo. Portanto as conchas tiveram que ser descalcificadas em solução de Raillet-Henry (3,5 \% $\mathrm{NaCl}, 10 \%$ Ácido Acético, 4\% formol, 86,5 \% H2O). Os espécimes menores $(<2 \mathrm{~cm})$ eram postos diretamente na solução, enquanto os maiores tinham suas conchas quebradas, removendo-se tanto quanto possível da concha, para acelerar o processo de descalcificação, que poderia durar de 6 a 36 h, dependendo da espessura da concha.

O animal sem a concha era, então, colocado dentro de uma cuba forrada com espuma densa de borracha (E.V.A.), para permitir sua fixação com alfinetes entomológicos, e imerso em álcool 70\%, para evitar a reidratação de muco, principalmente da glândula hipobranquial, que pode dificultar bastante o estudo. A dissecção era feita sob estéreo-microscópio, utilizando-se pinças, tesouras oftalmológicas e estiletes.

Inicialmente, separava-se o manto e massa visceral (assim separadas formam um conjunto aqui denominado massa pálio-visceral) da massa céfalo-pediosa. Essa separação é feita através de uma incisão feita, inicialmente, abaixo do sifão e que segue posteriormente ao longo da lateral do assoalho da cavidade do manto, por todo o circuito da cavidade. Desta maneira se preserva a integridade da maioria dos órgãos, com exceção do esôfago, próximo a sua junção com estômago, e da aorta anterior, que são secionados transversalmente. Na massa céfalo-pediosa a separação da cabeça e parede dorsal da hemocele do pé + músculo columelar foi feita através de incisão ao longo das margens 
laterais da hemocele. Este método permitia examinar os órgãos da hemocele e todo seu arranjo. A nomenclatura anatômica seguiu os recentes trabalhos de SIMONE (e.g. 1999, 2001), adicionalmente, na enumeração dos caracteres, é feita uma tentativamente de se estabelecer a homologia entre as nomenclaturas dos músculos intrínscecos do odontóforo utilizadas por SIMONE (op. cit.) e CARRIKER (1943).

\subsubsection{Ilustrações}

As fotografias foram feitas com máquinas digitais Nikon CoolPix 990 e Sony Cyber Shot DSC-S70, e editadas em programas gráficos. Os desenhos foram preparados a lápis com auxílio de microscópios estereoscópicos Zeiss SV-6 e SV-11, com luz incidente e câmaras claras acopladas, e posteriormente era feita arte final a nanquin ou micropigmento, sobre papel vegetal. Os desenhos eram então digitilizados em scanner com resolução de 600 dpi e editados em programas gráficos. As abreviaturas anatômicas das figuras têm seu significado expresso na própria legenda, de modo a facilitar o entendimento das mesmas.

\subsubsection{Análise Cladística}

As relações internas de parentesco da família Marginellidae foram estabelecidas através da sistemática filogenética, ou cladística. Este método foi proposto por HENNIG $(1950,1966)$ e desde então vem sendo discutido e desenvolvido por diversos autores (e.g., AMORIM, 1994; NELSON \& PLATNICK, 1981; RIEPPEL, 1988; WILEY, 1981), e praticamente se tornou o paradigma atual em sistemática (PINNA, 1991). 
O princípio de parcimônia estrita, ou de Wagner, foi utilizado para a geração das árvores, pois minimiza a necessidade de hipóteses ad-hoc para homoplasias FARRIS (1982) e considera igualmente reversões e paralelismos (SWOFFORD \& MADDISON, 1987).

A polarização dos caracteres foi feita através de comparações com grupo-externos (WATROUS \& WHELLER, 1981; MADDISON et al. 1984; NIXON \& CARPENTER, 1993). Como grupo externo foram escolhidas espécies da Superfamília Muricoidea (sensu PONDER, 1973), incluindo representantes de Cystiscidae e Volutidae.

Estados plesiomórficos foram codificados com "0" e apomórficos com números inteiros iguais ou superiores a "1". Dados indeterminados são tratados indistintamente pelos programas de computador atuais, mas comumente sua notação vem sido codificada na literatura de duas maneiras: “?”, quando o estado do caráter pode ser plesiomórfico ou apomórfico, devido a ausência de observação, e.g. estruturas do sistema reprodutor masculino, em espécies cuja amostra estudada só possui fêmeas; “-” quando o estado não pode ser apomórfico nem plesiomórfico, o caráter não existe, ou seja, fala de uma estrutura ausente, e.g., caracteres do odontóforo em um animal que não possui odontóforo.

Quando se percebeu uma seqüência evolutiva óbvia do caráter, este foi ordenado $a$ priori. A ordenação a priori é feita, portanto, da mesma forma que qualquer outra análise de homologia de caracteres, e consistente com o Princípio Auxiliar de Hennig (apud WILEY et al., 1991: 14) já que estados apomórficos similares devem denotar homologia primária até que prova em contrário seja apresentada (WILKINSON, 1992). 


\subsubsection{Otimização:}

Quando a distribuição dos caracteres na árvore era dúbia, possuindo interpretações igualmente parcimoniosas de suas seqüências evolutivas, a opção entre homoplasia e reversão foi feita analisando-se cada caso, discutindo-se as evidências presentes. Quando as evidências não eram claras, optou-se por empregar o método ACCTRAN, como formalizado por SWOFFORD \& MADDISON (1987). Este método foi preferido por preservar homologias primárias até que evidência contrária seja apresentada, e, portanto, condizente com o "Princípio Auxiliar de Hennig" (apud WILEY et al., 1991: 14).

\subsubsection{Programas de computador auxiliares na análise cladística:}

As análises de parcimônia foram realizadas utilizando-se o programa Hennig86 (FARRIS, 1988). Inicialmente Hennig86, versão 1.5, através de um outro programa Tree Gardener, versão 2.2.1 (RAMOS, 1997) que funciona como uma interface gráfica em ambiente Windows e utilitário para geração de matrizes. O Hennig86 foi preferido, pois este permite realizar uma busca exaustiva (enumeração implícita) pelas árvores mais parcimoniosas entre todas as possíveis (comando "ie*").

As arvores obtidas eram salvas através do comando "ts" e importadadas, juntamente com a matriz de caracteres, para o programa WinClada, versão 1.00 .08 (NIXON, 2002). Este programa foi utilizado para auxiliar na otimização dos caracteres e para exportar as árvores para programas de edição gráfica. 


\section{Resultados}

\subsection{Caracteres}

Após exame e dissecção dos espécimes e análise morfológica comparativa foram levantados 93 caracteres, sendo 12 coquiliológicos e 81 da morfologia das partes moles (Tabela 1). Nesta seção, os caracteres são enumerados, agrupados em 4 complexos, concha, massa céfalo pediosa, órgãos do manto e sistema digestório. Quando necessário, uma breve descrição é apresentada e, ao final de cada complexo de caracteres, os dados são discutidos e confrontados com a literatura.

\subsubsection{Concha}

1- Superfície da Concha (passos: 2; ic: 0,5 ; ir: 0,5 ).

0- opaca (Fig. 15, 16, 17); 1- brilhante (Fig. 2, 4 - 9) (Austroginella muscaria, Eratoidea aureocincta, Eratoidea eburneola, Eratoidea sp., Eratoidea scalaris, "Eratoidea" watsoni, "Marginella" ealesae, Marginella glabella, Marginella rosea, Marginella sebastiani, Marginellona gigas, Persicula sagittata, Prunum fulminatum, Leptegouana guttata, Prunum prunum, Prunum rubens, Prunum brasilianum, Leptegouana tripartita, Prunum warreni).

Plesiomorficamente, a superfície da concha dos gastropoda, e dos demais Conchifera, é recoberta pelo periostraco e a superfície calcária subjacente é opaca. Apomorficamente a superfície se torna lisa e brilhante. Esse é um caráter que parece ter surgido, independentemente, várias vezes ao longo da evolução dos Gastropoda (e.g. Vitrinellidae, Eulimidae) chegando algumas vezes ao extremo de um aspecto quase vítreo, presente nos Marginellidae (e.g., Fig. 19-22). 
2- Sutura (passos: 3 ; ic : 0,33 ; ir: 0,5 ).

0- distinta (Adelomelon brasilianus, Buccinanops gradatus, Marginellona gigas, "Marginella" ealesae, Trophon sp.); 1- indistinta (Austroginella muscaria, Eratoidea aureocincta, Eratoidea eburneola, Eratoidea scalaris, Eratoidea sp., "Eratoidea" watsoni, Leptegouana guttata, Leptegouana tripartita, "Marginella” ealesae, Marginella glabella, Marginella rosea, Marginella sebastiani, Persicula sagittata, Prunum brasilianum, Prunum fulminatum, Prunum prunum, Prunum rubens, Prunum warreni).

O contato entre as voltas da concha dos Gastropoda, normalmente, deixa um sulco visível, a sutura. A sutura pode ser mais ou menos evidente devido à forma das voltas e ou a características da superfície da concha.

3- Comprimento da abertura em relação ao comprimento da concha (passos: 5; ic: $0,5$; ir: 0,83$)$.

0 - menos que $1 / 2$ do comprimento da concha (e.g., Fig. 15,23 ); 1 - entre $2 / 3$ e $3 / 4$ do comprimento total da concha (e.g., Fig. 19, 36) (Austroginella muscaria, Eratoidea eburneola, Eratoidea scalaris, "Marginella” ealesae, Marginella glabella, Marginella rosea, Marginella sebastiani, Marginellona gigas, Prunum warreni); 2- mais de 4/5 do comprimento da concha (e.g., Fig. 30-35) (Adelomelon brasilianus, "Eratoidea" watsoni, Leptegouana guttata, Leptegouana tripartita, Persicula sagittata, Prunum brasilianum, Prunum fulminatum, Prunum prunum, Prunum rubens). 
4- Espira (passos: 9; ic: 0,33; ir: 0,45).

0- alta (e.g., Fig. 15, 20, 36); 1-baixa (Adelomelon brasilianus, Austroginella muscaria, Eratoidea scalaris, "Eratoidea" watsoni, "Marginella" ealesae, Marginella glabella, Marginella rosea, Marginella sebastiani, Marginellona gigas, Prunum fulminatum) (e.g., Fig. 19, 22, 27); 2- quase involuta (Leptegouana guttata, Leptegouana tripartita, Prunum brasilianum, Prunum fulminatum, Prunum prunum, Prunum rubens). 3- totalmente involuta (Persicula sagittata).

Os caracteres 3 e 4 demonstram uma alteração no formato geral da concha. Esta alteração consiste em um deslocamento gradual da abertura da concha da região anterior para a região lateral paralelo ao eixo de enrolamento e um estreitamento da mesma, tornando a concha mais cilíndrica.

5- Calo da parede parietal (não aditivo, passos: 4; ic: 0,45; ir: 0,87).

0- ausente ou indistinto (Fig. 1-5); 1- calo distinto (Fig. 16, 30), (Adelomelon brasilianus, Leptegouana guttata); 2- calo muito espesso ultrapassando o contorno da concha (Austroginella muscaria) (Fig. 19); 3- micro-granulado (Eratoidea aureocincta, Eratoidea eburneola, Eratoidea scalaris, Eratoidea sp., "Marginella" ealesae, Marginella glabella, Marginella rosea, Marginella sebastiani) (Fig. 37; SOUZA, 1993: fig. 1.).

O calo parietal é uma deposição de material conquiliológico que ocorre sobre a parede parietal (lábio interno da abertura). Nos Marginellini o calo parietal está recoberto por uma granulação microscópica (SOUZA, 1993, fig. 1.). 
6- Plicas columelares (não aditivo, passos: 2; ic: 1; ir: 1).

0- ausentes (Fig. 15, 17); 1- presentes em mesmo número desde a primeira volta da teleoconcha (Adelomelon brasilianus, Austroginella muscaria, Eratoidea aureocincta, Eratoidea eburneola, Eratoidea scalaris, Eratoidea sp., "Eratoidea" watsoni, "Marginella" ealesae, Marginella glabella, Marginella rosea, Marginella sebastiani, Marginellona gigas, Prunum fulminatum, Leptegouana guttata, Prunum prunum, Prunum rubens, Prunum brasilianum, Leptegouana tripartita, Prunum warreni); 2- presentes, mas aumentando em número de acordo com o crescimento da concha (Persicula sagittata).

7- Fusão da primeira plica columelar com parte anterior lábio externo (passos: 1; ic: 1 ; ir: 1$)$.

0- ausente; 1- presente (Fig. 39) (Austroginella muscaria, Eratoidea aureocincta, Eratoidea eburneola, Eratoidea scalaris, Eratoidea sp., "Eratoidea" watsoni, "Marginella" ealesae, Marginella glabella, Marginella rosea, Marginella sebastiani, Prunum fulminatum, Leptegouana guttata, Prunum prunum, Prunum rubens, Prunum brasilianum, Leptegouana tripartita, Prunum warreni).

8- Arranjo da plicas columelares (passos: 3 ; ic: 0,66; ir: 0,90).

0- plicas ausentes; 1 - ocupando menos da metade do comprimento do comprimento da abertura (Adelomelon brasilianus, Marginellona gigas, Persicula sagittata, Prunum fulminatum, Leptegouana guttata, Prunum brasilianum, Leptegouana tripartita, Prunum warreni) (e.g., Fig. 16, 30, 32) ; 2- ocupando mais da metade do comprimento da parede parietal (Austroginella muscaria, Eratoidea aureocincta, Eratoidea eburneola, Eratoidea scalaris, Eratoidea sp., "Eratoidea” watsoni, "Marginella” ealesae, Marginella glabella, 
Marginella rosea, Marginella sebastiani, Prunum prunum, Prunum rubens) (e.g., Fig. 26, $35)$.

Plicas columelares não são exclusivas dos Marginellidae, vários gastrópodes as possuem em vários graus de expressão (e.g. Turbinellidae, Mitridae, Costelariidae, Volutidae). Dentro do universo analisado, foi possível separá-las em diferentes graus de expressão e arranjos. Persicula sagittata possui o arranjo típico dos Cystiscidae (sensu COOVERT \& COOVERT, 1995), nos quais o número de plicas aumenta conforme o animal cresce. Adelomelon brasilianus e Marginellidae apresentam plicas em mesmo número desde as primeiras voltas da concha, mas apenas estes últimos apresentam a fusão da primeira plica com o lábio externo da abertura.

9- Dentes parietais (passos: 2; ic: 0,5; ir: 0,66).

0- ausentes (e.g., Fig. 30, 36); 1- presentes ("Eratoidea" watsoni, Prunum fulminatum, Prunum prunum, Prunum rubens) (Fig. 39).

Dentes parietais são estruturas muito variáveis encontradas em diversos grupos de Gastrópodes (e.g. Cypraeidae, Eratoidae), sendo provavelmente homoplásticas. Nos Marginellidae, estes dentes só estão presentes no animal adulto, com o lábio já espessado, e se estendem, posteriormente, por menos de meia volta a partir da abertura e podem ser muito semelhantes às plicas verdadeira e, portanto, foram chamados de "falsa plica" (false plication) por COOVERT \& COOVERT (1995). 
10- Dentes do lábio externo (passos: 3; ic: 0,33; ir: 0,66).

0- ausentes; 1- presentes (Fig. 37) (Eratoidea aureocincta, Eratoidea eburneola, Eratoidea sp., Eratoidea scalaris, "Eratoidea” watsoni, Marginella glabella, Marginella rosea, Marginella sebastiani).

COOVERT \& COOVERT (1995) chamam a atenção para distinção com liras internas da abertura, presentes nos Cystiscidae, que são cristas paralelas que iniciam sua formação antes do animal ter atingido seu tamanho máximo. Nos Marginellidae, os dentes do lábio externo estão entre as últimas estruturas a se formar na concha (SOUZA \& COOVERT, 2001), sendo associadas à defesa contra predação, por estreitar a área da abertura (NEHM, 2001).

11- Espessamento do lábio externo (não aditivo, passos: 2; ic: 1; ir: 1).

0- ausente (e.g., Fig. 16, 18); 1- presente (Fig. 40) (Austroginella muscaria, Eratoidea aureocincta, Eratoidea eburneola, Eratoidea scalaris, Eratoidea sp., "Eratoidea" watsoni, Leptegouana guttata, Leptegouana tripartita, Marginella glabella, Marginella rosea, Marginella sebastiani, Marginellona gigas, Prunum brasilianum); 2presente com sulco externo dorsal (Fig. 41) (Prunum fulminatum, Prunum prunum, Prunum rubens).

O espessamento do lábio externo é uma das características mais marcantes da família e daí deriva seu nome (do latim margo, margem). Como os marginellidae possuem crescimento determinado, o lábio espesso se forma ao final do crescimento do animal. Em alguns casos o espessamento do lábio é refletido externa e dorsalmente, formando um sulco na parte dorsal externa do lábio. 
12- Canal anal da abertura bem definido (passos: 2; ic: 0,5; ir: 0,5).

0- ausente (e.g., Fig. 32, 34); 1- presente (Fig. 38) (Austroginella muscaria, Eratoidea aureocincta, Eratoidea eburneola, Eratoidea scalaris, Eratoidea sp., “Eratoidea” watsoni, Marginella glabella, Marginella rosea, Marginella sebastiani).

\section{Discussão}

Historicamente, a maioria dos caracteres utilizados nas classificações malacológicas vem da concha. No entanto, alguns autores (e.g. DAVIS, 1979; KOOL, 1993; ROBERTSON, 1996) afirmam que caracteres conquiliológicos devem ser evitados, pois a concha, por ser a parte do molusco mais exposta ao ambiente, seria mais suscetível a processos seletivos, e portanto os caracteres dela derivados, mais homoplásticos. Mais recentemente, SCHANDER \& SUNDBERG (2001) examinaram 28 estudos filogenéticos que utilizaram caracteres de concha e das partes moles, e comparou estatisticamente os índices de consistência e retenção dos dois tipos de caracteres, e seus resultados não mostraram diferenças significativas entre eles. WAGNER (2001), também fez comparações estatísticas analisado 2 estudos filogenéticos que utilizaram caracteres de concha e das partes moles, e chegou a resultados indicando que caracteres conquiliológicos sofrem mais mudanças que caracteres morfológicos, mas observou que a ocorrência de homoplasias também é grande nas partes moles. No entanto, a comparação entre os comprimentos das árvores obtidas com estes dados, com matrizes randômicas contendo o mesmo número de táxons e caracteres, indicou que dados conquiliológicos são informativos.

Numa análise cladística é algumas vezes difícil utilizar caracteres conquiliológicos, pois se modificam de maneira gradual, sendo difícil estabelecer, sem ambigüidade, seus estados. Outro problema é a universalidade dos caracteres, caracteres que são homoplásticos em um determinado universo taxonômico, podem ser altamente congruentes e informativos em um subconjunto deste mesmo universo, WAGNER (2001) 
comenta sobre isso e sugere que em análises de ramos mais restritos, poderá obter estimativas filogenéticas mais acuradas utilizando-se caracteres conquiliológicos. Esse tipo de análise foi realizado por SOUZA \& COOVERT (2001), numa revisão conquiliológica do gênero Bullata.

No presente estudo o comportamento dos caracteres conquiliológicos variou muito, com alguns altamente informativos (e.g., caráter 7), outro, apresentando estados altamente homoplásticos e estados informativos (e.g., caráter 5). Mas a maioria, mesmo apresentando homoplasias ao longo da árvore, ajuda a sustentar alguns clados (caracteres 3, 4, 8, 9, etc.). Isso pode ser dito da maioria dos caracteres levantados aqui, conquiliológicos ou anatômicos, demonstrando que com uma ampla base de dados comparativos, as homoplasias, levantadas em um determinado órgão ou complexo, passam pelo crivo da congruência, e acabam por fortalecer o sinal filogenético e não mascará-lo.

A forma geral da concha é uma das mais conspícuas características da família Marginellidae. A combinação de superfície brilhante, lábio espesso (do qual se origina o nome Marginella), e plicas columelares conspícuas, geralmente é associada com essa família, mas não é exclusiva dela. A forma fusiforme, as plicas columelares e lábio externo espessado estão presentes isoladamente em diversas famílias (e.g. Eratoidae: Cypraeoidea), mas na família Cystiscidae, estes caracteres também estão combinados, levando a sua classificação entre os Marginellidae. No entanto a fusão da $1^{\underline{a}}$ plica com o lábio externo é única dos Marginellinae.

Outro aspecto interessante refletido na a concha é processo que aqui chamamos de "lateralização", que parece ter ocorrido independentemente algumas vezes em Gastropoda (e.g. Cypraeoidea, Stromboidea, Olividae) (SIMONE, 2000). Neste processo, a concha se torna mais cilíndrica, a abertura se torna mais longa, estreita e se alinha paralelamente ao eixo de enrolamento da concha. Como veremos a seguir esse processo também se reflete em vários sistemas de órgãos. 


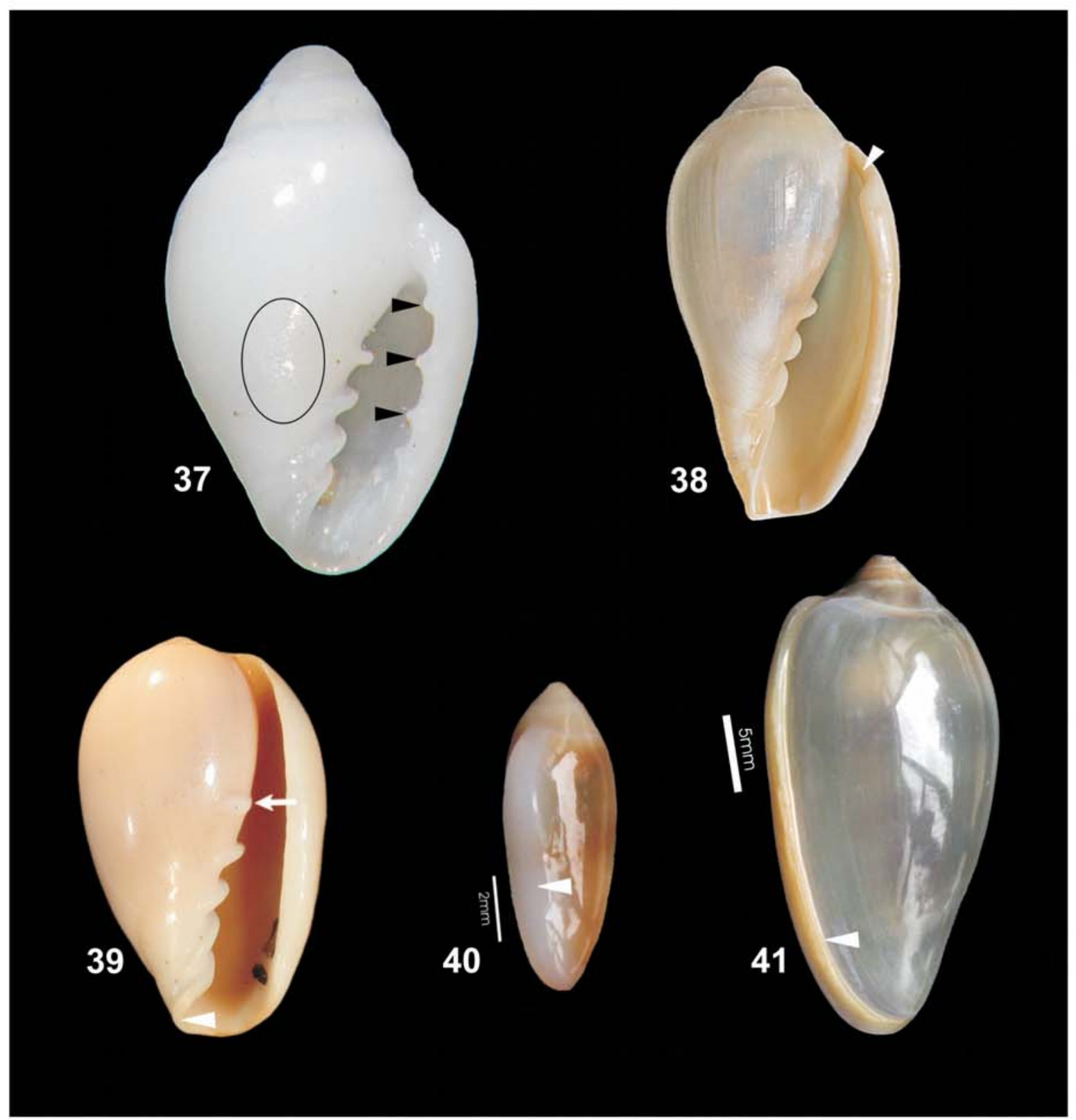

Figuras 37 - 41 Detalhes dos caracteres conquiliológicos. 37. Eratoidea scalaris, triângulos indicam dentes do lábio externo, círculo indica granulação no calo ventral. 38. Marginella sebastiani, triângulo indica canal anal da abertura. 39. Prunum rubens seta, indica dente parietal, triângulo indica fusão da primeira plica columelar com lábio externo. 40. Leptegouena tripartita triângulo indica lábio espessado sem sulco.41 Prunum prunum, triângulo indica lábio espessado com sulco dorsal. 


\subsubsection{Massa céfalo-pediosa}

13- Tamanho do pé quando retraído na concha (passos: 1 ; ic: 1 ; ir: 1 ).

0- menos de 1/2 volta (Trophon geversianus, Buccinanops gradatus, Persicula sagittata) (Fig. 42); 1- aproximadamente $3 / 4$ de volta (Adelomelon brasilianus, Marginellona gigas, Austroginella muscaria, Eratoidea scalaris, Eratoidea aureocincta, Eratoidea sp., "Eratoidea" watsoni, Prunum prunum, Prunum rubens, Prunum fulminatum, Prunum brasilianum, Prunum warreni) (Fig. 46).

14- Retração do pé (passos: 1; ic: 1; ir: 1).

0- por dobramento transversal (Fig. 42); 1- por dobramento longitudinal (Adelomelon brasilianus, Austroginella muscaria, Eratoidea aureocincta, Eratoidea eburneola, Eratoidea scalaris, Eratoidea sp., “Eratoidea” watsoni, Leptegouana guttata, Leptegouana tripartita, "Marginella” ealesae, Marginella glabella, Marginella rosea, Marginella sebastiani, Marginellona gigas, Persicula sagittata, Prunum brasilianum, Prunum fulminatum, Prunum prunum, Prunum rubens, Prunum warreni) (Fig. 46).

O dobramento transversal do pé é uma plesiomorfia de Gastropoda, posicionando o opérculo para ocluir a abertura da concha. Com a lateralização do animal, estreitamento da abertura e a perda do opérculo, o dobramento passa a ser longitudinal.

15- Forma da cabeça (passos: 1 ; ic: 1 ; ir: 1$)$.

0- séssil (Fig. 42); 1- em aba (Adelomelon brasilianus, Austroginella muscaria, Eratoidea aureocincta, Eratoidea eburneola, Eratoidea scalaris, Eratoidea sp., "Eratoidea" watsoni, Leptegouana guttata, Leptegouana tripartita, "Marginella" 
ealesae, Marginella glabella, Marginella rosea, Marginella sebastiani, Marginellona gigas, Prunum brasilianum, Prunum fulminatum, Prunum prunum, Prunum rubens, Prunum warreni) (Fig. 44, 45, 46, 47).

Chamamos de séssil quando a base dos tentáculos se situa diretamente na hemocele, acima do rincóstoma. Nos Volutidae e nos Marginellidae a base dos tentáculos se situa numa aba que cobre o rincóstoma.

16- Abas laterais da cabeça (passos: 2; ic: 0,5; ir: 0).

0- ausente (Fig 43, 47). ; 1- presente (Adelomelon brasilianus, Marginellona gigas) (Fig. 44).

Adelomelon brasilianus e Marginellona gigas possuem a aba basal de suas cabeças muito expandidas com projeções laterais, esse é um caráter normalmente associado aos Volutidae (CLENCH \& TURNER, 1964).

17- Base dos tentáculos (não aditivo; passos: 3 ; ic: 0,66; ir: 0,66).

0- distantes (Fig. 42, 44); 1- próximas (Austroginella muscaria, Eratoidea aureocincta, Eratoidea eburneola, Eratoidea scalaris, Eratoidea sp., "Eratoidea" watsoni, Leptegouana guttata, Leptegouana tripartita, "Marginella" ealesae, Marginella glabella, Marginella rosea, Marginella sebastiani, Prunum brasilianum, Prunum fulminatum, Prunum prunum, Prunum rubens, Prunum warreni) (Fig. 45, 47) 2modificadas (Persicula sagittata) (Fig. 43).

A extrema proximidade das bases dos tentáculos em Marginellidae difere dos demais Muricoidea, que normalmente possuem uma convexidade próxima à região do rincóstoma que afasta as bases dos tentáculos uma da outra. Em Persicula sagittata há 
uma grande modificação das bases dos tentáculos em forma de aba vertical, e se projetam anteriormente.

18- Músculo columelar (passos: 1; ic: 1; ir: 1)

0- liso (Fig. 42); 1- lobado (Austroginella muscaria, Eratoidea aureocincta, Eratoidea eburneola, Eratoidea scalaris, Eratoidea sp., "Eratoidea" watsoni, Leptegouana guttata, Leptegouana tripartita, "Marginella” ealesae, Marginella glabella, Marginella rosea, Marginella sebastiani, Prunum brasilianum, Prunum fulminatum, Prunum prunum, Prunum rubens, Prunum warreni) (Fig. 45, 46)

As plicas columelares estão presentes em Persicula sagittata, Adelomelon brasilianus e Marginellona gigas, mas apenas nos Marginellinae o músculo columelar tem sua forma significativamente alterada por elas. Os lóbulos não chegam a formar unidades distintas, mas regiões mais grossas e delgadas são bem marcadas, assim como sua borda posterior.

19- Forma da hemocele e passagem do esôfago e aorta para a massa pálio-visceral (passos: 1; ic: 1; ir: 1).

0- semi-simétrica, em forma de gota, saída do esôfago posterior (Fig. 21, 22); 1assimétrica, posteriormente arredondada, saída do esôfago lateral (Fig. 23) (Austroginella muscaria, Eratoidea aureocincta, Eratoidea eburneola, Eratoidea scalaris, Eratoidea sp., "Eratoidea" watsoni, Leptegouana guttata, Leptegouana tripartita, "Marginella" ealesae, Marginella glabella, Marginella rosea, Marginella sebastiani, Prunum brasilianum, Prunum fulminatum, Prunum prunum, Prunum rubens, Prunum warreni).

A forma da hemocele é determinada pela posição da comunicação entre esta e a massa pálio-visceral. Esta comunicação fica evidenciada na hemocele pela presença de um septo musculoso, por ela passam a aorta e o esôfago. 

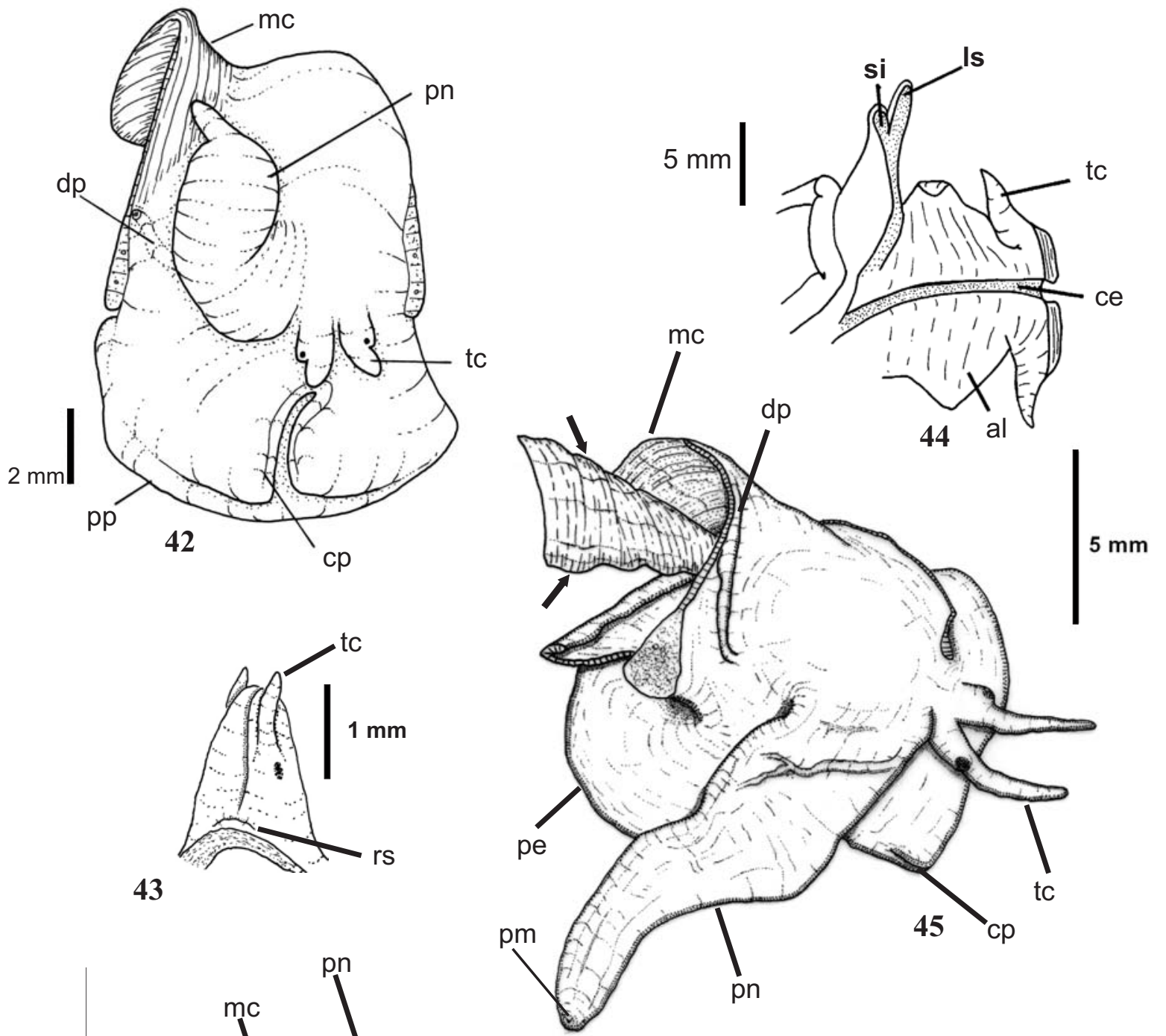

43
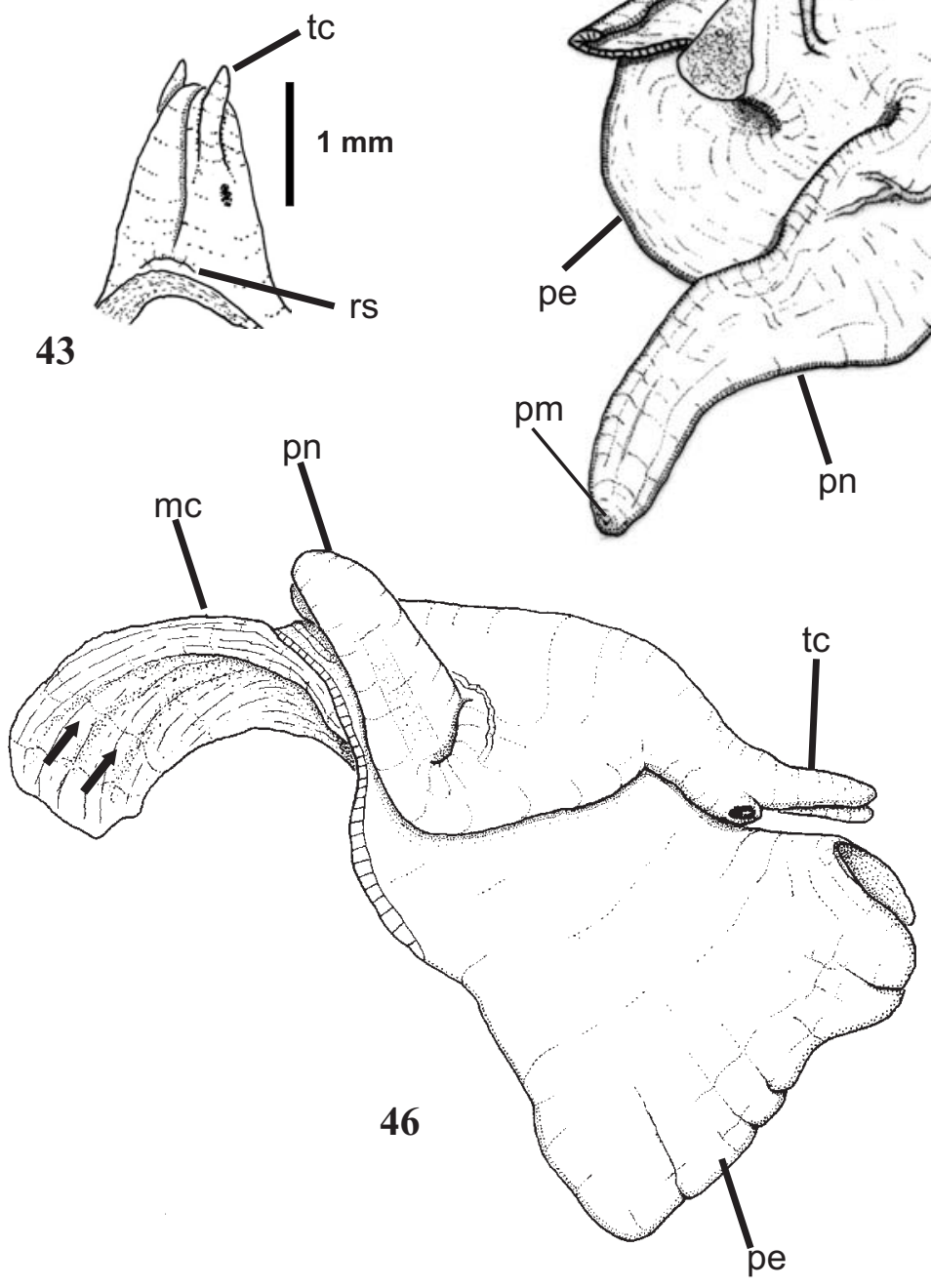

$1 \mathrm{~mm}$

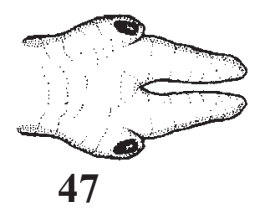

Figuras 42 - 47. 42. Massa céfalo-pediosa de Trophon sp. 43. Cabeça de Persicula sagitta. 44. Cabeça e sifão de Marginellona gigas (modificado de Harasewych \& Kantor, 1991). 45. Massa céfalo-pediosa de Marginella rosea. 46 . Massa céfalo-pediosa de Eratoidea scalaris. 47. Cabeça de Eratoidea scalaris. al - aba lateral da cabeça; ce - calha cefálica; cp - calha da glândula pediosa; dp - duto peniano; mc - músculo columelar; pe - pé; pm - poro genital masculino; pn - pênis; pp - margem posterior do pé; rs - rincóstoma; si - sifão inalante; tc - tentáculo cefálico. 


\section{Discussão:}

Já foi observado (GRAY, 1857) que o tamanho do pé geralmente está relacionado com o habitat, ou seja, é possível deduzir que o animal vive em sedimento ou substrato inconsolidado quando o pé é mais amplo. Boa parte dos Marginellidae que se tem informação sobre sua história natural (e.g., FRETTER, 1976; GOFAS, PONDER \& TAYLOR, 1992) vivem associados ao sedimento inconsolidado (observação pessoal em Prunum brasilianum, Leptegouana guttata).

A massa céfalo-pediosa apresenta dois caracteres que evidenciam o processo de lateralização do animal, entre ele podemos destacar o dobramento longitudinal do pé, que em alguns Muricoidea já ocorre na parte anterior do pé, e a forma da hemocele determinada pela posição da comunicação com a massa pálio-visceral. Apesar de este caráter ter sido codificado como plesiomórfico em Marginellona gigas, este táxon se encontra num estágio intermediário, pois sua hemocele já apresenta uma forma mais arredondada como as dos demais Marginellidae. No entanto, a passagem do esôfago para a massa pálio-visceral ainda é posterior aos demais órgãos da hemocele, que foi o critério utilizado para se estabelecer o estado apomórfico.

Já Persicula sagittata apresenta a sua hemocele ainda num estágio mais plesiomórfico, com a comunicação para a massa céfalo pediosa, bem posterior, enquanto outros caracteres já vistos, como o alongamento da abertura e seu alinhamento com o eixo de enrolamento da concha, e dobramento do pé, indicam que a evolução distinta, ainda que em muitos aspectos convergentes, desta transformação. Esse processo de lateralização pode ser entendido como um deslocamento da massa pálio-visceral em relação à massa céfalo pediosa, no sentido horário, grosseiramente, em cerca de $45^{\circ}$ (Fig. 48), efetivamente contra o sentido da torção dos Gastropoda. 


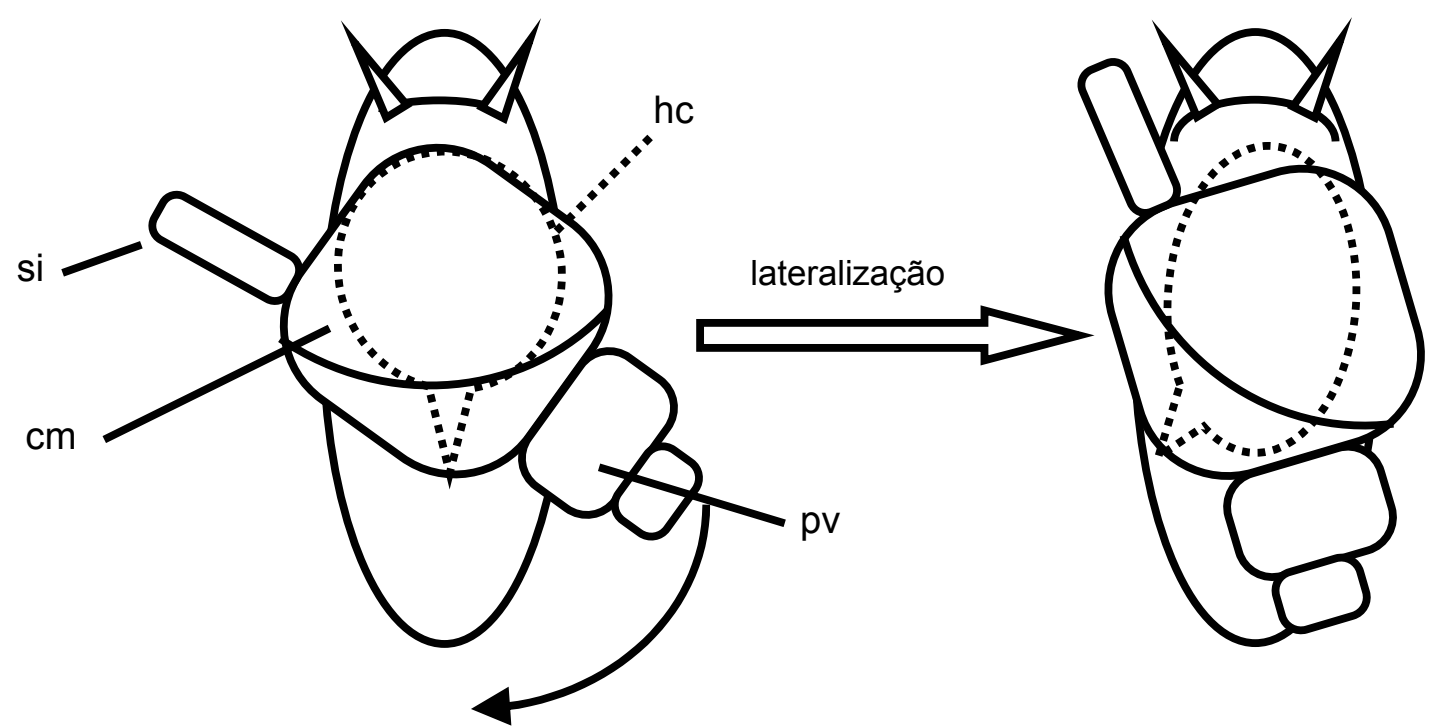

Figura 48. Diagrama do processo de lateralização ocorrido nos Marginellidae. $\mathrm{cm}$ - cavidade palial; hc - hemocele; pv - massa pálio-visceral; si - sifão inalante.

Dado que no grupo estudado todos os táxons que apresentam aspectos de lateralização, vivem associados ao sedimento e pelo menos os Marginellinae e os Cystiscidae possuem hábitos de se enterrar durante o dia, então podemos especular que essas modificações sejam adaptações a esse habitat. Ou seja, a lateralização observada em vários órgãos, seria uma reflexo da modificação a concha para uma forma mais fusiforme, que oferece menos resistência ao atrito do sedimento.

PRICE (2003) testou, experimentalmente, hipóteses funcionais sobre a relação entre o músculo columelar e plicas columelares, como o aumento da área entre contato do músculo e plicas servindo como guias para a contração do músculo, mas não examinou seus dados morfológicos em um contexto evolutivo. A autora concluiu que a forma do músculo se altera para se amoldar à presença das plicas sem nenhuma correlação funcional significativa. As plicas columelares dos Marginellidae são muito características assim como a morfologia do músculo columelar, não faz parte deste estudo analisar morfologia funcional, mas uma estrutura tão constante dificilmente permaneceria assim, caso não tivesse um significado evolutivo. 


\subsection{3. Órgãos do manto e sistemas circulatório e excretor.}

20- Sifão anal (passos: 4; ic: 0,75 ; ir: 0,93 ).

0- ausente (Fig. 49).; 1- rudimentar (Leptegouana guttata, Leptegouana tripartita, Prunum brasilianum, Prunum fulminatum, Prunum prunum, Prunum rubens, Prunum warreni) (Fig. 56); 2- distinto e muscular (Fig. 51, 52) (Austroginella muscaria, "Marginella" ealesae, Marginella rosea, Marginella glabella, Marginella sebastiani); 3alongado (Fig. 53) (Eratoidea aureocincta, Eratoidea eburneola, Eratoidea scalaris, Eratoidea sp.).

O sifão anal é uma estrutura relativamente incipiente, se comparada ao sifão inalante, mas em seu estado mais rudimentar (estado 1) pode ser percebido por um espessamento do manto, como uma ligeira flexão externa e um dobramento agudo. Em Austroginella muscaria ele é bastante muscular e o tegumento é repleto de dobras, indicando ser capaz de considerável protração. Nos Marginellini o sifão anal é ainda mais desenvolvido, formando uma dobra bastante distinta, podendo ser mais muscular e arredondado em Marginella, ou mais delgado e falciforme, em Eratoidea.

21- Filamentos do osfrádio (passos: 4; ic: 0,25 ; ir: 0,5 ).

0- quase simétricos (Fig. 49, 54); 1- claramente assimétricos (Eratoidea aureocincta, Eratoidea eburneola, Eratoidea scalaris, Eratoidea sp., "Eratoidea" watsoni, "Marginella" ealesae, Prunum brasilianum) (Fig. 52).

Com exceção de "Marginella" ealesae, todas as espécies que possuem o osfrádio assimétrico (filamentos esquerdos bem mais curtos que os direitos) são pequenas (entre $3.5-8 \mathrm{~mm}$ ) podendo este caráter estar associado a uma miniaturização. 
22- Nervo do osfrádio (passos: 3; ic: 0,66; ir: 0,92).

0- sem septo (Fig. 49, 52). ; 1- sobre um septo, conecta-se ao gânglio osfradial passando sob as lamelas do osfrádio (Austroginella muscaria); 2- sobre um septo conectase diretamente ao gânglio osfradial (Leptegouana guttata, Leptegouana tripartita, Prunum prunum, Prunum fulminatum, Prunum rubens, Prunum brasilianum, Prunum warreni) (Fig. 54).

O nervo do osfrádio, plesiomorficamente, é imperceptível ao exame sob estéreomicroscópio, nos Marginellinae, esse nervo se desloca para superfície, correndo sob a borda de um pequeno septo. No estado 1, esse septo, apesar de perceptível, é baixo, e o nervo ao se aproximar das lamelas, passa por baixo destas para se conectar ao gânglio osfradial. No estado 2, o septo é muito mais pronunciado, pois se estende do soalho da cavidade palial até o gânglio osfradial.

23- Relação entre comprimento do osfrádio e comprimento do ctenídio (passos: 1; ic: 1 ; ir: 1).

0- aproximadamente 1/2 do ctenídio (Fig. 49); 1- mais de 3/4 do ctenídio (Fig. 49, 52, 54) (Adelomelon brasilianus, Buccinanops gradatus, Eratoidea aureocincta, Eratoidea eburneola, Eratoidea scalaris, Eratoidea sp., "Eratoidea" watsoni, Leptegouana guttata, Leptegouana tripartita, “Marginella” ealesae, Marginella glabella, Marginella rosea, Marginella sebastiani, Marginellona gigas, Persicula sagittata, Prunum brasilianum, Prunum rubens).

24- Extremidade anterior do osfrádio (passos: 1; ic: 1; ir: 1).

0- junto à extremidade anterior do ctenídio (Fig. 49, 52, 54); 1- anterior à extremidade anterior do ctenídio (Marginella glabella, Marginella sebastiani). 
25- Borda livre dos filamentos do ctenídio (passos: 2; ic: 0,5; ir: 0,87).

0- reta (Fig. 52, 54); 1- truncada (Fig. 49) (Eratoidea aureocincta, Eratoidea eburneola, Eratoidea scalaris, Eratoidea sp., "Eratoidea” watsoni, Marginella glabella, Marginella rosea, Marginella sebastiani).

26- Conexão entre na veia ctenidial e aurícula (passos: 2 ; ic: 0,5 ; ir: 0,85 ).

0- terminal (Fig. 50); 1- sub-terminal (Fig. 53) (Austroginella muscaria, Leptegouana guttata, Leptegouana tripartita, Prunum brasilianum, Prunum fulminatum, Prunum prunum, Prunum rubens, Prunum warreni).

Plesiomorficamente, a extremidade posterior da veia ctenidial se conecta à aurícula. Em Austroginella muscaria e nos Prunini, essa conexão se dá antes de extremidade posterior, formando uma ligação em $\mathrm{T}$.

27- Posição do pericárdio em relação à extremidade posterior do ctenídio (passos: 1; ic: 1 ; ir: 1).

0- posterior; 1- à esquerda (Adelomelon brasilianus, Austroginella muscaria, Eratoidea aureocincta, Eratoidea eburneola, Eratoidea scalaris, Eratoidea sp., "Eratoidea" watsoni, Leptegouana guttata, Leptegouana tripartita, "Marginella" ealesae, Marginella glabella, Marginella rosea, Marginella sebastiani, Marginellona gigas, Prunum brasilianum, Prunum fulminatum, Prunum prunum, Prunum rubens, Prunum warreni) (Fig. 49, 52, 54). 
O pericárdio, plesiomorficamente, está situado na extremidade posterior esquerda da cavidade do manto. No seu estado apomórfico, o pericárdio situa-se mais anteriormente, ao lado da porção posterior do ctenídio.

28- Posição do reto em relação ao oviduto (passos: 1; ic: 1; ir: 1).

0- à esquerda; 1- dorsal (Austroginella muscaria, Eratoidea aureocincta, Eratoidea eburneola, Eratoidea scalaris, Eratoidea sp., "Eratoidea” watsoni, Leptegouana guttata, "Marginella" ealesae, Marginella glabella, Marginella rosea, Marginella sebastiani, Marginellona gigas, Persicula sagittata, Prunum brasilianum, Prunum fulminatum, Prunum prunum, Prunum rubens, Prunum warreni).

29- Forma do rim (passos: 2; ic: 0,5 ; ir: 0,85 ).

0- alongada (Fig. 49); 1- curto e largo (Fig. 54) (Leptegouana guttata, Leptegouana tripartita, "Marginella" ealesae, Prunum brasilianum, Prunum rubens).

30- Cavidade renal (passos: 3; ic: 0,33; ir: 0,75).

0- não envolvendo a parte posterior do pericárdio; 1- envolvendo a parte posterior do pericárdio (Adelomelon brasilianus, Austroginella muscaria, "Eratoidea" watsoni, "Marginella" ealesae, Marginella glabella, Marginella sebastiani, Marginellona gigas, Prunum brasilianum, Prunum fulminatum, Prunum prunum, Prunum warreni).

Plesiomorficamente a cavidade renal, que abriga os lóbulos renais e a glândula nefridial, fica aderida ao lado direito do pericárdio. No estado 1 deste caráter, a cavidade renal se estende, também, pela parede posterior do pericárdio. 

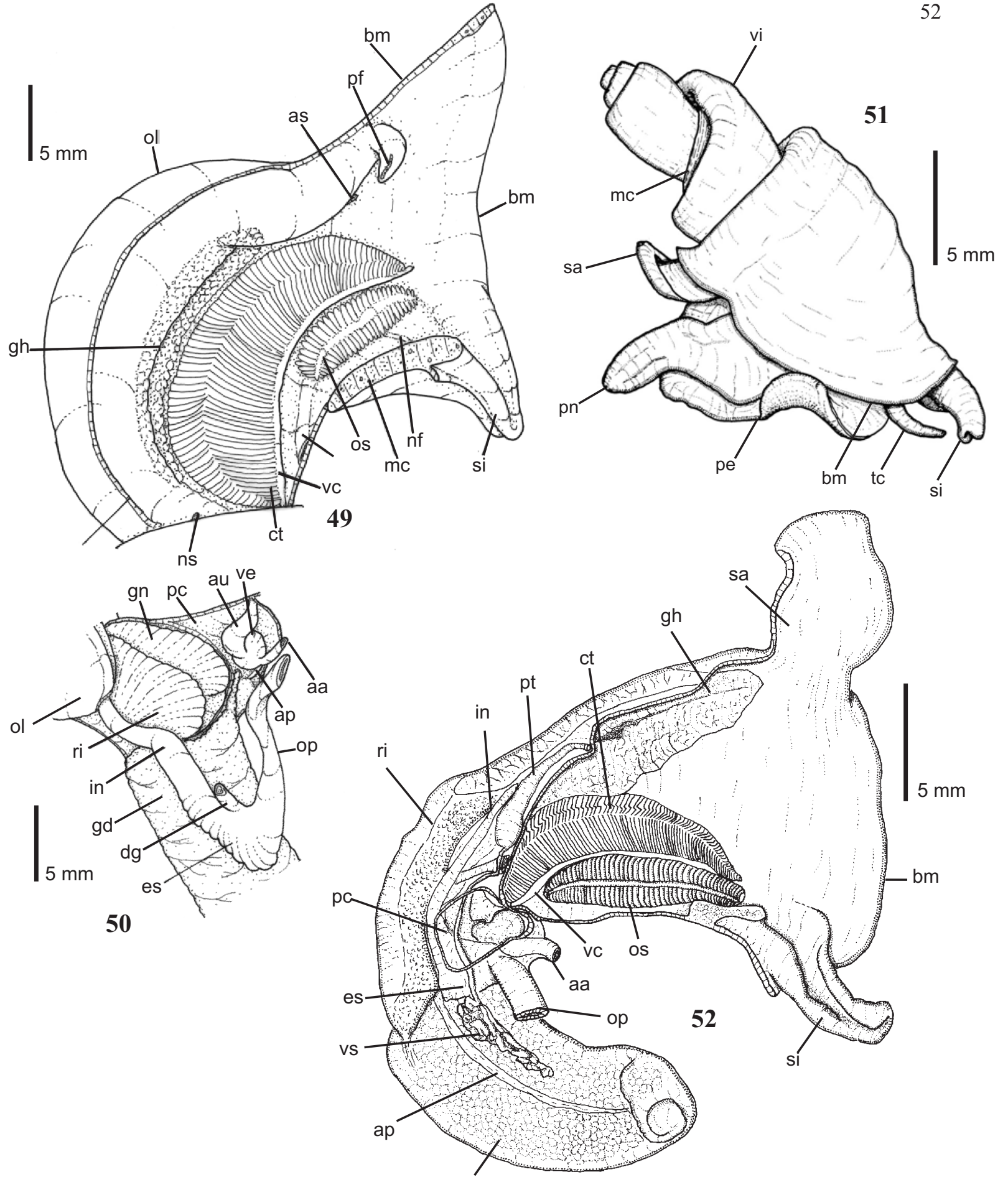

gg

Figuras 49 - 52. 49. Massa pálio-visceral de Trophon geversianus, fêmea. 50. Detalhe da região do pericárdio de Trophon geversianus. 51. Animal sem concha de Marginella rosea, macho. 52. Massa pálio-visceral de Marginella rosea, macho. aa - aorta anterior; ap - aorta posterior; as - ânus; au - aurícula; bm - borda do manto; ct - ctenídio; dg - duto da glândula digestiva; es estômago; gd - glândula anal; gg - glândula digestiva; gh - glândula hipobranquial; gn -glândula nefridial; in intestino; mc - músculo columelar; nf - nervo osfradiano; ns - nefróstoma; ol - oviduto palial; op - esôfago posterior; os - osfrádio; pc - pericárdio; pf - poro genital feminino; pn pênis; pt - próstata; ri - rim; sa - sifão anal; si - sifão inalante; tc - tentáculo cefálico; vc - veia ctenidial; vi - massa visceral; ve - ventrículo; vs - vesícula seminal. 

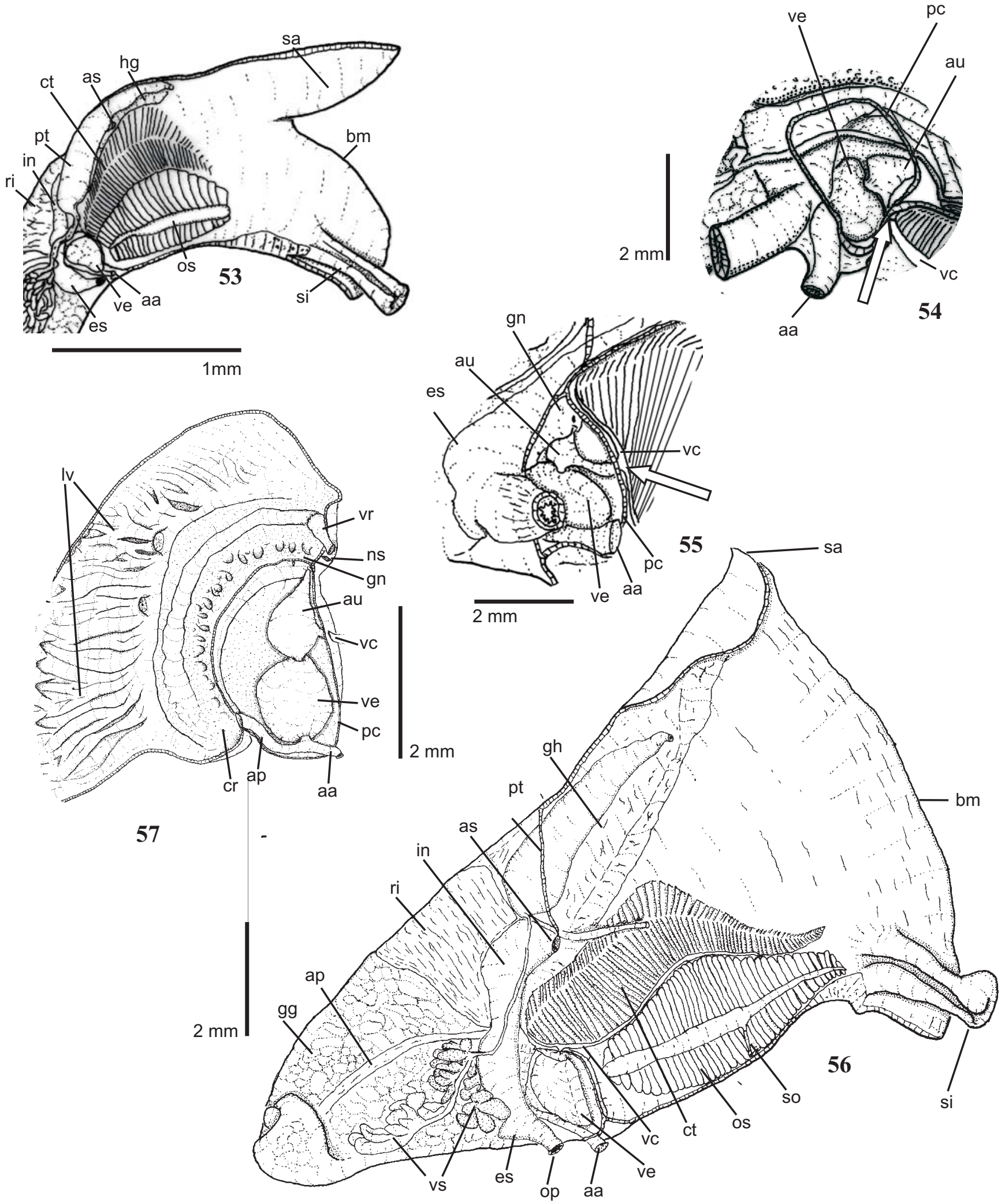

Figuras 53 - 57. 53. Cavidade palial de Dentimargo aureocincta. 54. Detalhe da região do pericárdio de Marginella rosea, seta indica a conexão terminal vc-au. 55. Detalhe da região do pericárdio de Leptegouana tripartita, seta indica a conexão subterminal vc-au. 56. Massa páliovisceral de Leptegouana tripartita, macho. 57. Detalhe da região do pericárdio e cavidade renal de Austroginella muscaria. aa - aorta anterior; ap - aorta posterior; as - ânus; au - aurícula; bm - borda do manto; cr - cavidade renal; ct - ctenídio; es - estômago; gg - glândula digestiva; gh - glândula hipobranquial; gn -glândula nefridial; in - intestino; lv - lobo ventral do rim; ns - nefróstoma; op - esôfago posterior; os - osfrádio; pc - pericárdio; pt - próstata; ri - rim; sa - sifão anal; si - sifão inalante; so - septo do nervo osfradiano; vc - veia ctenidial; ve - ventrículo; vr - vaso renal; vs - vesícula seminal. 


\section{Discussão}

$\mathrm{Na}$ presente análise, o sifão anal nem sempre está associado a um canal anal na abertura, mas em Gastropoda nem sempre sifões estão associados a estruturas adjacentes da concha e vice-versa. Canais sifonais na concha podem ser formados sem nenhuma modificação aparente do manto (e.g. Stromboidea, maioria dos Cerithioidea, SIMONE, 2001, 2004), e em outros casos o canal sifonal da concha pode ser secundariamente perdido (e.g., canal sifonal inalante de alguns Marginellini e Prunini).

LINDBERG \& PONDER (2001) afirmam que os mecanismos de circulação de água pela cavidade do manto e evolução de suas estruturas foram fatores importantes na evolução dos Gastropoda e que estruturas, que promovem as correntes inalante e exalante, se tornam especialmente importantes nos Caenogastropoda (e.g. sifão inalante, ciliações específicas). Em alguns Marginellidae, essa tendência evolutiva se reflete num maior desenvolvimento do um sifão anal destacado (Fig. 51, 52, 53).

O arranjo dos órgãos na cavidade do manto, também, parece ter sofrido influência do processo de lateralização, dentre os quais podemos destacar o septo do osfrádio, a posição do pericárdio e a posição ventral dos elementos paliais do sistema reprodutor.

O septo do nervo osfradiano parece ser uma conseqüência da extrema lateralização alcançada nos Prunini, pois o nervo sai quase verticalmente da massa céfalo-pediosa em direção ao gânglio osfradiano. Esta foi a primeira observação deste tipo de estrutura em gastrópodes.

A função químio-receptora do osfrádio já foi reconhecida há algum tempo (LINDBERG \& PONDER, 2001 e referências aí citadas). Nos Caenogastropoda há uma correlação direta entre hábito alimentar carnívoro e o aumento de tamanho e complexidade do osfrádio (TAYLOR \& MILLER, 1989). A maioria dos Muricoidea é carnívora, 
portanto pode-se afirmar que o aumento da área do osfrádio, verificado neste estudo, seja reflexo da especialização a este hábito.

Os caracteres 26 e 27 refletem outro aspecto da lateralização: a posição anterior do pericárdio, sendo que isso gerou uma modificação também na conexão entre a veia ctenidial e a aurícula (caráter 24). Uma modificação análoga também ocorreu nos Cypraeidae, mas, ao contrário dos Marginellidae, o pericárdio está à direita da extremidade posterior do ctenídio e a conexão subterminal da veia ctenidial se dá por uma extensão da aurícula, dorsal ao ctenídio (SIMONE, 2004). 


\subsubsection{Sistema digestório}

31- Parede rincodeal (passos: 4; ic: 0,25; ir: 0,4).

0- musculosa (Fig. 67); 1- membranosa (Fig. 68) (Austroginella muscaria, Leptegouana guttata, Leptegouana tripartita, Prunum brasilianum, Prunum prunum, Prunum rubens).

A parede rincodeal é a porção que se inverte na retração das probóscides pleuroembólicas, também, chamada de bainha da probóscide (FRETTER \& GRAHAM, 1994). Plesiomorficamente, esta porção é indistinguível do resto da probóscide, ou seja, bastante musculosa. Já no estado 1, ela se torna extremamente delgada, membranosa, chegando a ser translúcida, distinta da parte anterior que permanece musculosa.

32- Músculos retratores laterais da probóscide (passos: 2; ic: 0,5; ir: 0,5).

0- par simetricamente disposto na hemocele (Fig. 58, 63); 1- retrator direito dorsal, retrator esquerdo ventral (Fig. 59, 64, 65, 96) (Austroginella muscaria, Eratoidea aureocincta, Eratoidea eburneola, Eratoidea scalaris, Eratoidea sp., "Eratoidea" watsoni, Leptegouana guttata, Leptegouana tripartita, "Marginella” ealesae, Marginella glabella, Marginella rosea, Marginella sebastiani, Marginellona gigas, Persicula sagittata, Prunum brasilianum, Prunum prunum, Prunum rubens).

Os Muricoidea possuem um par de músculos retratores laterais, que plesiomorficamente estão posicionados à esquerda e à direita da probóscide, no Cystiscidae e Marginellidae, a probóscide aparenta estar deitada sobre seu lado esquerdo, portanto o músculo retrator esquerdo se origina do soalho da hemocele, enquanto o direito se origina do teto. 


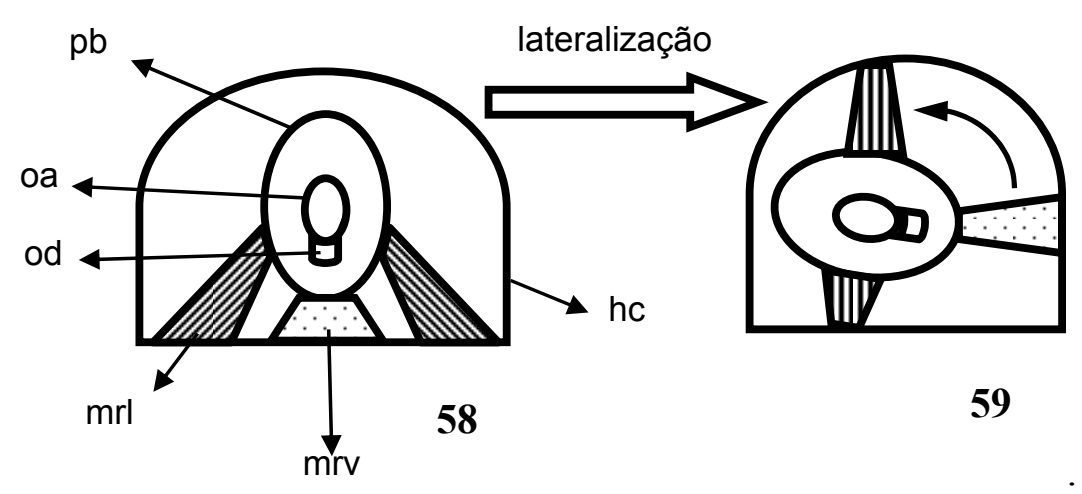

Figuras 58 - 59. Diagrama de um corte transversal da hemocele visto em direção anterior com a disposição da probóscide e de seus músculos retratores, mostrando a transição do caráter 32.58 - estado 0. 59- estado 1. hc - hemocele; mrl - músculo retrator lateral; mrv - músculo retrator ventral; oa - esôfago anterior; od - odontóforo; $\mathrm{pb}$ - probóscide.

33- Músculo acessório da probóscide (passos: 1; ic: 1; ir: 1).

0- ausente, 1- presente (Marginella glabella, Marginella rosea, Marginella sebastiani).

Este músculo tem forma de fita, é semicircular localizado na face dorsal da probóscide, posteriormente aos músculos retratores laterais.

34- Glândulas salivares acessórias (passos: 7; ic: 0,28; ir: 0).

0- um par (Fig. 66); 1- única (Eratoidea aureocincta, Eratoidea eburneola, Eratoidea scalaris, Eratoidea sp., Leptegouana tripartita, "Marginella" ealesae, Marginella glabella, Marginella rosea, Marginella sebastiani, Persicula sagittata, Prunum brasilianum, Prunum prunum, Prunum rubens) (Fig. 68, 71, 72); 2- ausentes (Austroginella muscaria, Buccinanops gradatus, "Eratoidea" watsoni, Leptegouana guttata) (Fig. 70). 
As glândulas salivares acessórias nos Cystiscidae e, especialmente nos Marginellidae, é um ceco membranoso e fracamente muscular. Em Persicula sagittata sua porção mais posterior ainda parece ter resquícios de tecido glandular.

35- Forma das glândulas salivares (passos: 2; ic: 0,5; ir: 0,75).

0- indefinida (Fig. 66, 67); 1- longas e saculiformes (Fig. 72) (Eratoidea aureocincta, Eratoidea eburneola, Eratoidea scalaris, Eratoidea sp., Persicula sagittata,).

36- Fusão das glândulas salivares (passos: 2; ic: 0,5; ir: 0,85).

0- ausente (Fig. 66, 72); 1- presente (Fig. 65, 67) (Austroginella muscaria, "Eratoidea" watsoni, Leptegouana guttata, Leptegouana tripartita, "Marginella" ealesae, Marginella glabella, Marginella rosea, Marginella sebastiani, Marginellona gigas, Prunum brasilianum, Prunum fulminatum, Prunum prunum, Prunum rubens, Prunum warreni).

A fusão das glândulas salivares ocorre apenas em suas porções glandulares, enquanto os dutos salivares permanecem separados.

37- Dutos salivares (passos: 3; ic: 0,33; ir: 0,66).

0- imersos na parede do esôfago (fig. 69, 70); 1- livres ou aderidos superficialmente à parede do esôfago (Eratoidea aureocincta, Eratoidea eburneola, Eratoidea scalaris, Eratoidea sp., Leptegouana guttata, Leptegouana tripartita, Marginella glabella, Marginella rosea, Marginella sebastiani, Marginellona gigas, 
Prunum brasilianum, Prunum fulminatum, Prunum prunum, Prunum rubens, Prunum warreni) (Fig. 71).

38- Posição das glândulas salivares com a probóscide retraída (não aditivo, passos: 5; ic: 0,6 ; ir: 0,83$)$.

0- fora da probóscide, ventral (Fig. 66); 1- a direita da probóscide dorsal ao esôfago (Fig. 67) (Marginellona gigas, "Marginella" ealesae, Marginella rosea, Marginella glabella, Marginella sebastiani); 2- a esquerda da probóscide (Fig. 65) (Leptegouana tripartita, Leptegouana guttata, Prunum brasilianum, Prunum fulminatum, Prunum prunum, Prunum rubens, Prunum warreni); 3- dentro da probóscide (Fig. 72) (Eratoidea aureocincta, Eratoidea eburneola, Eratoidea scalaris, Eratoidea sp., Persicula sagittata)

A mudança do posicionamento da probóscide dentro da hemocele, decorrente da lateralização (caráter 32, estado 1), foi acompanhada por um rearranjo dos demais órgãos da hemocele. O estado 1 seria uma manutenção da posição relativa das glândulas salivares, em relação à parte ventral da probóscide, ainda que alguns Marginellidae tenham mantido a posição original das glândulas, ventrais à probóscide. Os Prunini apresentam um deslocamento das glândulas salivares à esquerda da probóscide, que relativamente seria dorsal a esta.

39- Odontóforo (passos: 1; ic: 1; ir: 1).

0- presente (Fig. 70, 71, 73, 75); 1- ausente (Fig. 72) ("Marginella" ealesae, Eratoidea aureocincta, Eratoidea eburneola, Eratoidea scalaris, Eratoidea sp., Marginella glabella, Marginella rosea, Marginella sebastiani). 
O odontóforo e todos os seus constituintes (rádula, cartilagens, músculos) formam a estrutura mais típica dos Mollusca, ainda assim foi perdida inúmeras vezes ao longo de sua evolução. COOVERT \& COOVERT (1995) afirmam que a perda do odontóforo ocorreu duas vezes nos Marginellidae, na tribo Marginellini e no gênero Hyalina Schumacher, 1817, do qual não foram obtido exemplares para estudo.

40- Forma do odontóforo (passos: 2; ic: 0,5; ir: 0).

0- curto (Fig. 73); 1- alongado (Fig. 70, 71, 75) (Buccinanops gradatus, Persicula sagittata, Adelomelon brasilianus, Marginellona gigas, "Eratoidea" watsoni, Leptegouana tripartita, Leptegouana guttata, Prunum prunum, Prunum rubens, Prunum brasilianum); - - inaplicável, sem odontóforo (Eratoidea aureocincta, Eratoidea eburneola, Eratoidea scalaris, Eratoidea sp., “Marginella” ealesae, Marginella glabella, Marginella rosea, Marginella sebastiani).

41- Conexão do odontóforo com o tubo oral (passos: 1; ic: 1; ir: 1).

0- direta (fig. 73); 1- através de tubo (Fig. 71) (Adelomelon brasilianus, Austroginella muscaria, Eratoidea watsoni, Leptegouana guttata, Leptegouana tripartita, Marginellona gigas), 2-através de um tubo alongado (Fig. 75) (Prunum prunum, Prunum rubens, Prunum brasilianum, Prunum warreni, Prunum fulminatum); ; - - inaplicável, sem odontóforo (Eratoidea aureocincta, Eratoidea eburneola, Eratoidea scalaris, Eratoidea sp., "Marginella” ealesae, Marginella glabella, Marginella rosea, Marginella sebastiani).

Nos Caenogastropoda, o esôfago anterior se abre no tubo oral, cujo assoalho se encontra todo ocupado pelo odontóforo. Nos Muricoidea o odontóforo é mais destacado 
do tubo oral e não ocupa todo assoalhodeste. Nos Marginellidae há a tendência do odontóforo se tornar mais afastado do tubo oral, a ligação se alonga formando o tubo do odontóforo que se abre no tubo oral por uma abertura. Nas espécies examinadas do gênero Prunum este tubo é bastante alongado.

42- Rádula (passos: 2; ic: 1; ir: 1).

0- triserial (raquiglossa) (Fig. 76); 1- uniserial com perda dos laterais (Fig. 77, 78, 79) (Adelomelon brasilianus, Austroginella muscaria, "Eratoidea" watsoni, Leptegouana guttata, Leptegouana tripartita, Marginellona gigas, Persicula sagittata, Prunum brasilianumPrunum prunum, Prunum rubens); 2- ausente (Eratoidea aureocincta, Eratoidea eburneola, Eratoidea scalaris, Eratoidea sp., "Marginella" ealesae, Marginella glabella, Marginella rosea, Marginella sebastiani).

43- Base do dente raquidiano (passos: 3; ic: 0,66; ir: 0,85).

0- claramente curva (Fig. 76, 77); 1- fendida (Fig. 79) (Austroginella muscaria); 2 reta (fig. 78) ("Eratoidea" watsoni, Leptegouana guttata, Leptegouana tripartita, Marginellona gigas, Prunum brasilianum, Prunum fulminatum, Prunum prunum, Prunum rubens, Prunum warreni); ; -- inaplicável, sem odontóforo (Eratoidea aureocincta, Eratoidea eburneola, Eratoidea scalaris, Eratoidea sp., "Marginella" ealesae, Marginella glabella, Marginella rosea, Marginella sebastiani). 
44- Ceco sublingual (passos: 3; ic: 0,33; ir: 0,33).

0- com paredes musculosas; 1- com parede membranosa (Fig. 83) ("Eratoidea" watsoni, Leptegouana guttata, Leptegouana tripartita, Marginellona gigas, Persicula sagittata, Prunum brasilianum, Prunum fulminatum, Prunum prunum, Prunum rubens, Prunum warreni); -- inaplicável, sem odontóforo (Eratoidea aureocincta, Eratoidea eburneola, Eratoidea scalaris, Eratoidea sp., "Marginella" ealesae, Marginella glabella, Marginella rosea, Marginella sebastiani).

Ceco sublingual é uma pequena cavidade, ventral à parte exposta do odontóforo, onde se aloja a parte mais velha da radula. A parede ventral deste ceco, plesiomorficamente, não possui diferenciação no tegumento, mas em Persicula sagittata e algumas espécies de Marginellidae, ela se torna muito delgada e translúcida.

45- M2a (não aditivo, passos: 3; ic: 0,66; ir: 0,75).

0- indefinidos (Fig. 73); 1- conecta-se ao saco radular (Fig. 84, 86) (Austroginella muscaria, Buccinanops gradatus, Marginellona gigas); 2- conecta-se à parte posterior e lateral do odontóforo (Fig. 75, 88) ("Eratoidea" watsoni, Leptegouana guttata, Leptegouana tripartita, Prunum brasilianum, Prunum fulminatum, Prunum prunum, Prunum rubens, Prunum warreni); - - inaplicável, sem odontóforo (Eratoidea aureocincta, Eratoidea eburneola, Eratoidea scalaris, Eratoidea sp., "Marginella" ealesae, Marginella glabella, Marginella rosea, Marginella sebastiani).

Ramo dorsal do retrator do odontóforo (CARRIKER, 1943) Os músculos retratores do odontóforo normalmente seguem em único ramo, mas podem se dividir em ramos distintos. O ramo ventral invariavelmente conecta-se a parte posterior do odontóforo, enquanto o ramo dorsal pode conectar-se ao saco radular, ou na parte posterior lateral do odontóforo. 
46- Músculos jugais anteriores do odontóforo (não aditivo; passos: 6; ic: 0,5; ir: $0,4)$.

0- indefinidos 1- conectando-se somente ao esôfago (fig. 75, 86) (Adelomelon brasilianus, Austroginella muscaria, Leptegouana guttata, Prunum fulminatum, Prunum rubens, Prunum warreni) 2- conectando-se ao esôfago e à probóscide ("Eratoidea" watsoni, Prunum brasilianum, Prunum prunum); 3 conectando-se somente à probóscide (Fig. 71) (Leptegouana tripartita); - - inaplicável, sem odontóforo (Eratoidea aureocincta, Eratoidea eburneola, Eratoidea scalaris, Eratoidea sp., "Marginella" ealesae, Marginella glabella, Marginella rosea, Marginella sebastiani).

47- Músculo transversal (passos: 1; ic: 1; ir: 1).

0- circundando o tubo oral; 1 - circundando apenas a parte anterior do odontóforo (Fig. 73) (Austroginella muscaria, "Eratoidea" watsoni, Leptegouana guttata, Leptegouana tripartita, Marginellona gigas, Prunum brasilianum, Prunum fulminatum, Prunum prunum, Prunum rubens, Prunum warreni); - - inaplicável, sem odontóforo (Eratoidea aureocincta, Eratoidea eburneola, Eratoidea scalaris, Eratoidea sp., “Marginella” ealesae, Marginella glabella, Marginella rosea, Marginella sebastiani).

Músculo circular bucal (CARRIKER, 1943). Este é um músculo aparentemente derivado de uma parte do músculo mandibular dos Caenogastropoda, que foi posteriorizado e passa a circundar apenas a parte anterior do odontóforo próximo a junção deste com o tubo oral. 
48- Envoltório dorsal do odontóforo (m3) (passos: 1; ic: 1; ir: 1).

0-músculo membranoso (Fig. 73), 1- músculo distinto em forma de fita (Fig. 75, 88) (“Eratoidea" watsoni, Leptegouana guttata, Leptegouana tripartita, Prunum brasilianum, Prunum fulminatum, Prunum rubens, Prunum warreni); - - inaplicável, sem odontóforo (Eratoidea aureocincta, Eratoidea eburneola, Eratoidea scalaris, Eratoidea sp., “Marginella" ealesae, Marginella glabella, Marginella rosea, Marginella sebastiani).

Músculo protrator dorsal (CARRIKER, 1943).

49- Envoltório ventral do odontóforo (ev) (passos: 1; ic: 1; ir: 1).

0- membranoso; 1- musculoso (Fig. 71, 87, 89) (Adelomelon brasilianus, Austroginella muscaria, "Eratoidea" watsoni, Leptegouana guttata, Leptegouana tripartita, Marginellona gigas, Persicula sagittata, Prunum brasilianum, Prunum fulminatum, Prunum prunum, Prunum rubens, Prunum warreni); - - inaplicável, sem odontóforo (Eratoidea aureocincta, Eratoidea eburneola, Eratoidea scalaris, Eratoidea sp., "Marginella" ealesae, Marginella glabella, Marginella rosea, Marginella sebastiani).

Músculo protrator ventral (CARRIKER, 1943).

50- M4 (par) (passos: 1; ic: 1; ir: 1).

0- formam um único ramo (Fig. 81); 1- dividem-se em dois ramos, anterior (m4an) e posterior $(\mathrm{m} 4 \mathrm{p})$ (Fig. 84, 85, 88, 80, 92), que corre ventral ao anterior (Adelomelon brasilianus, Austroginella muscaria, "Eratoidea" watsoni, Leptegouana guttata, Leptegouana tripartita, Marginellona gigas, Persicula sagittata, Prunum brasilianum, 
Prunum fulminatum, Prunum prunum, Prunum rubens, Prunum warreni); - - inaplicável, sem odontóforo (Eratoidea aureocincta, Eratoidea eburneola, Eratoidea scalaris, Eratoidea sp., "Marginella” ealesae, Marginella glabella, Marginella rosea, Marginella sebastiani).

Músculos retratores subradulares dorsais (CARRIKER 1943)

51- Inserção de m4p (passos: 2; ic: 1; ir: 1).

0- m4p ausente; 1- látero-posterior (Fig. 85) (Adelomelon brasilianus, Marginellona gigas); 2- ventral (Fig. 90) (Austroginella muscaria, "Eratoidea” watsoni, Leptegouana guttata, Leptegouana tripartita, Prunum brasilianum, Prunum fulminatum, Prunum prunum, Prunum rubens, Prunum warreni); - - inaplicável, sem odontóforo (Eratoidea aureocincta, Eratoidea eburneola, Eratoidea scalaris, Eratoidea sp., “Marginella” ealesae, Marginella glabella, Marginella rosea, Marginella sebastiani).

$\mathrm{O} \mathrm{m} 4 \mathrm{p}$ parece ser um ramo derivado do $\mathrm{m} 4$. Plesiomorficamente, não há esse ramo, mas quando surge, ele se insere numa região próxima a inserção da porção mais posterior do m4 não dividido. No estado mais apomórfico, essa inserção passa a ser na face ventral da cartilagem subradular.

52- Extremidades anteriores de m4p e m5 (passos: 2; ic: 1; ir: 1).

0- livres (Fig. 81, 85); 1- fundidas (Fig. 90, 92) (Austroginella muscaria, "Eratoidea" watsoni, Leptegouana tripartita, Leptegouana guttata, Prunum prunum, Prunum rubens, Prunum brasilianum Prunum warreni); - - inaplicável, sem odontóforo (Eratoidea aureocincta, Eratoidea eburneola, Eratoidea scalaris, Eratoidea sp., "Marginella" ealesae, Marginella glabella, Marginella rosea, Marginella sebastiani) ou sem m5 (Prunum fulminatum). 
Músculo (m5) retrator ventral da membrana subradular (CARRIKER, 1943). Nos Muricoidea, o m5 se insere na face ventral da cartilagem subradular, com a migração da inserção do $\mathrm{m} 4 \mathrm{p}$, há a tendência a fusão destes feixes musculares.

53- Forma da origem do m5 (passos: 1 ; ic: 1 ; ir: 1 ).

0- estreita (Fig. 81, 83); 1- espalmada (Fig. 91) (Adelomelon brasilianus, "Eratoidea" watsoni, Leptegouana guttata, Leptegouana tripartita, Marginellona gigas, Prunum brasilianum, Prunum fulminatum, Prunum prunum, Prunum rubens, Prunum warreni); - - inaplicável, sem odontóforo ou sem m5 (Eratoidea aureocincta, Eratoidea eburneola, Eratoidea scalaris, Eratoidea sp., “Marginella” ealesae, Marginella glabella, Marginella rosea, Marginella sebastiani, Prunum fulminatum).

A origem do m5 parece acompanha a forma da parte posterior da cartilagem odontofórica. Plesiomorficamente, a extremidade posterior da cartilagem é quase cilíndrica, e a origem do músculo é estreita, acompanhando esse formato. Quando a cartilagem do odontóforo se torna mais plana, em forma de calha, a origem do m5 se espalha por uma superfície maior.

54- M6 (músculo horizontal) (passos: 3; ic: 0,66; ir: 0,88).

0- bem desenvolvido (Fig. 81, 85, 91); 1- reduzido (Fig. 93) (Austroginella muscaria, Leptegouana guttata, Leptegouana tripartita); 2- ausente (Fig. 94) (Prunum brasilianum, Prunum fulminatum, Prunum prunum, Prunum rubens, Prunum warreni); - inaplicável, sem odontóforo (Eratoidea aureocincta, Eratoidea eburneola, Eratoidea scalaris, Eratoidea sp., "Marginella” ealesae, Marginella glabella, Marginella rosea, Marginella sebastiani).

Músculo transversal (CARRIKER, 1943). 
55- M11 (passos: 1; ic: 1; ir: 1).

0- presente (Fig. 82); 1- ausente (Fig. 87, 89) ("Eratoidea" watsoni, Adelomelon brasilianus, Austroginella muscaria, Leptegouana guttata, Leptegouana tripartita, Marginellona gigas, Prunum brasilianum, Prunum fulminatum,Prunum prunum, Prunum rubens, Prunum warreni); - - inaplicável, sem odontóforo (Eratoidea aureocincta, Eratoidea eburneola, Eratoidea scalaris, Eratoidea sp., "Marginella" ealesae, Marginella glabella, Marginella rosea, Marginella sebastiani).

O m11 é o par de músculos tensores ventrais da rádula presentes nos cenogastrópodes mais basais.

56- M11a (passos: 4; ic: 0,75; ir: 0,87).

0- ausente; 1- um par livre (Fig. 83) (Buccinanops gradatus, Persicula sagittata); 2- fundido anteriormente (Adelomelon brasilianus, Austroginella muscaria, Marginellona gigas) (fig. 87); 3- fundido completamente ("Eratoidea" watsoni, Leptegouana guttata, Leptegouana tripartita, Prunum brasilianum, Prunum fulminatum, Prunum prunum, Prunum rubens, Prunum warreni) (fig. 89); - - inaplicável, sem odontóforo (Eratoidea aureocincta, Eratoidea eburneola, Eratoidea scalaris, Eratoidea sp., "Marginella" ealesae, Marginella glabella, Marginella rosea, Marginella sebastiani).

M11 e m11a, são músculos retratores radulares ventrais do odontóforo, enquanto o m11 vem direto da parede da probóscide, o m11a tem sua origem na parte posterior da cartilagem odontofórica. 
57- $\mathrm{Mg}$ (passos: 1 ; ic: 1 ; ir: 1$)$.

0- ausente; 1- presente ("Eratoidea" watsoni, Leptegouana guttata, Leptegouana tripartita, Prunum brasilianum, Prunum fulminatum, Prunum prunum, Prunum rubens, Prunum warreni) (fig. 49); - - inaplicável, sem odontóforo (Eratoidea aureocincta, Eratoidea eburneola, Eratoidea scalaris, Eratoidea sp., "Marginella" ealesae, Marginella glabella, Marginella rosea, Marginella sebastiani).

É um músculo muito delgado presente na face ventral anterior da cartilagem do odontóforo.

58- Origem do $\mathrm{m} 8$ (passos: 1 ; ic: 1 ; ir: 1 ).

0- próxima à origem de $\mathrm{m} 4 \mathrm{p}$ (fig. 46); 1- afastada de m4p (fig. 48) (Leptegouana guttata, Leptegouana tripartita); - - inaplicável, sem odontóforo (Eratoidea aureocincta, Eratoidea eburneola, Eratoidea scalaris, Eratoidea sp., "Marginella" ealesae, Marginella glabella, Marginella rosea, Marginella sebastiani).

Músculo elevador da cartilagem (CARRIKER, 1943). Este é um músculo que se estende pela borda externa da cartilagem do odontóforo, em seu estado mais apomórfico, fica mais restrito a porção anterior da borda da cartilagem.

59- Relação entre as cartilagens do odontóforo (passos: 4; ic: 0,5; ir: 0,5).

0- unidas por m6 (Fig. 60, 81); 1- unidas por m6, mas com a parte anterior do m6 se estendendo até a extremidade anterior formando a borda anterior do conjunto (Fig. 61, 85) (Adelomelon brasilianus, Marginellona gigas); 2- fundidas anteriormente (Fig. 62, 9094) (Austroginella muscaria, Buccinanops gradatus, "Eratoidea” watsoni, Leptegouana guttata, Leptegouana tripartita, Prunum brasilianum, Prunum fulminatumPrunum 
prunum, Prunum rubens, Prunum warreni); - - inaplicável, sem odontóforo (Eratoidea aureocincta, Eratoidea eburneola, Eratoidea scalaris, Eratoidea sp., "Marginella" ealesae, Marginella glabella, Marginella rosea, Marginella sebastiani).

Plesiomorficamente, os Caenogastropoda possuem um par de cartilagens, unidas pelo m6, o músculo horizontal. No estado 1, a forma geral deste conjunto já se assemelha muito ao par fundindo encontrado no estado 2. As cartilagens ainda são unidas pelo m6, mas este se estende até a extremidade anterior formando a borda anterior do conjunto. A inserção do músculo a partir de um certo ponto deixa de ser na face ventral e passa para a face lateral interna do conjunto, dando ao conjunto um aspecto de calha encontrado no estado 2 (ver caráter 61).

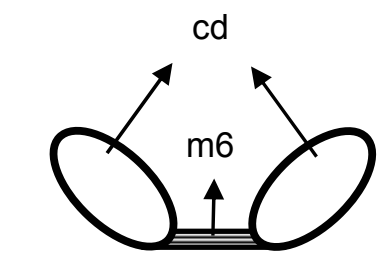

60

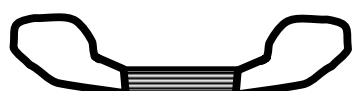

61

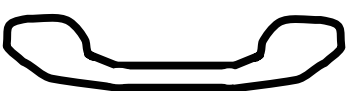

62

Figuras 60-62. Diagrama de um corte transversal da parte anterior das cartilagens do odontóforo, mostrando as transições do caráter 60. 60- estado 0;61- estado 1; 62- Estado 2. cd - cartilagens odontofóricas; m6 - músculo horizontal.

60- Fusão posterior das cartilagens do odontóforo (passos: 2; ic: 1; ir: 1).

0- ausente; 1- presente na parte mais posterior, deixando passagem para m5 (Fig. 94) (Prunum brasilianum, Prunum prunum, Prunum rubens, Prunum warreni), 2cartilagens completamente fundidas, passagem de m5 ocluída (Prunum fulminatum); - inaplicável, sem odontóforo (Eratoidea aureocincta, Eratoidea eburneola, Eratoidea 
scalaris, Eratoidea sp., "Marginella" ealesae, Marginella glabella, Marginella rosea, Marginella sebastiani).

O estado1 deste caráter é acompanhado da perda do m6. No estado 2 ocorre a fusão completa das cartilagens e a perda do m5.

61- Perfil em corte transversal das cartilagens (passos: 2; ic: 0,5; ir: 0).

0- elipsóide (Fig. 60, 81); 1- em forma de calha (Fig. 61, 62, 85, 90-94) (Adelomelon brasilianus, Austroginella muscaria, Buccinanops gradatus, "Eratoidea" watsoni, Leptegouana guttata, Leptegouana tripartita, Marginellona gigas, Prunum brasilianum, Prunum fulminatum, Prunum prunum, Prunum rubens, Prunum warreni); - inaplicável, sem odontóforo (Eratoidea aureocincta, Eratoidea eburneola, Eratoidea scalaris, Eratoidea sp., “Marginella” ealesae, Marginella glabella, Marginella rosea, Marginella sebastiani).

62- Cartilagem subradular (passos: 1; ic: 1; ir: 1).

0- espessa (Fig. 80); 1- membranosa (Fig. 86, 88) (Austroginella muscaria, “Eratoidea” watsoni, Leptegouana guttata, Leptegouana tripartita, Marginellona gigas, Prunum brasilianum, Prunum fulminatum, Prunum prunum, Prunum rubens, Prunum warreni); - - inaplicável, sem odontóforo (Eratoidea aureocincta, Eratoidea eburneola, Eratoidea scalaris, Eratoidea sp., "Marginella” ealesae, Marginella glabella, Marginella rosea, Marginella sebastiani).

A cartilagem subradular envolve a porção anterior da cartilagem odontofórica, é onde se apóia a rádula e onde se insere a maioria dos músculos, que fazem a movimentação da rádula. Nos Caenogastropoda e nos Muricoidea mais basais, esta cartilagem é espessa e rígida, enquanto nos Marginellidae ela se torna mais maleável. 
63- Saco radular (passos: 2; ic: 1; ir: 1).

0- estendendo-se além do odontóforo (Fig. 73); 1- reduzido e estreito (Fig. 86) (largura inferior a $1 / 3$ à largura do odontóforo) (Adelomelon brasilianus, Austroginella muscaria) (Fig. 86); 2- reduzido e largo (Fig. 84) (largura superior a 1/3 à largura do odontóforo) (Marginellona gigas, "Eratoidea" watsoni, Leptegouana guttata, Leptegouana tripartita, Prunum brasilianum, Prunum fulminatum, Prunum prunum, Prunum rubens, Prunum warreni); - - inaplicável, sem odontóforo (Eratoidea aureocincta, Eratoidea eburneola, Eratoidea scalaris, Eratoidea sp., "Marginella" ealesae, Marginella glabella, Marginella rosea, Marginella sebastiani).

64- Tubo oral (passos: 2; ic: 1; ir: 1).

0- anterior ao odontóforo, distinto do esôfago (Fig. 74); 1- termina posterior ao odontóforo, gradualmente transformando-se em esôfago (fig. 95) (Austroginella muscaria, "Eratoidea" watsoni, Leptegouana guttata, Leptegouana tripartita, Prunum brasilianum, Prunum fulminatum, Prunum prunum, Prunum rubens, Prunum warreni); 2- ausente (Fig. 72) ("Marginella" ealesae, Marginella rosea, Marginella glabella, Marginella sebastiani, Eratoidea scalaris, Eratoidea aureocincta, Eratoidea sp., Eratoidea eburneola).

O tubo oral, nos Caenogastropoda, é a região mais anterior do tubo digestivo, aonde o odontóforo se abre no esôfago, conectando a boca com a massa bucal (odontóforo e esôfago). Esta região primitivamente possui especializações como calhas quitinosas ventrais (CARRIKER, 1943) e mandíbulas dorsais e é facilmente distinguível do esôfago anterior. Nos Marginellinae (nó 2) esta distinção é bem menos clara, geralmente se limitando a um espessamento do epitélio. Nos Marginellini houve a perda do odontóforo, portanto não se nota qualquer diferença entre esôfago e tubo oral. 
65- Forma da glândula de Leiblein (passos: 3; ic: 0,66; ir: 0,8).

0- Curta e sólida (Fig. 63, 66); 1-Curta e oca (Marginellona gigas); 2- Tubular e gladular (Fig. 67) (Adelomelon brasilianus, Austroginella muscaria, "Eratoidea” watsoni, "Marginella" ealesae, Eratoidea aureocincta, Eratoidea eburneola, Eratoidea scalaris, Eratoidea sp., Leptegouana guttata, Leptegouana tripartita, Marginella glabella, Marginella rosea, Marginella sebastiani, Prunum brasilianum, Prunum fulminatum, Prunum prunum, Prunum rubens, Prunum warreni).

O estado 0 representa a glândula de Leiblein presente na maioria dos Muricoidea. No estado 1 ela deixa de ser sólida, mas sua superfície interna é forrada por epitélio glandular. No estado 2 ela sofre um alongamento extremo, se tornando um tubo com um bulbo na extremidade posterior.

66- Parede da glândula de Leiblein (passos: 2; ic: 0,5; ir: 0,66).

0- membranosa (Fig. 66); 1- musculosa (Fig. 67) (Adelomelon brasilianus, "Marginella" ealesae, Marginella rosea, Marginella glabella, Marginella sebastiani, Eratoidea scalaris, Eratoidea aureocincta, Eratoidea sp., Eratoidea eburneola, Leptegouana tripartita, Leptegouana guttata, Prunum prunum, Prunum rubens, Prunum brasilianum, Prunum warreni, Prunum fulminatum).

A glândula de Leiblein quando se torna alongada, pode apresentar paredes musculosas, por toda sua extensão. 
67- Bulbo da glândula de Leiblein (passos: 4; ic: 0,5; ir: 0,5).

0- ausente (Fig. 66) ; 1- pouco distinto, musculoso (Fig. 67) ("Marginella" ealesae, Marginella rosea, Marginella glabella, Marginella sebastiani, Eratoidea scalaris, Eratoidea aureocincta, Eratoidea sp., Eratoidea eburneola, Leptegouana tripartita, Prunum prunum, Prunum rubens, Prunum brasilianum, Prunum warreni, Prunum fulminatum); 2- distinto com grossa parede musculosa (Fig. 65) (Adelomelon brasilianus, Leptegouana guttata).

A formação de um bulbo musculoso, na extremidade posterior da glândula de Leiblein, a torna muito semelhante com a glândula de peçonha dos Conoidea (ver discussão desta seção).

68- Ligação do bulbo da glândula de Leiblein, com parede dorsal da hemocele (não aditivo; passos: 4 ; ic: 0,5 ; ir: 0,77$)$.

0- sem feixes musculares distintos; 1- com um único feixe muscular posterior(Fig. 65) (Leptegouana guttata, Leptegouana tripartita, Prunum brasilianum, Prunum fulminatum, Prunum prunum, Prunum warreni); 2- com "braçadeiras" musculares ("Marginella" ealesae, Marginella glabella, Marginella rosea, Marginella sebastiani, Prunum rubens)

Vários Marginellinae apresentam feixes musculares, que saem do soalho da hemocele e se ligam ao teto da mesma. Estes geralmente são mais evidentes nas espécies maiores (e.g. Prunum prunum, Marginella sebastiani) No entanto em algumas espécies estes músculos se concentram e são mais fortes em torno do bulbo da glândula de Leiblein 
69- Abertura da glândula de Leiblein (aditivo; passos: 4; ic: 0,75; ir: 0,94).

0- posterior ao anel nervoso (Fig 66); 1- duto passando pelo anel nervoso, conectando-se logo anterior a este (Fig. 67) (Austroginella muscaria, "Eratoidea" watsoni, "Marginella" ealesae, Marginella glabella, Marginella rosea, Marginella sebastiani); 2- duto passando pelo anel nervoso e se conectando imediatamente atrás do odontóforo (Fig. 68, 71) (Leptegouana tripartita, Leptegouana guttata, Prunum brasilianum, Prunum fulminatum, Prunum prunum, Prunum rubens, Prunum warreni); 3próximo a boca (Fig. 72) (Eratoidea aureocincta, Eratoidea eburneola, Eratoidea scalaris, Eratoidea sp.).

70- Válvula de Leiblein (passos: 4; ic: 0,5; ir: 0,87).

0- presente (Fig. 66, 96, 98); 1- vestigial (Fig. 99) ("Eratoidea" watsoni, Marginella glabella, Marginella rosea, Marginella sebastiani,); 2- ausente (68, 72 (Eratoidea scalaris, Eratoidea aureocincta, Eratoidea sp., Eratoidea eburneola, Leptegouana guttata, Leptegouana tripartita, Prunum brasilianum, Prunum fulminatum, Prunum prunum, Prunum rubens, Prunum warreni).

A válvula de Leiblein (também conhecida como faringe de Leiblein) é uma estrutura, que limita a parte anterior do esôfago médio, presente nos Muricoidea e Cancellarioidea (SIMONE, 2000). Trata-se de uma dilatação que contem uma crista interna circular, dotada de longos cílios que circunda quase toda válvula, voltados anteriormente. Ela separa toda a luz do esôfago, a não ser por uma breve lacuna por onde passa uma calha ciliada (FRETTER \& GRAHAM, 1994), aqui chamada de ponte (“by pass", PONDER, 1973; COOVERT \& COOVERT, 1995). Em Marginella rosea, M. glabella, M. sebastiani e "Eratoidea" watsoni observa-se que o duto da glândula de 
Leiblein se abre logo anterior ao anel nervoso (caráter 67 estado 1), onde, topologicamente, estaria localizada a válvula de Leiblein. Ao se examinar esta porção do esôfago, nota-se uma interrupção das pregas do esôfago posterior com hiato de parede fina, antes do espessamento da parede do esôfago anterior. Em M. rosea, M. glabella, $M$. sebastiani, observou-se um espessamento glandular nesta porção do esôfago formação de um esfíncter. Este hiato é interpretado como um vestígio da válvula de Leiblein, sem nenhuma de suas estruturas, i.e., a crista de células ciliadas e a ponte.

71- Ponte da válvula de Leiblein (passos: 1 ; ic: 1 ; ir: 1).

0- aberta em calha (Fig. 98) ; 1- fechada em tubo (Fig. 96) (Austroginella muscaria, "Marginella" ealesae); - - não aplicável, sem válvula de Leiblein, ou vestigial (Eratoidea aureocincta, Eratoidea eburneola, Eratoidea scalaris, Eratoidea sp., "Eratoidea” watsoni, Leptegouana guttata, Leptegouana tripartita, Marginella glabella, Marginella rosea, Marginella sebastiani, Prunum brasilianum, Prunum fulminatum, Prunum prunum, Prunum rubens, Prunum warreni).

72- Ceco esofágico (passos: 1 ; ic: 1 ; ir: 1 ).

0- ausente (Fig. 66, 67); 1- presente (Fig. 65, 97) ("Eratoidea" watsoni, Leptegouana guttata, Leptegouana tripartita, Prunum brasilianum, Prunum fulminatum, Prunum prunum, Prunum rubens, Prunum warreni).

O ceco esofágico (“oesophageal caecum”: GRAHAM, 1966; COOVERT \& COOVERT, 1995) é uma expansão do esôfago, imediatamente posterior ao anel nervoso. 
73- Estômago (passos: 2; ic: 5; ir: 5).

0- com 2 aberturas da glândula digestiva (Fig. 101); 1- com 1 abertura da glândula digestiva (Fig. 102, 103) (Austroginella muscaria, Eratoidea aureocincta, Eratoidea eburneola, Eratoidea scalaris, Eratoidea sp., "Eratoidea” watsoni, Leptegouana guttata, Leptegouana tripartita, "Marginella" ealesae, Marginella glabella, Marginella rosea, Marginella sebastiani, Marginellona gigas, Persicula sagittata, Prunum brasilianum, Prunum fulminatum, Prunum prunum, Prunum rubens, Prunum warreni).

74- Pregas do revestimento interno do estômago (passos: 3 ; ic: 0,33 ; ir: 0,5).

0- simples; 1- dicotômicas (Fig. 103) (Eratoidea sp., Marginella glabella, Marginella rosea, Marginella sebastiani, Prunum prunum).

Estas pregas do revestimento interno do estômago são de difícil observação, pois são constituídas por tecido glandular e ciliado, que muitas vezes se aderem ao muco coagulado presente nos estômagos dos espécimes fixados.

75- Parede externa do estômago (passos: 2; ic: 0,5; ir: 0,85).

0- não musculosa; 1- com reforço musculoso (Fig. 102) (Eratoidea aureocincta, Eratoidea eburneola, Eratoidea scalaris, Eratoidea sp., Marginella glabella, Marginella rosea, Marginella sebastiani, Prunum fulminatum).

O estado 1 deste caráter representa vários feixes de músculos que podem estar presentes na parede posterior dorsal do estômago. 
76- Intestino em relação ao lobo renal (passos: 2; ic: 0,5; ir: 0,5).

0- atravessando (Fig. 50); 1- aderido à superfície ventral (Fig. 52, 53, 56) (Austroginella muscaria, Buccinanops gradatus, Eratoidea aureocincta, Eratoidea eburneola, Eratoidea scalaris, Eratoidea sp., "Eratoidea” watsoni, Leptegouana guttata, Leptegouana tripartita, "Marginella" ealesae, Marginella glabella, Marginella rosea, Marginella sebastiani, Marginellona gigas, Prunum brasilianumPrunum fulminatum, Prunum prunum, Prunum rubens, Prunum warreni).

77- Revestimento interno do intestino (passos: 2; ic: 0,5; ir: 0).

0- Liso (Fig. 103); 1- com pregas longitudinais ("Marginella" ealesae, Marginella sebastiani)

78-Origem relativa do duto da glândula anal (passos: 2; ic: 0,5; ir: 0,5).

0- anterior (Fig. 100); 1- posterior (Fig. 103) (Eratoidea aureocincta, Eratoidea eburneola, Eratoidea scalaris, Eratoidea sp., “Eratoidea” watsoni, Leptegouana guttata, Leptegouana tripartita, Marginella glabella, Marginella rosea, Marginella sebastiani, Marginellona gigas, Persicula sagittata, Prunum brasilianum, Prunum fulminatum, Prunum prunum, Prunum rubens, Prunum warreni)

79- Posição do ânus na cavidade palial (passos: 4; ic: 0,25; ir: 0,62).

0- próximo à borda do manto(Fig. 49); 1- posterior (Fig. 56) (Eratoidea aureocincta, Eratoidea eburneola, Eratoidea scalaris, “Eratoidea” watsoni, Leptegouana guttata, Leptegouana tripartita, Prunum fulminatum, Prunum brasilianum, Prunum rubens, Prunum warreni). 


\section{Discussão}

A lateralização parece afetar a probóscide dos Cystiscidae e dos Marginellidae da mesma forma, dispondo os músculos da probóscide assimetricamente na hemocele (caráter 32, estado 1). Na otimização ACCTRAN, este caráter aparece como sinapomorfia do nó C, ocorrendo uma reversão em Adelomelon brasilianus. Uma otimização igualmente parcimoniosa coloca este caráter como homoplasias surgindo no nó 1 e na Persicula sagittata, e as evidências para se escolher uma ou outra otimização são conflitantes. Se por um lado a combinação da forma da hemocele e torção da probóscide, presentes em Marginellona gigas e $P$. sagittata, mostra que a torção da probóscide pode ocorrer antes da assimetria da forma da hemocele (caráter 19, estado 1), por outro temos aspectos da concha de $P$. sagittata que sugerem um estado de lateralização mais avançado do que o presente em $M$. gigas. A presença de 11 homoplasias, detectadas entre $P$. sagittata e os Marginellidae, reforça que esta possa ser apenas mais uma.

Duas modificações importantes do odontóforo foram detectadas nesta análise, primeiro temos um alongamento geral deste acompanhado de diversas modificações na sua estrutura, que indicam uma modificação importante na ação da rádula, outra é a total supressão do odontóforo.

Nos Caenogastropoda mais basais (e.g., Cerithioidea, SIMONE 2001) temos um odontóforo curto, globoso que ocupa quase todo assoalho do tubo oral. A cartilagem subradular nestes odontóforos é bem curta e se limita a parte exposta da rádula. Nos Muricoidea ocorre um alongamento do odontóforo acompanhado pelo alongamento da cartilagem radular, dorsal e ventralmente, com a formação do ceco sublingual. Em Buccinanops gradatus e Adelomelon brasilianus e nos Marginellidae essa tendência se acentua, com a conformação em calha na parte anterior, maior alongamento do odontóforo, acompanhado de uma fusão parcial ou total das cartilagens do odontóforo, que passam a formar uma única unidade funcional. A musculatura também sofre modificações 
importantes como, das quais podemos destacar a posteriorização da origem do m4 seguido da formação de um ramo posterior, a diminuição com eventual perda do m6.

SIMONE (2000) discute ao funcionamento do odontóforo nos Caenogastropoda, observando que a forma do odontóforo e disposição da sua musculatura intrínseca não permitiriam uma movimentação radular estereotípica. Neste tipo de movimentação, observada em Monodonta (FRETTER \& GRAHAM, 1994), a rádula corre sobre as cartilagens odontofóricas, movimentada pela ação antagonista de um músculo tensor dorsal e um outro ventral. Segundo SIMONE (2000) nos Caenogastropoda a musculatura intrínseca do odontóforo serviria para tensionar a rádula e tornar o conjunto rígido, enquanto o odontóforo como um todo se movimenta para realizar a ação de raspagem. No entanto, o trabalho funcional de CARRIKER (1943) aliado às observações feitas aqui, sugerem que em Muricoidea há uma reversão na forma de ação do odontóforo em que a rádula corre sobre as cartilagens do odontóforo, acionado pela ação antagonista de tensores dorsais $(\mathrm{m} 4+\mathrm{m} 5)$ e um tensor ventral (m11a), enquanto outros músculos $(\mathrm{m} 8$, mg) tensionam as cartilagens do odontóforo dando mais firmeza ao conjunto. Foi detectado, que a cartilagem subradular se torna mais flexível, o que facilitaria essa ação de deslizamento, fornecendo mais um indício para este cenário.

COOVERT \& COOVERT (1995) afirmam que a perda do odontóforo ocorreu independentemente em Marginellini e no gênero Hyalina. A presença do ceco esofágico, recentemente confirmada por ESPINOSA \& ORTEA (2003), parece corroborar esta hipótese. Todas as espécies sem odontóforo, aqui observadas, pertencem à tribo Marginellini e apresentam uma probóscide extremamente musculosa, fato também observado por COAN \& ROTH (1976) em Hyalina pallida (Linnaeus, 1758). O reforço musculoso no estômago observado em quase todos os Marginellini, menos "Marginella" ealesae, sugere que este caráter também está associado com a perda da rádula.

PONDER (1970) traça um paralelo entre os vários aspectos da glândula de Leiblein, presentes nos Marginellidae, Cystiscidae e Mitridae, e a evolução da glândula de 
veneno dos Conoidea. Ele especula que essa transformação se daria através do destacamento de um par de pregas dorsais glandulares do esôfago, a partir da abertura da glândula de Leiblein, em direção ao esôfago anterior. A evidência para isso seria uma “cicatriz" presente no esôfago dos Mitridae e dos Marginellidae. No entanto nos Marginellinae, examinados neste estudo, não foi encontrada nenhuma cicatriz evidente posterior à abertura da glândula de Leiblein. Tal conformação leva a crer que, neste caso, o alongamento da glândula Leiblein seria independente da anteriorização da sua abertura, talvez decorrente do alongamento do esôfago posterior e um encurtamento dos esôfagos médio e anterior, e em Eratoidea, também do tubo oral até a sua perda, restando apenas o esôfago posterior.

A semelhança da glândula de Leiblein dos Marginellidae com a dos Conoidea inclui a presença de músculos ao longo de toda sua extensão e a formação de um bulbo muscular na extremidade posterior. Pode-se especular, portanto, que, assim como nos Conoidea, a glândula libera rapidamente suas secreções, enquanto a redução do esôfago médio levaria o ponto de secreção para mais perto da boca, onde poderia entrar em contato mais rapidamente com a presa. A função da secreção da glândula de Leiblein parece variar internamente na família. Austroginella johnstoni perfura bivalves e foi observado que a ação perfuradora é realizada, principalmente, por agentes químicos (PONDER \& TAYLOR, 1992), enquanto que Rivomarginella electrum foi observada paralisando rapidamente oligoquetas vivos, oferecidos em aquários (DJAJASAMITA \& COOMANS, 1980). 

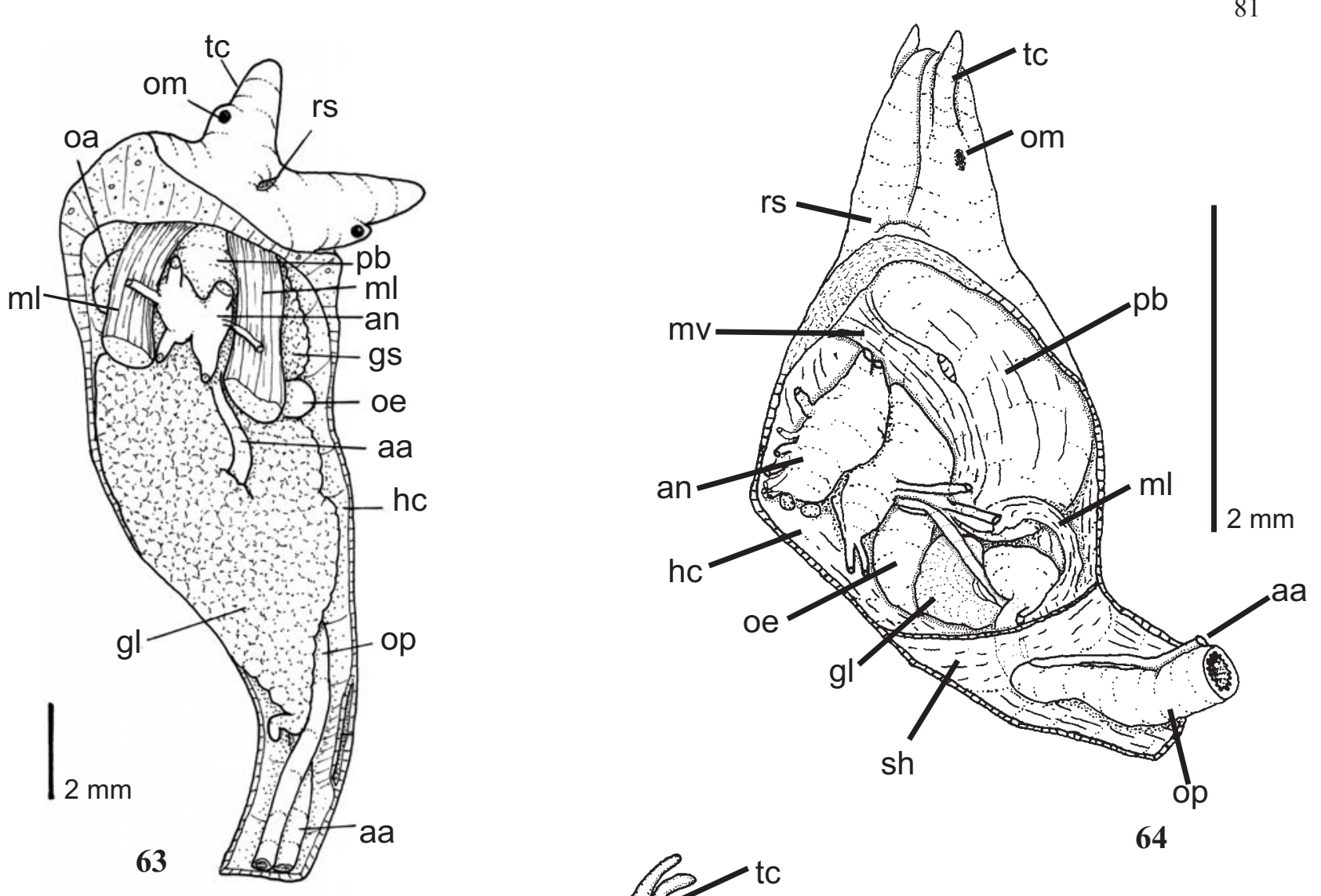

64

Figuras 63 - 65. 63. Hemocele de Trophon geversianus. 64. Hemocele de Persicula sagittata. 65. Hemocele de Prunum guttatum. aa - aorta anterior; an - anel nervoso; bl - bulbo da glândula de Leiblein; co - ceco esofagiano; gl - glândula de Leiblein; gs - glândula salivar; hc hemocele; mb - músculo do bulbo da glândula de Leiblein; ml - músculo retrator da probóscide lateral; mv - músculo retrator da probóscide ventral; oa - esôfago anterior; oe - esôfago médio; om omatóforo; op - esôfago posterior; pb probóscide; $\mathrm{pb}$ probóscide; rs rincóstoma; sh - septo da hemocele; tc - tentáculo cefálico. 

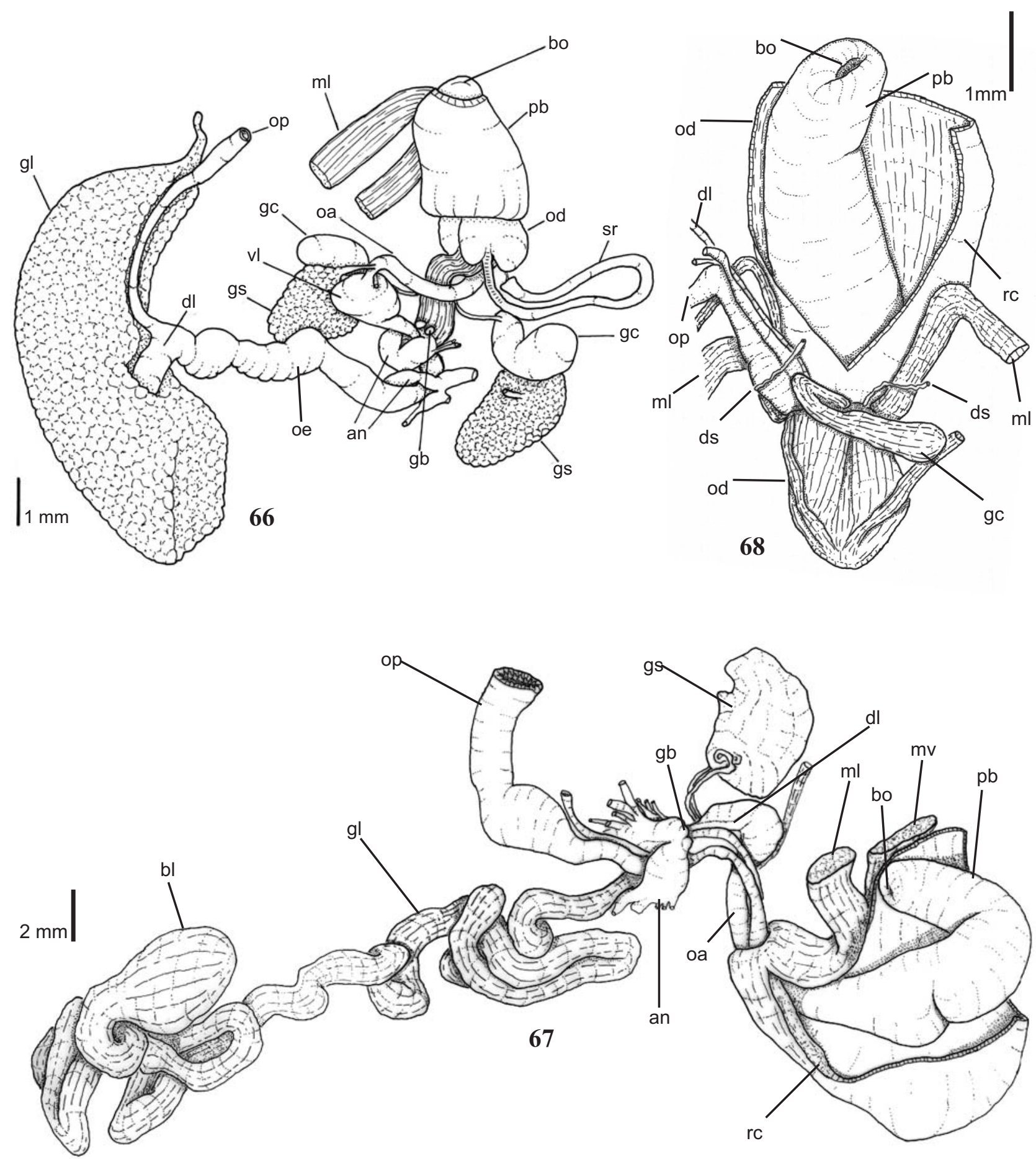

Figuras 66 - 68. 66. Sistema digestório anterior de Trophon geversianus. 67. Sistema digestório anterior de Marginella sebastiani. 68. Probóscide de Leptegouena tripartita. an - anel nervoso; bl - bulbo da glândula de Leiblein; bo boca; dl - duto da glândula de Leiblein; ds - duto da glândula salivar; gb - gânglio bucal; gc - glândula salivar acessória; gl - glândula de Leiblein; gs - glândula salivar; $\mathrm{ml}$ - músculo retrator da probóscide lateral; $\mathrm{ml}$ - músculo retrator da probóscide lateral; mv - músculo retrator da probóscide ventral; oa - esôfago anterior; od odontóforo; oe - esôfago médio; rc - parede rincodial; sr - saco radular; vl - válvula de Leiblein. 

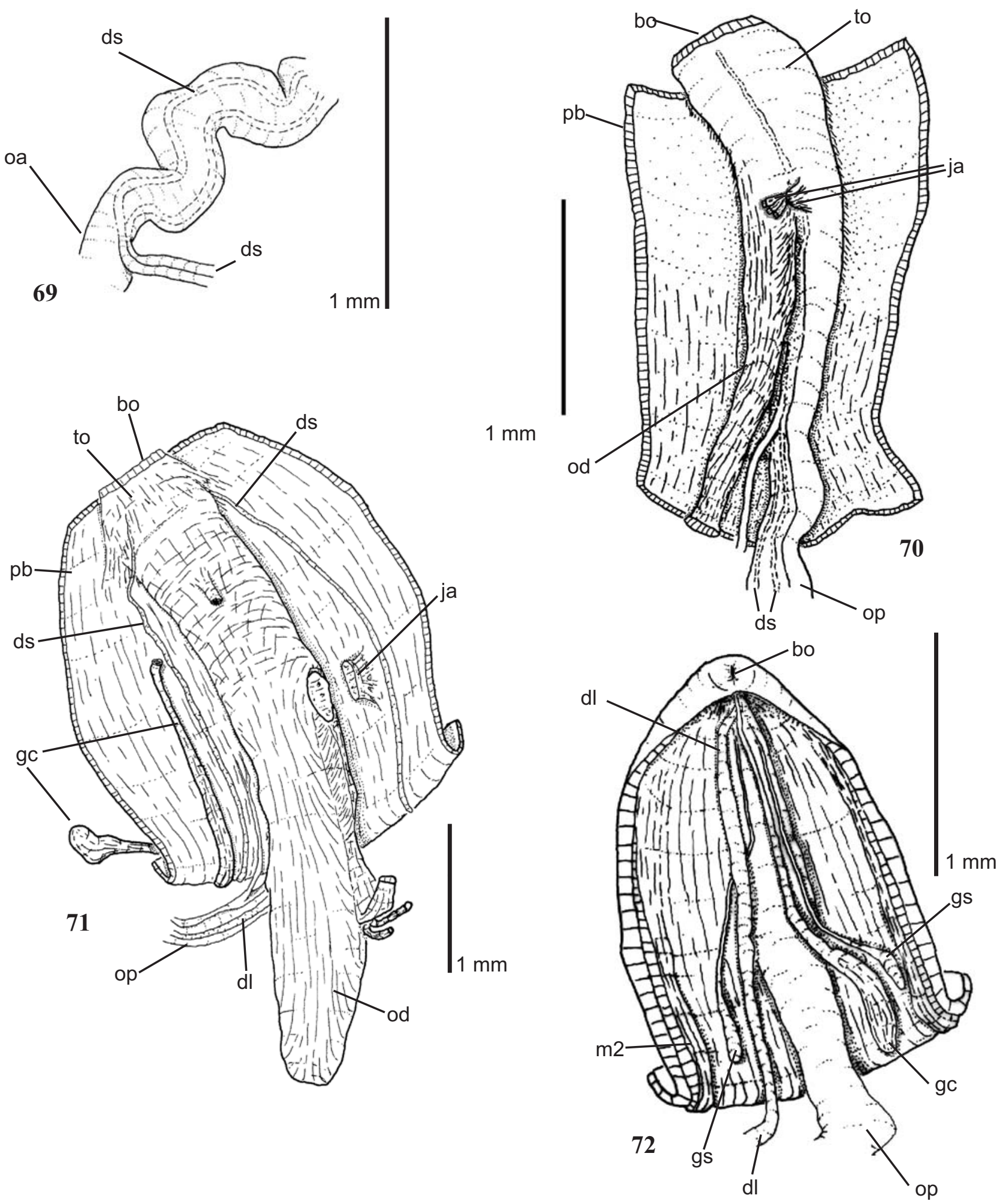

Figuras 69 - 72. 69. Esôfago de "Eratoidea" watsoni. 70. Probóscide aberta de "Eratoidea" watsoni. 71. Probóscide aberta de Leptegouena tripartita. 72. Probóscide aberta de Eratoidea scalaris. bo - boca; dl - duto da glândula de Leiblein; ds - duto da glândula salivar; ds - duto da glândula salivar; gc - glândula salivar acessória; ja - jugais anteriores; mt - músculo transversal; oa - esôfago anterior; od - odontóforo; op - esôfago posterior; pb - probóscide; to - tubo oral. 

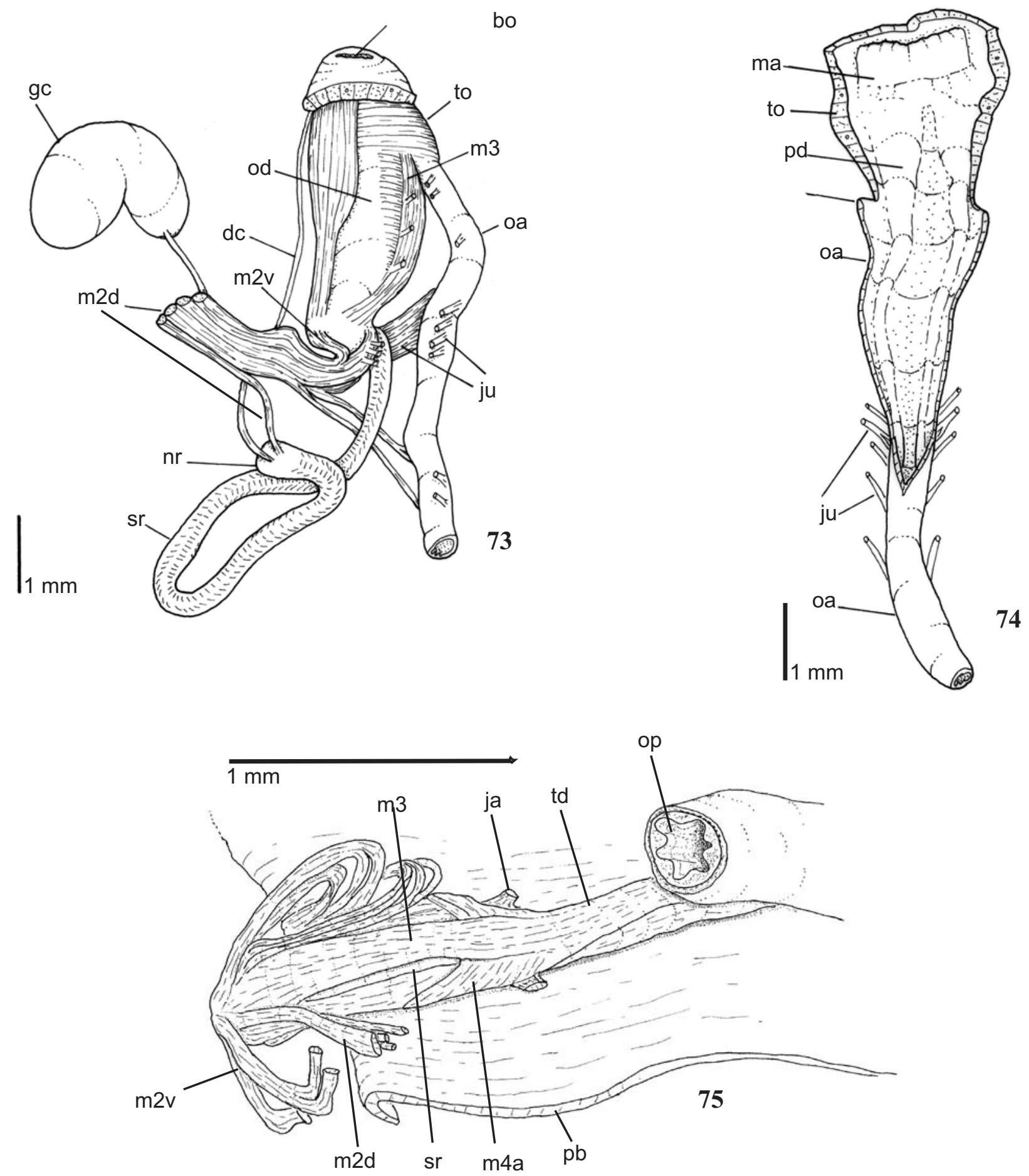

Figuras 73 - 75. 73. Massa bucal de Trophon geversianus. 74. Tubo oral de Trophon geversianus. 75. Odontóforo de Prunum rubens. bo - boca; dc - duto da glândula salivar acessória; gc - glândula salivar acessória; ja - jugais anteriores; ju - músculos jugais; m2d - ramo dorsal do retrator do odontóforo; $\mathrm{m} 2 \mathrm{v}$ - ramo ventral do retrator do odontóforo; $\mathrm{m} 3$ - músculo protrator dorsal; $\mathrm{m} 4$ - músculo dorsal retrator subradular dorsal; m4a - ramo anterior de m4; ma mandíbulas; $\mathrm{nr}$ - núcleo radular; oa - esôfago anterior; od odontóforo; op - esôfago posterior; pb probóscide; pd - prega dorsal do esôfago; sr - saco radular; td - tubo do odontóforo; to - tubo oral; to - tubo oral. 


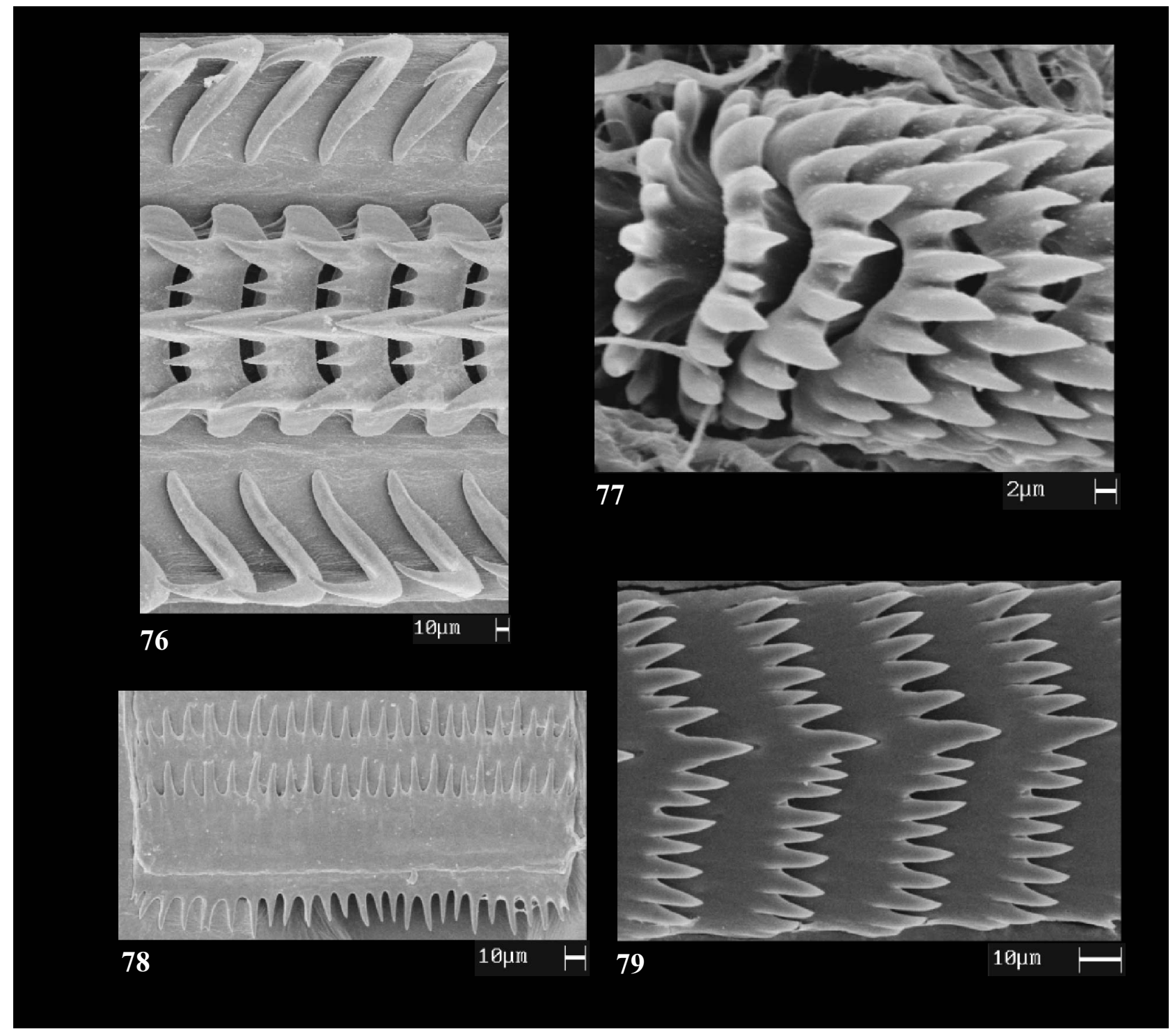

Figuras 76 - 79. 36. Rádula de Trophon geversianus. 37. Rádula de Persicula sagittata. 38. Rádula de Prunum rubens. 39. Rádula de Austroginella muscaria. 

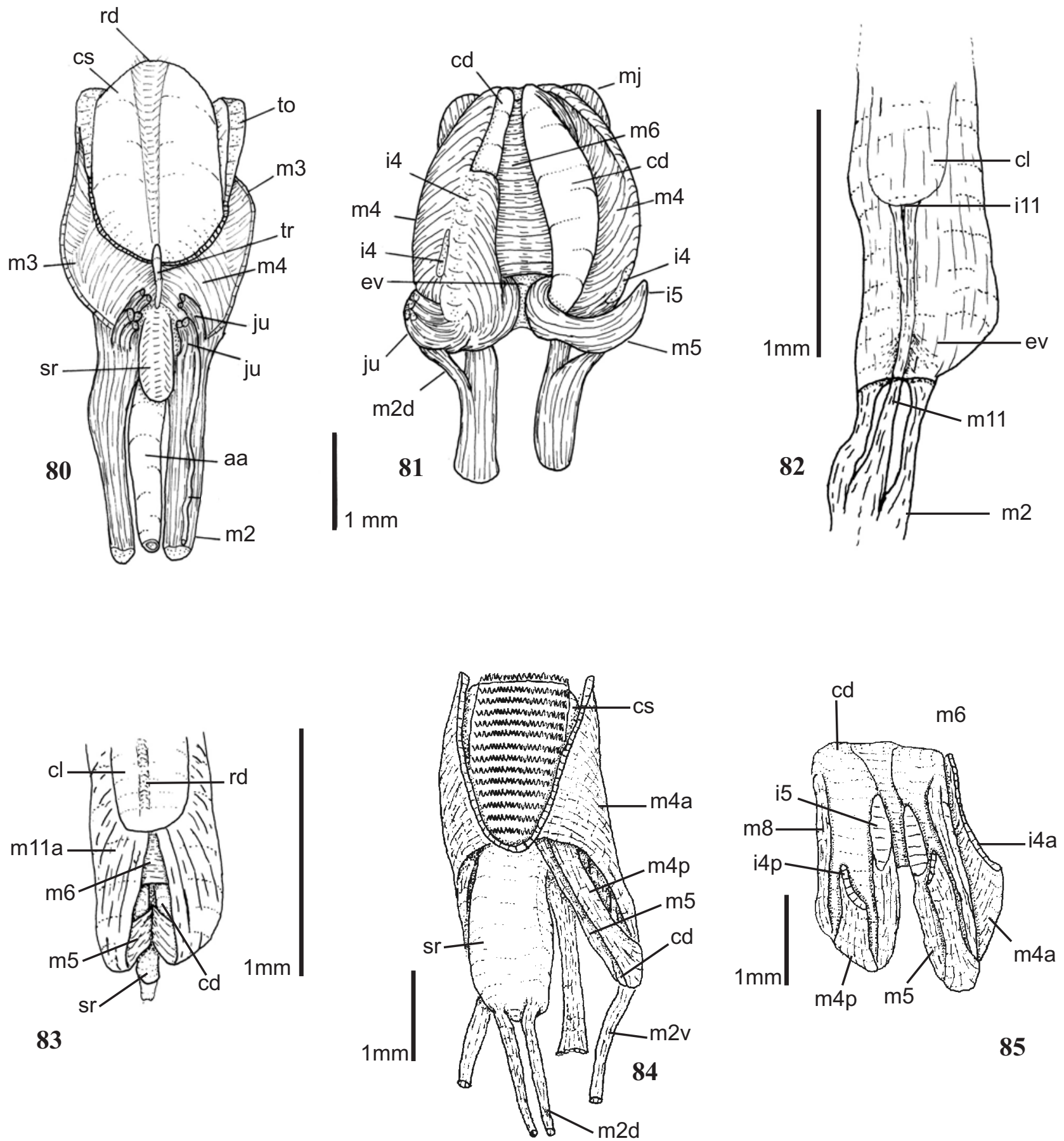

83 

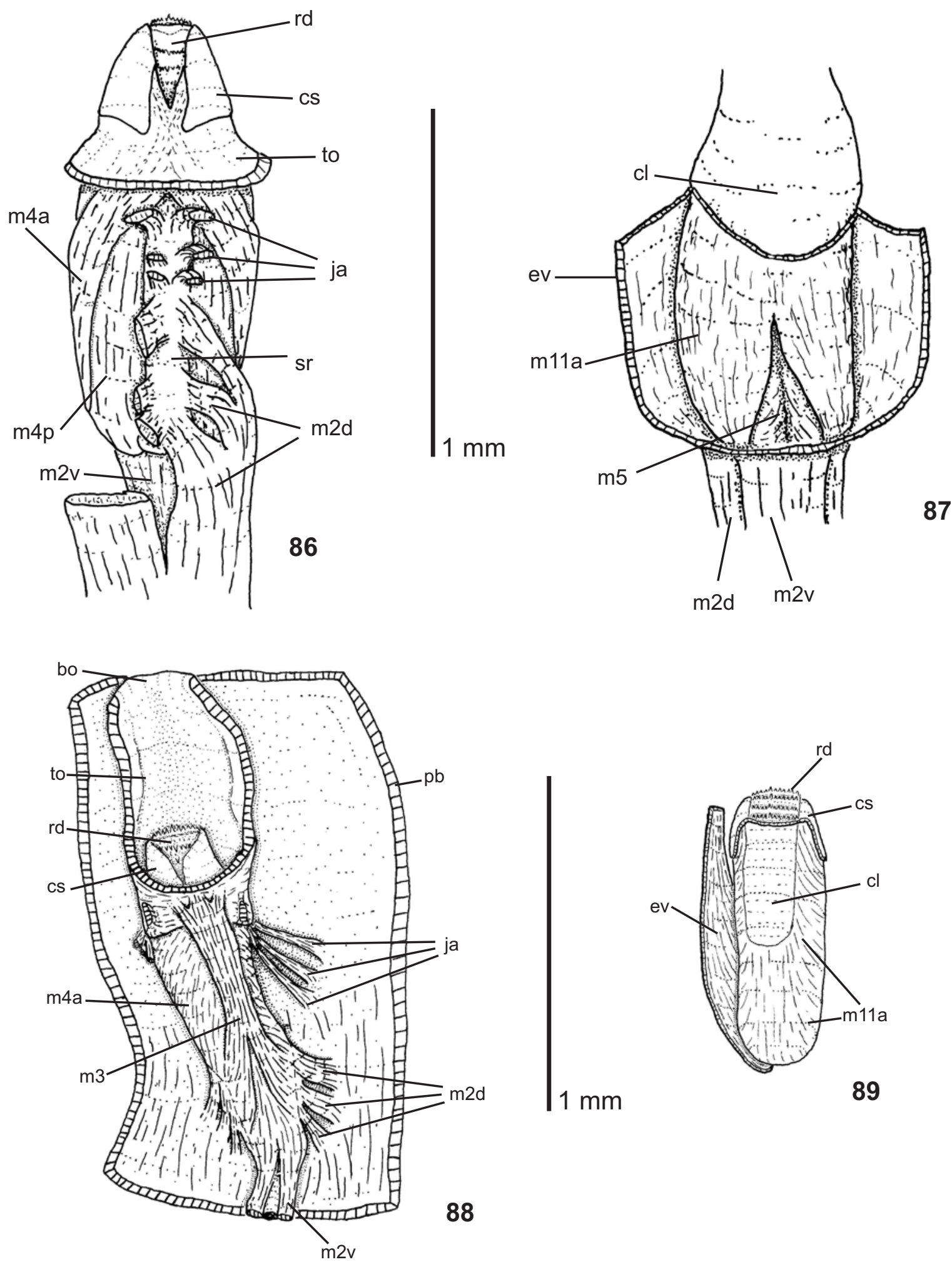

Figuras 86 - 89. 86 Odontóforo de Austroginella muscaria, vista dorsal, jugais anteriores e tubo oral parcialmente removidos. 87 Odontóforo de Austroginella muscaria, vista ventral, envoltório ventral aberto. 88 Odontóforo de "Eratoidea" watsoni, vista dorsal. 89 Odontóforo de Austroginella muscaria, vista ventral, envoltório ventral parcialmente removido. bo - boca; cl - ceco sublingual; cs - cartilagem sub-radular; ev - envoltório ventral do odontóforo; ja - jugais anteriores; m11a - músculo retrator subradular ventral intrínseco; $\mathrm{m} 2 \mathrm{~d}$ - ramo dorsal de $\mathrm{m} 2 ; \mathrm{m} 2 \mathrm{v}$ - ramo ventral de $\mathrm{m} 2 ; \mathrm{m} 3$ - músculo protrator dorsal; $\mathrm{m} 4 \mathrm{a}$ - ramo anterior de $\mathrm{m} 4 ; \mathrm{m} 4 \mathrm{p}$ - ramo posterior de $\mathrm{m} 4$; $\mathrm{pb}$ probóscide; rd rádula; to - tubo oral. 

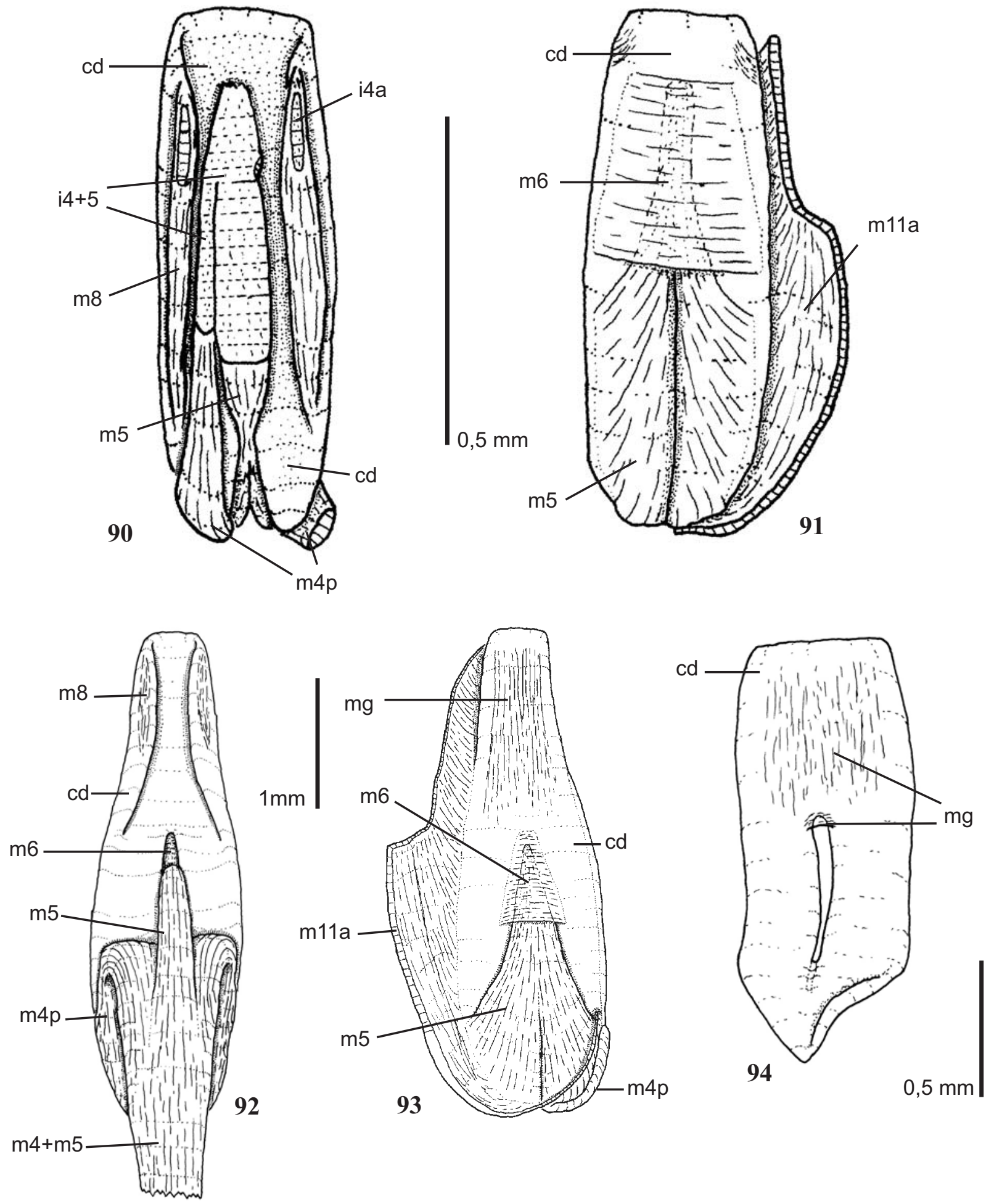

Figuras 90 - 94. 90. Odontóforo dissecado de "Eratoidea" watsoni, vista dorsal, apenas com musculatura interna. 91. Odontóforo dissecado de "Eratoidea" watsoni, vista ventral, apenas com musculatura interna. 92. Odontóforo dissecado de Leptegouena tripartita., vista dorsal, apenas com musculatura interna. 93. Odontóforo dissecado de Leptegouena tripartita., vista ventral, apenas com musculatura interna. 94. Cartilagens odontofóricas de Prunum rubens. cd - cartilagem do odontóforo; $\mathrm{i} 4+5$ - inserção de $\mathrm{m} 4+\mathrm{m} 5$ na membrana sub-radular; $\mathrm{m} 4 \mathrm{a}$ - ramo anterior de $\mathrm{m} 4 ; \mathrm{m} 8$ - músculo elevador da cartilagem; m5 - músculo ventral retrator subradular dorsal; $\mathrm{m} 4 \mathrm{p}$ - ramo posterior de $\mathrm{m} 4 ; \mathrm{m} 6$ - músculo horizontal; m11a - músculo retrator subradular ventral intrínseco; mg- músculo membranoso anterior. 

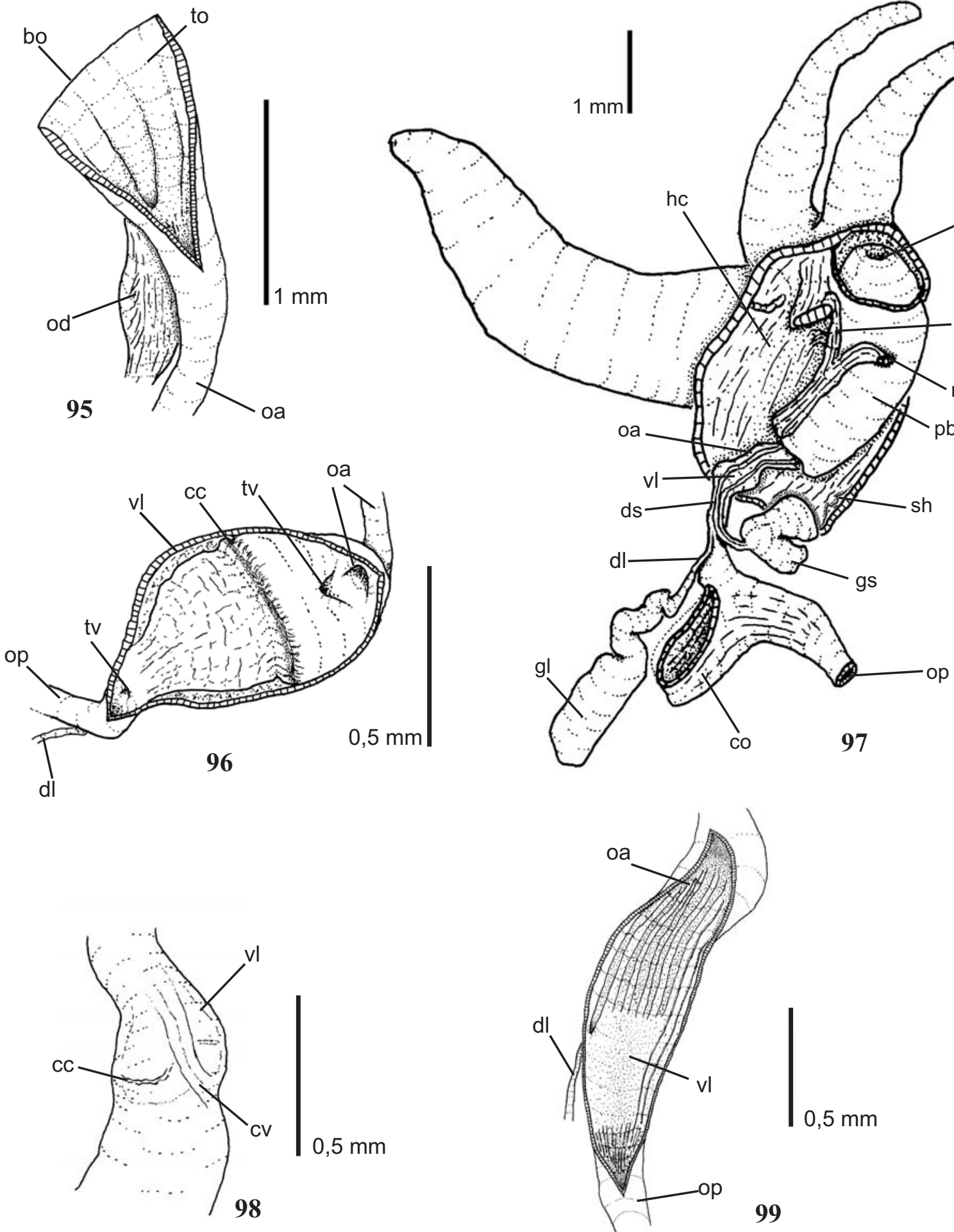

Figuras 95 - 99. 95. Tubo oral aberto e odontóforo de "Eratoidea" watsoni. 96. Válvula de Leiblein, de Pesicula sagittata. 97. Hemocele de "Eratoidea" watsoni. 98. Válvula de Leiblein dissecada de Austroginella muscaria. 99 Região limítrofe entre os esôfagos posterior e anterior, dissecada, de "Eratoidea" watsoni. bo boca; cc - crista de células ciliadas; co - ceco esofagiano; cv - Ponte da válvula de Leiblein em calha; dl - duto da glândula de Leiblein; ds - duto da glândula salivar; gl - glândula de Leiblein; gs - glândula salivar; hc hemocele; ml - músculo retrator da probóscide lateral; mv - músculo retrator da probóscide ventral; oa - esôfago anterior; od odontóforo; op - esôfago posterior; pb probóscide sh - septo da hemocele; to - tubo oral; tv - Ponte da válvula de Leiblein em tubo; vl - válvula de Leiblein. 

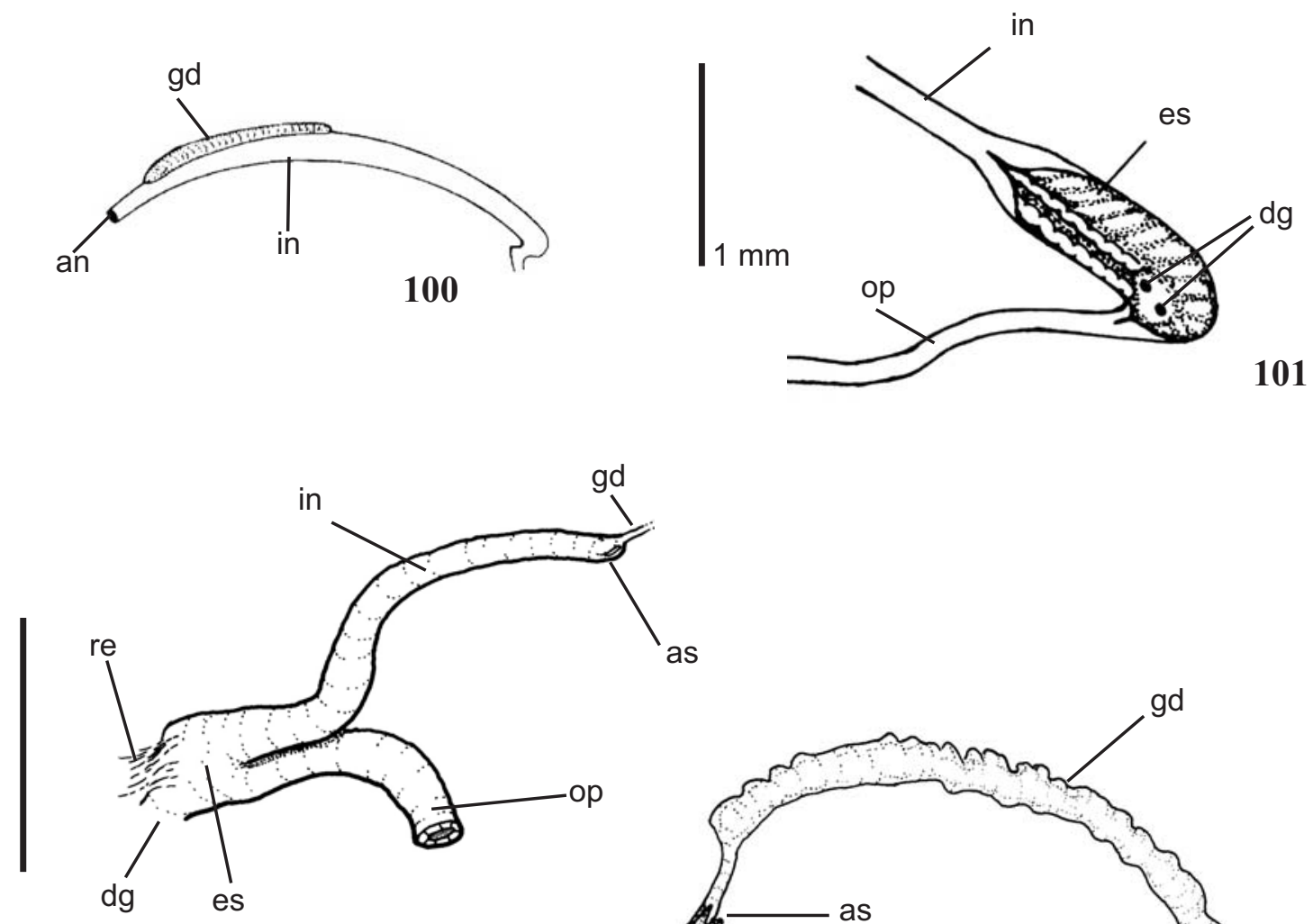

$0,5 \mathrm{~mm}$

102

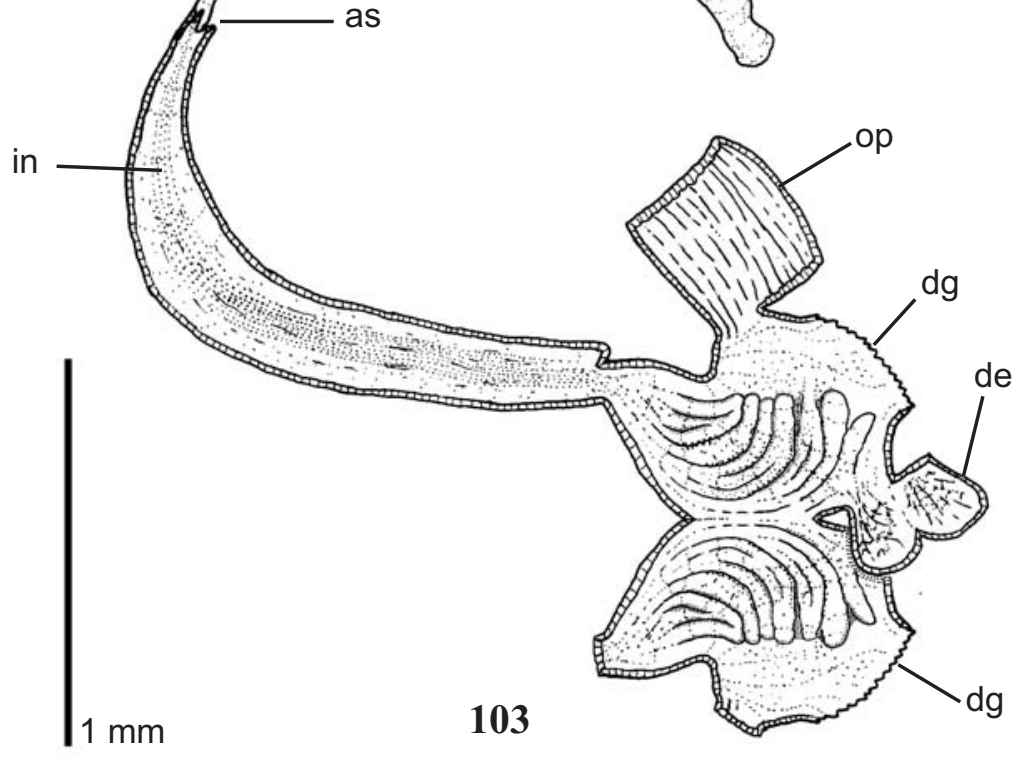

Figuras 100 - 103. 100. Intestino e glândula anal de Trophon geversianus (modificado de HARASEWYCH, 1984). 101. Estômago de Trophon geversianus (modificado de HARASEWYCH, 1984). 102. Sistema digestório posterior de Eratoidea scalaris. 103. Sistema digestório posterior dissecado de "Eratoidea" watsoni. as ânus; de - divertículo do estômago; dg - duto da glândula digestiva; es estômago; gd - glândula anal; in intestino; op - esôfago posterior; re - reforço muscular do estômago. 


\subsubsection{Sistema reprodutor}

80- Testículos e vesícula seminal (passos: 3 ; ic: 0,5; ir: 0,66).

0- ocupando o lado direito da massa visceral; 1 - interdigitado e ventral à glândula digestiva (Fig. 52, 56, 104) (Eratoidea aureocincta, Eratoidea scalaris, "Eratoidea watsoni”, Leptegouana tripartita, Marginella glabella, Marginella rosea, Marginella sebastiani, Prunum brasilianum, Prunum fulminatum, Prunum rubens, Prunum warreni); ?- não observado (Eratoidea eburneola, Eratoidea sp., Leptegouana guttata, Leptegouana tripartita, "Marginella" ealesae, Marginellona gigas, Persicula sagittata, Prunum prunum).

81- Vesícula seminal (passos: 2; ic: 0,5; ir: 0,83).

0- convoluta simples (Fig. 104); 1- com cecos glandulares, próximos a junção com a próstata (Fig. 105) (Leptegouana tripartita, Marginella glabella, Marginella rosea, Marginella sebastiani, Prunum brasilianum, Prunum fulminatum, Prunum rubens, Prunum warreni); ?- não observado (Eratoidea eburneola, Eratoidea sp., Leptegouana guttata, Leptegouana tripartita, "Marginella” ealesae, Marginellona gigas, Persicula sagittata, Prunum prunum).

82- Posição dos elementos paliais do sistema reprodutor (oviduto e próstata) (passos: 1 ; ic: 1 ; ir: 1 ).

0- aderidos ao teto da cavidade palial (Fig. 49); 1- aderidos ao assoalho da cavidade palial (Fig. 52, 53, 56, 104) (Austroginella muscaria, Eratoidea aureocincta, 
Eratoidea eburneola, Eratoidea scalaris, Eratoidea sp., "Eratoidea" watsoni, Leptegouana guttata, Leptegouana tripartita, “Marginella” ealesae, Marginella glabella, Marginella rosea, Marginella sebastiani, Prunum brasilianum, Prunum fulminatum, Prunum prunum, Prunum rubens, Prunum warreni).

83- Espermoduto (não aditivo; passos: 2; ic: 1; ir: 1).

0- sobre a superfície externa da hemocele; 1 - internamente a hemocele, firmemente aderida à parede por fibras musculares (Eratoidea aureocincta, Eratoidea scalaris, "Eratoidea" watsoni, Marginella glabella, Marginella rosea, Marginella sebastiani, Prunum brasilianum, Prunum fulminatum, Prunum rubens, Prunum warreni); 2internamente a hemocele, fracamente aderida à parede (Austroginella muscaria); ?- não observado (Eratoidea eburneola, Eratoidea sp., Leptegouana guttata, Leptegouana tripartita, "Marginella" ealesae, Marginellona gigas, Persicula sagittata, Prunum prunum).

84- Duto peniano (não aditivo; passos: 3; ic:0,66; ir: 0,75).

0- não musculoso; 1- musculoso, sem câmara ejaculatória distinta (Fig. 107) (Austroginella muscaria, "Eratoidea" watsoni, Leptegouana tripartita, "Marginella" ealesae, Marginella glabella, Marginella rosea, Marginella sebastiani, Prunum brasilianum, Prunum fulminatum, Prunum prunum, Prunum rubens, Prunum warreni); 2musculoso com câmara ejaculatória distinta (Fig. 106) (Eratoidea aureocincta, Eratoidea scalaris,); ?- não observado (Eratoidea sp., Leptegouana guttata, Leptegouana tripartita, “Marginella” ealesae, Marginellona gigas, Persicula sagittata, Prunum prunum). 
85- Poro genital masculino (passos: 3; ic: 0,66; ir: 0,80, não aditivo).

0- terminal (Fig. 107); 1- subterminal (Austroginella muscaria); 2- em papila ejaculatória (Fig. 106) (Eratoidea aureocincta, Eratoidea eburneola, Eratoidea scalaris); ?- não observado (Eratoidea sp., Leptegouana guttata, Leptegouana tripartita, “Marginella” ealesae, Marginellona gigas, Persicula sagittata, Prunum prunum).

86- Ovário (passos: 1 ; ic: 1 ; ir: 1).

0- ao lado da glândula digestiva se estendendo por toda massa visceral; 1 - pequeno e ventral à glândula digestiva (Austroginella muscaria, Eratoidea aureocincta, Eratoidea scalaris, Eratoidea sp., "Eratoidea" watsoni, Leptegouana guttata, Leptegouana tripartita, "Marginella” ealesae, Marginella glabella, Marginella rosea, Marginella sebastiani, Prunum brasilianum, Prunum fulminatum, Prunum prunum, Prunum rubens, Prunum warreni); ?- não observado (Eratoidea eburneola).

87- Oviduto visceral (passos: 3 ; ic: 0,33 ; ir: 0,71 ).

0- conectado à glândula da cápsula (Fig. 108, 109, 112); 1- conectado à glândula de albúmen (Fig. 110, 111) (Leptegouana guttata, "Marginella” ealesae, Marginella glabella, Marginella rosea, Marginella sebastiani, Persicula sagittata, Prunum brasilianum, Prunum fulminatum, Prunum prunum, Prunum rubens, Prunum warreni); ?não observado (Eratoidea eburneola). 
88- Glândula de albúmen (passos: 3; ic: 0,66; ir: 0,66).

0- junta com a glândula da cápsula (Fig, 108); 1- separada da glândula da cápsula por uma constrição (Adelomelon brasilianus); 2- separada da glândula da cápsula por um duto e pela glândula ingestória (Fig. 109 - 112) (Austroginella muscaria, Eratoidea aureocincta, Eratoidea eburneola, Eratoidea scalaris, Eratoidea sp., "Eratoidea" watsoni, Leptegouana guttata, Leptegouana tripartita, "Marginella” ealesae, Marginella glabella, Marginella rosea, Marginella sebastiani, Marginellona gigas, Persicula sagittata, Prunum brasilianum, Prunum fulminatum, Prunum prunum, Prunum rubens, Prunum warreni); ?- não observado (Eratoidea eburneola).

89- Vestíbulo (passos: 2; ic: 0,33; ir: 0,5).

0- sem câmara distinta (Fig. 108, 110); 1- com câmara distinta (Fig. 109, 112) ("Eratoidea" watsoni, Marginella glabella, Marginella rosea, Marginella sebastiani); ?não observado (Eratoidea eburneola)

90- Vestíbulo (passos: 3; ic: 0,33; ir: 0,71).

0- abrindo-se (q.v., caráter 91) diretamente (Fig.109); 1- abrindo-se (q.v., caráter 91) através de tubo (Fig. 111) (Austroginella muscaria, Eratoidea scalaris, "Marginella" ealesae, Marginella glabella, Marginella rosea, Marginella sebastiani, Prunum prunum, Prunum rubens); ?- não observado (Eratoidea eburneola) 
91- Abertura do vestíbulo (passos: 6; ic: 0,16; ir: 0,44).

0- próximo ao poro genital feminino (Fig. 108 - 110); 1- na bursa copulatrix (Fig, 111) (Austroginella muscaria, "Marginella" ealesae, Marginella rosea, Marginella glabella, Marginella sebastiani, Eratoidea scalaris, Eratoidea sp., Leptegouana guttata, Prunum rubens, Prunum fulminatum); ?- não observado (Eratoidea eburneola).

92- Posição da bursa copulatrix em relação ao resto do oviduto (não aditivo; passos: 5 ; ic: 0,4 ; ir: 0,5$)$.

0- dorsal (fig. 108, 109); 1- ventral (Fig, 110, 111) (Adelomelon brasilianus, Austroginella muscaria, Leptegouana guttata, Marginella glabella, Marginella rosea, Marginella sebastiani, Marginellona gigas, Persicula sagittata); 2- Anterior (Eratoidea aureocincta, Eratoidea scalaris, Eratoidea sp., Prunum fulminatum, Prunum rubens, Prunum warreni); ?- não observado (Eratoidea eburneola).

93- Parede da bursa copulatrix (passos: 3 ; ic: 0,33 ; ir: 0,5 ).

0- pouco musculosa (Fig. 109); 1- fortemente musculosa (Fig, 111, 112) (Eratoidea scalaris, Eratoidea sp., Marginella glabella, Marginella rosea, Marginella sebastiani, Persicula sagittata); ?- não observado (Eratoidea eburneola).

\section{Discussão}

A dificuldade em se obter material para este estudo fica clara na análise dos caracteres do sistema reprodutor. Vários táxons tiveram codificações dúbias (estado "?” na Tabela 1) pois não se obteve espécimes de ambos sexos nas pequenas amostras 
examinadas. Um caso especial foi o da espécie Eratoidea eburneola, da qual só se obteve indivíduos imaturos, o único caráter sexual observado foi a papila peniana, observada em um macho jovem. Outro foi o de Persicula sagittata que, apesar da grande amostra examinada, só se obteve fêmeas.

O deslocamento destes elementos, próstata e oviduto palial, para o soalho da cavidade palial também é considerado como um reflexo da lateralização. O fato de este caráter ocorrer novamente apenas em Marginellinae (nó 2) leva a crer que o processo de lateralização ocorrido em Persicula sagittata, seja independente do ocorrido em Marginellidae.

O oviduto palial dos Marginellidae apresentou uma grande diversidade morfológica, principalmente em seus elementos anteriores, bursa copulatrix e o vestíbulo. Isso acarretou em uma certa dificuldade em codificar os caracteres, que talvez tenha gerado alguns problemas de resolução, dado que os valores dos índices de congruência foram bastante baixos para estes caracteres. Por outro lado caracteres do sistema reprodutor masculino foram bem mais conservativos, com apenas uma modificação importante ocorrendo no pênis de Eratoidea.

Uma outra fonte de homoplasias entre P. sagittata, e os Marginellidae, foi o oviduto palial. A estrutura geral dos ovidutos é praticamente idêntica, principalmente no que diz respeito à disposição da glândula de albúmen em relação à glândula da cápsula e a presença de uma glândula ingestória, entre as duas. Todos os espécimes de $P$. sagittata examinados possuíam uma cápsula ovígera na bursa copulatrix,o que indica que a bursa parece ser utilizada como ovopositor. 

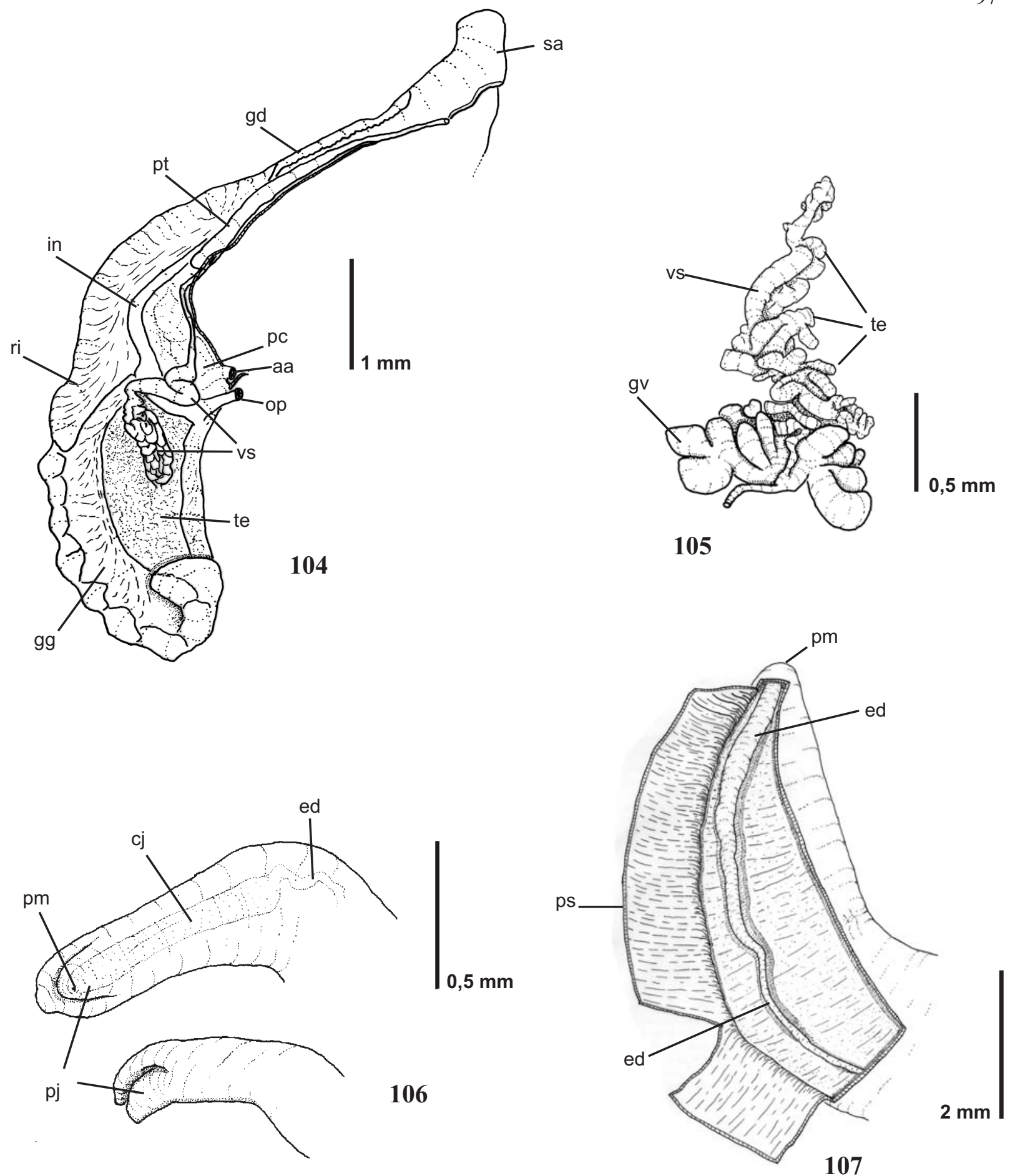

Figuras 104 - 107. 104. Massa visceral e parte do manto de "Eratoidea" watsoni, macho. 105. Vesícula seminal de Leptegouena tripartita. 106. Pênis de Eratoidea scalaris. 107. Pênis dissecado de "Eratoidea" watsoni. aa - aorta anterior ; cj - cápsula ejaculatória; ed - espermoduto; gd - glândula anal; gg - glândula digestiva; gv - glândulas da vesícula seminal; in - intestino; op - esôfago posterior; pc - pericárdio; pj - papila ejaculatória; pm - poro genital masculino; ps - parede do pênis; pt - próstata; ri rim; sa - sifão anal; te - testículo; vs - vesícula seminal. 

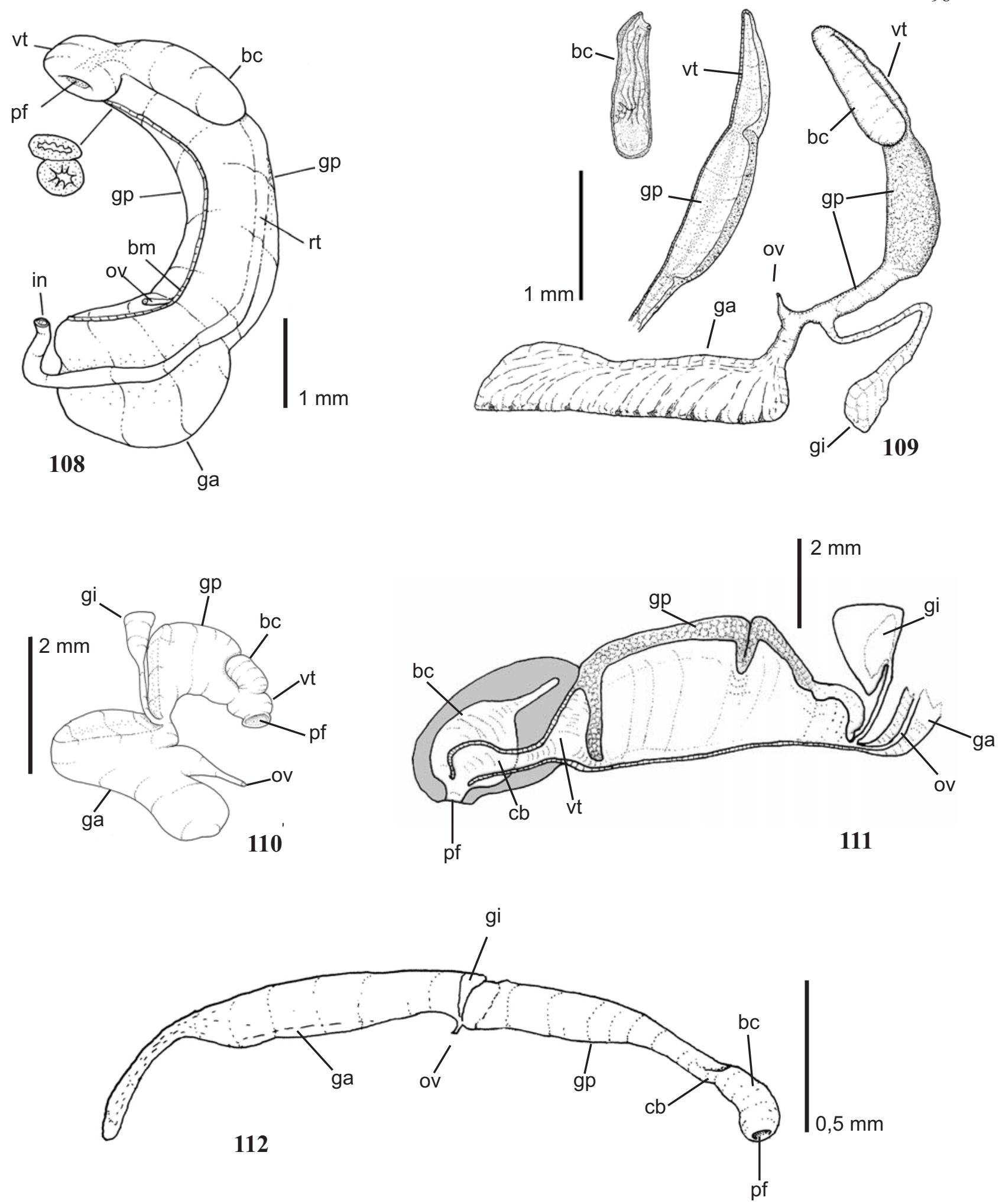

Figuras 108 - 112. 108. Oviduto palial de Trophon geversianus. 109. Oviduto palial de "Eratoidea" watsoni inteiro e com cortes longitudinais da glândula da cápsula e bursa copulatrix. 110. Oviduto palial de Persicula sagittata. 111. Corte longitudinal diagramático do oviduto palial de Marginella sebastiani. 112. Oviduto palial de Eratoidea scalaris. bc - bursa copulatrix; cb - conexão vestíbulo - bursa copulatrix; ga - glândula de albúmen; gi - glândula ingestória; gp - glândula da cápsula; ov - oviduto visceral; pf - poro genital feminino; vt vestíbulo. 


\subsection{Matriz de carcteres}

Tabela 1. Matriz de caracteres levantados da análise morfológica da família Marginellidae. Grupos externos estão nas 4 primeiras linhas.

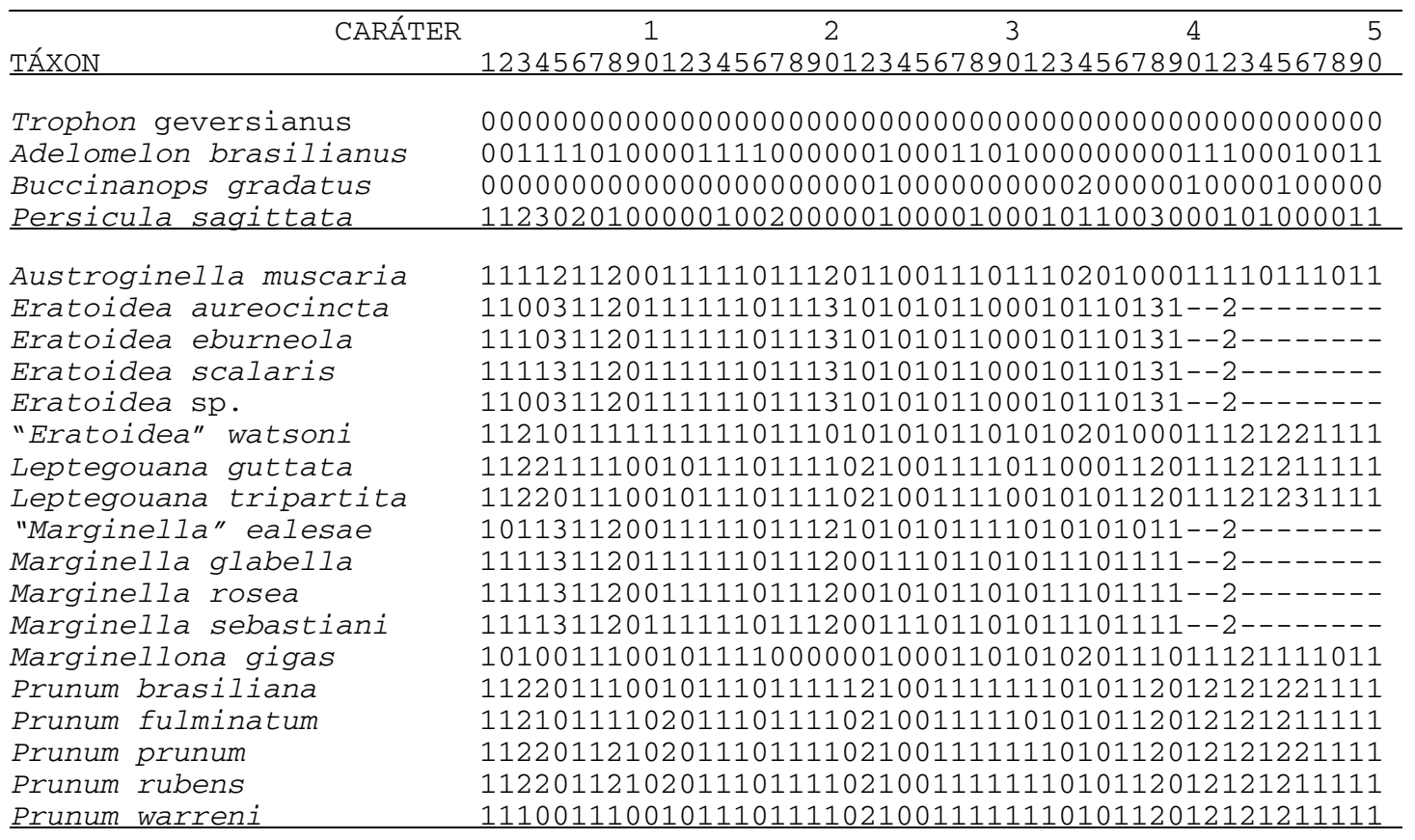

\begin{tabular}{|c|c|}
\hline CARÁTER & $\begin{array}{lcccc}5 & 6 & 7 & 8 & 9 \\
1234567890123456789012345678901234567890123 \\
\end{array}$ \\
\hline Trophon geversianus & 0000000000000000000000000000000000000000000 \\
\hline Buccinanops gradatus & 0000010000100000000000000100000000000000000 \\
\hline Adelomelon brasilianus & 1010120010101021200000000000000000000100010 \\
\hline Persicula sagittata & 10000100000000000000001000010 ?? 0 ?? ?00200011 \\
\hline Austroginella muscaria & 2111120020111121101010100101000110111201110 \\
\hline Eratoidea aureocincta & $---------2211032-0101101110112210200020$ \\
\hline Eratoidea eburneola & --- \\
\hline Eratoidea scalaris & $---2211032-0101101110112210201121$ \\
\hline Eratoidea sp. & $---------2211032-01111010$ ? ?1??? 10200120 \\
\hline "Eratoidea" watsoni & $21101210201111211011-1100101110111010210000$ \\
\hline Leptegouana guttata & 21111111201111212122-11001011??1???11200110 \\
\hline Leptegouana tripartita & 21111111201111211122-11001011??1??? 11200010 \\
\hline "Marginella" ealesae & ----2211211101001110 ? ?1?? 011201100 \\
\hline Marginella glabella & $---2211211-0111101011111011211111$ \\
\hline Marginella rosea & $---2211211-0111101011111011211111$ \\
\hline Marginella sebastiani & $----------2211211-0111111011111011211111$ \\
\hline Marginellona gigas & 10101200101120100000001001010 ? ? 011011200110 \\
\hline Prunum brasiliana & $21121210211111211122-1100101111111011200020$ \\
\hline Prunum fulminatum & $2--21210221111211122-1101101111111011200120$ \\
\hline Prunum prunum & 21121210211111211122-11101010??1??? 11201010 \\
\hline Prunum rubens & $21121210211111211222-1100101011111011201120$ \\
\hline Prunum warreni & $21121210211111211122-1100101111111011210020$ \\
\hline
\end{tabular}




\subsection{Cladograma}

A análise da matriz, inicialmente, foi feita através de enumeração implícita, que obtém todas as árvores possíveis, com os caracteres sem qualquer ponderação. Nesta análise, foram obtidas 4 árvores igualmente parcimoniosas (237 passos, IC: 0,55, IR: 0,79), das quais o consenso estrito apresenta dois nós não resolvidos (fig. 113)

A partir deste resultado, uma análise utilizando ponderação sucessiva (Farris, 1969; Carpenter, 1988), também foi feita para se minimizar a influência de homoplasias que possam ser causadas pela várias ocorrências de dados não observados, principalmente do sistema reprodutor. Após a primeira passagem já se obtinha o número mínimo de 3 árvores igualmente parcimoniosas (982 passos, IC: 0,75, IR: 0,9), cujo consenso apresenta apenas um nó não resolvido (Fig. 114). Esta árvore, por estar melhor resolvida, e com todos os clados suportados (Fig. 115), será a utilizada para as discussões a seguir. 

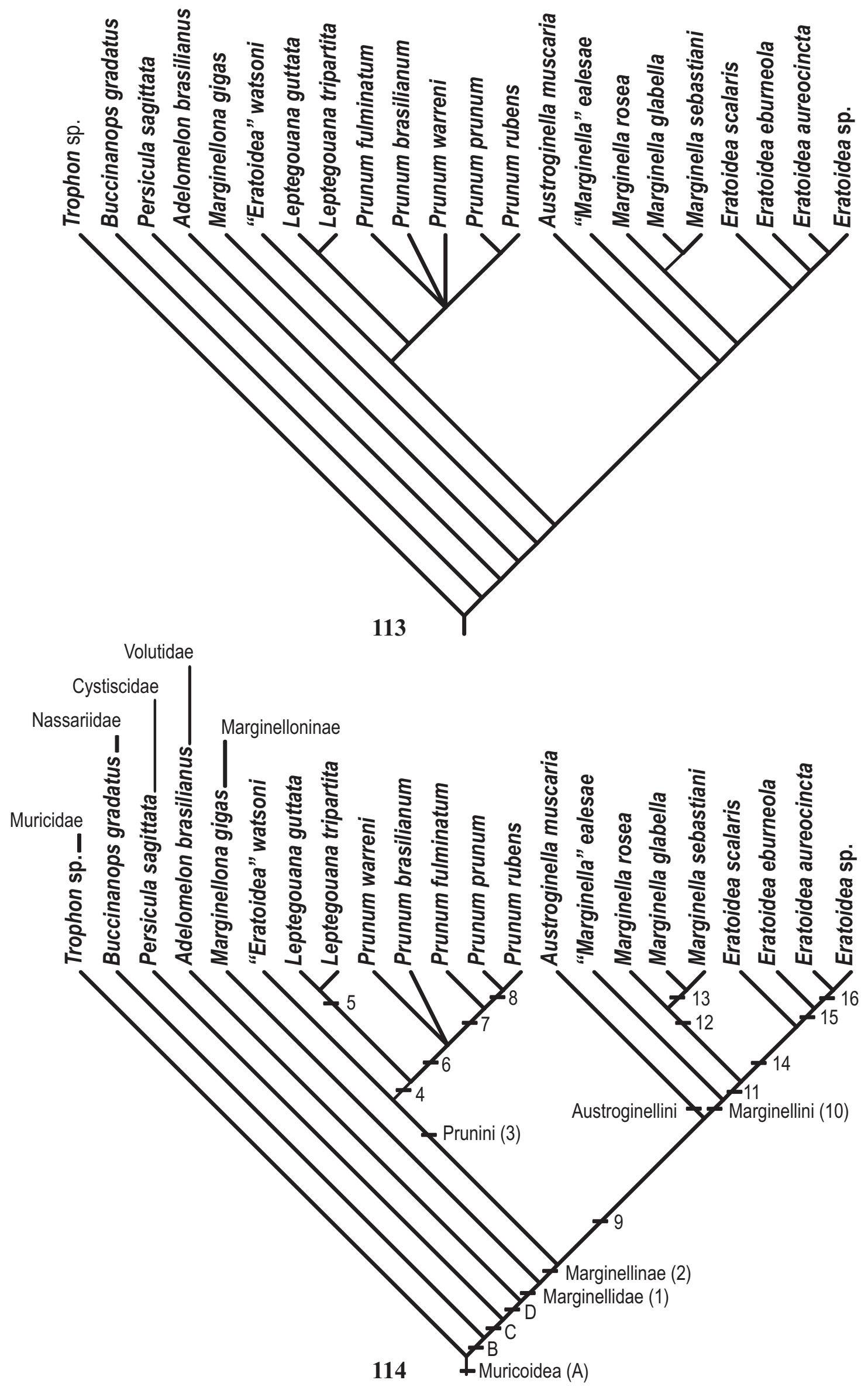

Figuras 113 - 114. 113. Cladograma obtido a partir do consenso estrito de 4 árvores igualmente parcimoniosas (237 passos, IC: 0,55, IR: 0,79). 114. Consenso estrito de 3 árvores igualmente parcimoniosas obtidas após ponderação sucessiva. 


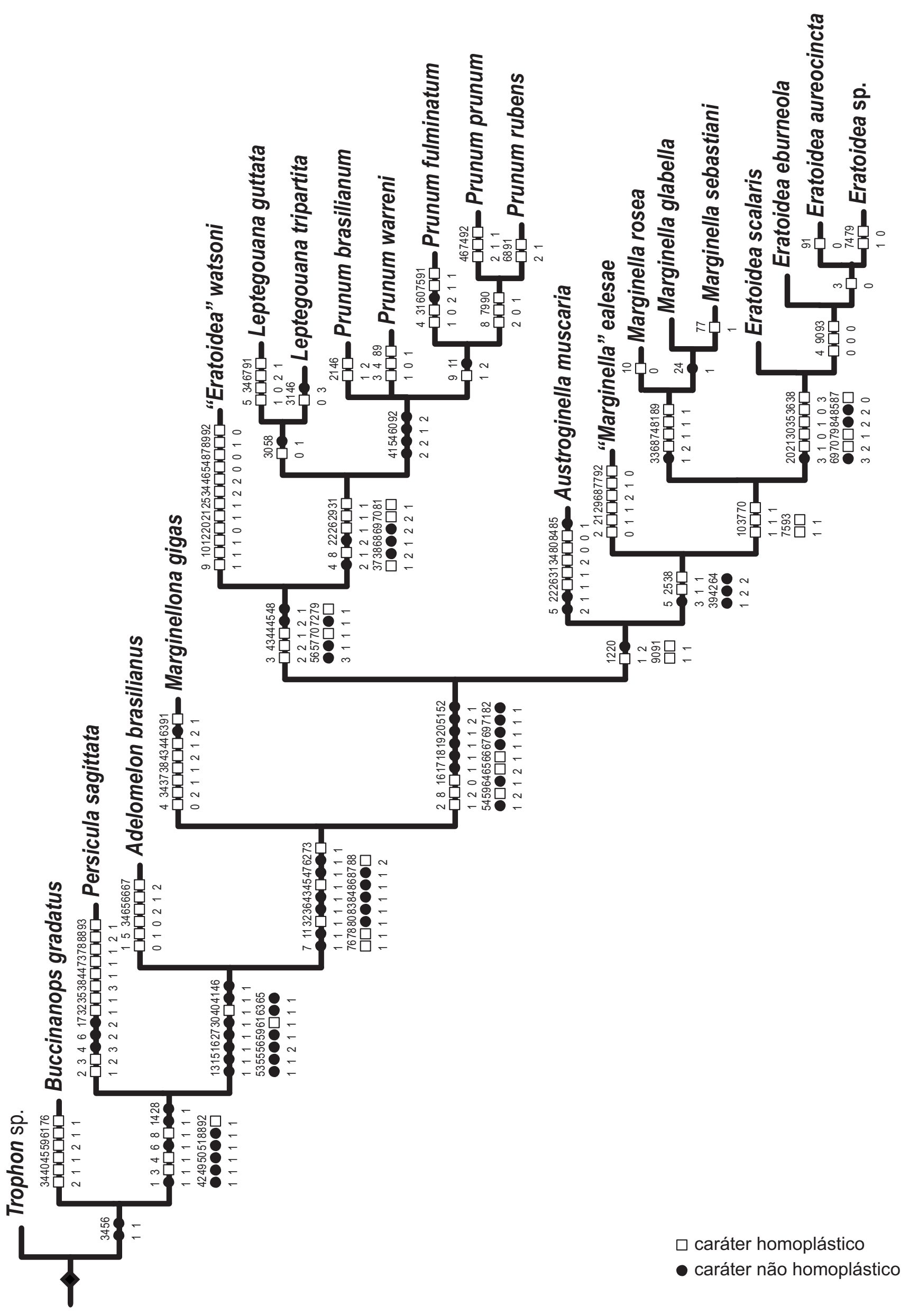

Figura 115. Cladograma obtido a partir de análise cladística e da posterior ponderação sucessiva dos dados (982 passos, IC: 0,75, IR: 0,9), com caracteres otimizados. 


\section{Discussão}

Nesta seção será discutido o cladograma obtido na presente análise (Fig. 115), confrontando-o com dados da literatura.

Clado A: corresponde, dentro do universo analisado, a superfamília Muricoidea (sensu PONDER, 1973). Trophon foi utilizado como grupo externo mais distante, como representante da família Muricidae. Esta família é considerada, por muitos (e.g. THIELE, 1929; WENZ, 1941; BOSS, 1982), como a mais primitiva dentre os Muricoidea. PONDER (1973) e VOKES (1971) sugeriram que a subfamília Trophoninae seria um grupo basal dentro de Muricidae, portanto, os estados presentes em Trophon geversianus foram considerados plesiomórficos no presente estudo.

O enraizamento de Muricoidea aqui utilizado foi elaborado por SIMONE (2000) que analisou 10 táxons, polarizados a partir do plano básico de Tonnoidea. Entre as sinapomorfias levantadas pelo autor podemos destacar: crescimento determinado (caráter 4 daquele estudo); cabeça séssil (“embutida” caráter 5); alongamento posterior do odontóforo (odontóforo conectado anteriormente ao esôfago, caráter 17); dutos das glândulas salivares livres do anel nervoso (caráter 27); válvula de Leiblein (caráter 29); glândula de Leiblein (glândula ventral ímpar do esôfago conectada por um duto, caráter 30). KANTOR (1996) examinou as relações de Neogastropoda e levantou como sinapomorfias para Muricoidea [corresponde no seu trabalho ao ramo que inclui (Olivelloidei (Pseudolivoidei + Muricoidei))], a presença da válvula e a glândula de Leiblein "verdadeira", que concordam com o estudo de SIMONE (2000). 
Clado B: reúne todos os representantes amostrados exceto Trophon geversianus. Buccinanops gradatus foi escolhido por já possui vários caracteres mais derivados do que T. geversianus, como a fusão anterior das cartilagens odontofóricas, e poderia estar relacionado com Marginellidae. Apesar da amostra de representantes de Muricoidea, fora de Marginellidae, ser pequena, parece ser claramente um grupo monofilético suportado por 3 sinapomorfias: caráter 23 (estado 1), que reflete o aumento da área do osfrádio; caráter 34 (estado 1) que representa a redução no número de glândulas salivares acessórias; caráter 56 (estado 1) representa a presença do m11a, músculo tensor ventral da cartilagem subradular, que indica a mudança no funcionamento do movimento de raspagem dá rádula.

Clado C: Reúne Persicula sagittata (Cystiscidae) como grupo irmão de Adelomelon brasilianum (Volutidae) e Marginellidae. Este clado é sustentado por 13 sinapomorfias. Destas podemos destacar a superfície da concha brilhante (caráter 1, estado 1), presença de plicas columelares (caráter 4, estado 1), o dobramento longitudinal do pé (caráter 14, estado1), presença do ramo posterior do retrator subradular dorsal odontóforo (caráter 45, estado 1) e envoltório ventral do odontóforo musculoso.

Persicula sagittata, representando a família Cystiscidae, que até a revisão de COOVERT \& COOVERT (1995) era considerada como uma subfamília de Marginellidae (ver aquele trabalho para um detalhamento dos caracteres de Cystiscidae). Mais recentemente PONDER (1998) e RIEDL (2000) não aceitaram essa nova classificação, sem, no entanto, discutir suas posições. Na presente análise a hipótese de Coovert \& Coovert foi confirmada, apesar de $P$. sagittata apresentar 13 caracteres homoplásticos com os Marginellidae. Este grau de homoplasia, do qual podemos destacar a concha elipsóide, com plicas columelares e a rádula uniserial, certamente levou a classificação dos Cysticidae como Marginellidae, mas talvez os mais chamativos sejam as semelhanças entre 
as probóscides lateralizadas (caráter 32, estado 1) e forma geral do oviduto palial (caracteres 88, estado 2 e 93, estado 1 ).

COOVERT \& COOVERT (1995) especularam que a família Cystiscidae seria próxima à Olividae, devido à reabsorção parcial das voltas internas da concha3, a estrutura columelar semelhante e a semelhança entre as rádulas de Plesiocystiscus (considerado por estes autores, como gênero basal de Cystiscidae) e de alguns Olividae. Olividae, Volutidae e Marginellidae faziam parte, dentro da classificação de WENZ (1938), da superfamília "Volutacea". Após a revisão de PONDER (1973) estas famílias foram incluídas dentro da superfamília Muricoidea. No entanto, dentro do presente estudo, estes "Volutacea" resultaram num grupo monofilético.

Clado D: Reúne $A$. brasilianum (Volutidae) como grupo irmão de Marginellidae. Adelomelon brasilianum, representa os Volutidae, pois historicamente esta foi considerada a família mais próxima de Marginellidae. Adicionalmente, varias espécies (e.g. Voluta glabella Linné, 1758 = Marginella glabella $;$ Voluta bullata Born, $1778=$ Bullata bullata $)$ e o gênero Marginella Lamarck, 1799, e subfamília Marginellinae Fleming, 1828 foram descritos dentro da família Volutidae.

Este clado é sustentado por 13 sinapomorfias. Podemos destacar as modificações no odontóforo (caracteres: 40, estado 1; 41 estado 1; 53, estado 1; 56, estado 2; 61 estado 1) que refletem o funcionamento do odontóforo com o deslizamento da rádula como principal agente de raspagem. De fato, a conformação geral dos odontóforos, de Volutidae e Marginellidae, é muito semelhante na forma geral das cartilagens odontofóricas e disposição dos músculos, apesar do odontóforo em Volutidae em geral ser mais alongados.

\footnotetext{
${ }^{3}$ caráter observado nas dissecções de Persicula sagittata, na qual notou-se que a parte posterior da massa visceral forma um bloco único sem as voltas internas.
} 
COOVERT \& COOVERT (1995) discutiram a posição dos Volutidae como grupo "aliado" dos Marginellidae, comparando algumas características de Marginellona gigas, considerada por eles como membro mais primitivo da família, com outros Volutidae. As características levantadas por COOVERT \& COOVERT (1995) para indicar o parentesco entre as duas famílias foram o formato da cabeça, a concha com plicas altas e a semelhança entre as rádulas. $\mathrm{Na}$ presente análise se confirma a posição dos Volutidae como grupo irmão dos Marginellidae, inclusive a cabeça em aba (caráter 15 estado 1) como uma das sinapomorfias unindo os dois grupos.

Clado 1: O monofiletismo da família Marginellidae é sustentado por 17 sinapomorfias, das quais apenas 2 são conquiliológicas. Dentre as sinapomorfias, provenientes das partes moles, observa-se 7 modificações no odontóforo, e 6 modificações no sistema reprodutivo. Este clado reúne as subfamílias Marginelloninae e Marginellinae.

A topologia deste clado é idêntica à do clado basal da filogenia intuitiva dos Marginellidae, apresentado por COOVERT \& COOVERT (1995: 102, fig. 75) com Marginelloninae (Marginellona + Afrivoluta), aqui representada apenas por Marginellona gigas, como primeiro ramo terminal da família. O exame do odontóforo desta espécie, feito pela primeira vez neste estudo, mostra uma conformação muito semelhante à de Adelomelon brasilianus, a exceção do comprimento.

Historicamente, Marginellona gigas e Afrivoluta pringlei (Tomlin, 1947) (outro membro da subfamília Marginelloninae) foram incluídas em Marginellidae devido à forma de sua rádula (HARASEWYCH \& KANTOR, 1991: figs. 11-13). Os dentes da rádula de alguns Marginellidae, especificamente dos Prunini (fig. 36), se assemelham à dos Marginelloninae, por parecerem com um pente, ou seja, largos, curtos e com muitas cúspides. No entanto a rádula de $M$. gigas não se encaixa exatamente dentro do padrão 
Prunini, pois possuem um número excessivo de cúspides (83 - 85 em adultos), se comparados com os Marginellidae (até 45 cúspides), (COOVERT \& COOVERT, 1995: 56) reconhecem isso ao chamarem esta rádula de "tipo 7" e as dos Prunini de "tipo 6". Para testar se a rádula destes grupos é homóloga, a forma da base do raquidiano foi codificada com mesmo estado (caráter 43 estado 2), mas a topologia da árvore indica que esse caráter surgiu independentemente, em Marginelloninae e nos Prununi (clado 3).

HARASEWYCH \& KANTOR (1991) discutem sobre a presença de um "ceco bucal", i. e. o odontóforo posteriorizado, separado do tubo oral. Esta é uma característica presente em todos os Muricoidea (ver SIMONE 2000), mas nos Volutidae e nos Marginellidae o odontóforo alongou-se e posteriorizou-se no tubo oral, dando esta impressão de ceco (Fig. 70, 71, 73; Ponder, 1970: fig. 7). Esta característica, aqui codificada no caráter 40 , estado 1 , aliada ao estado membranoso da cartilagem subradular, parece mostrar um avançando na tendência de deslizamento da rádula sobre as cartilagens do odontóforo.

O odontóforo posteriormente alongado, também, está presente em Buccinanops gradatus, assim como outras características do odontóforo, existindo, portanto, duas otimizações igualmente parcimoniosas para este caráter. Na otimização ACCTRAN este caráter surgiria no clado $\mathrm{B}$, com uma reversão em $P$. sagittata, e na otimização DELTRAN, o caráter surge, independentemente, em B. gradatus e o no ramo D. Apesar das várias semelhanças, há também várias diferenças, principalmente no aspecto posterior das cartilagens e da musculatura intrínseca, portanto a segunda otimização (DELTRAN) foi preferida.

Clado 2: A subfamília Marginellinae é sustentada por 18 sinapomorfias. Destas podemos destacar o surgimento caracteres mais avançados dos quais podemos destacar: 
músculo columelar lobado (caráter 15, estado 1); hemocele assimétrica (caráter 18, estado 1); glândula salivar acessória simples (caráter 34, estado 1); tubo oral pouco distinto (caráter 64, estado 1); abertura da glândula de Leiblein a frente do anel nervoso (caráter 69, estado 1); ponte da válvula de Leiblein fechada em tubo (caráter 71, estado 1); glândula de Leiblein alongada, tubular com o aspecto da glândula de veneno dos Conoidea (caráter 65, estado 2); oviduto palial e próstata no soalho da cavidade do manto (caráter 82, estado 1).

No filograma de COOVERT \& COOVERT (1995), a subfamília Marginellinae abriga um ramo contendo as tribos recentes, Austroginellini, Marginellini e Prunini, e o gênero fóssil do Cretáceo Myobarbum (Myobarum sic.). Este gênero foi descrito para abrigar uma única espécie M. laevigatum, do Cretáceo Superior, formações Ripley, Owl Creek e Prairie Bluff. Myobarbum assemelha-se coquiliologicamente aos Marginellidae por possuir uma superfície aparentemente brilhante, sutura indistinta e, principalmente, a fusão da primeira plica com a borda anterior do lábio externo. A espécie, originalmente descrita na família Volutidae, foi posteriormente assinalada a Marginellidae por PONDER (1973). Esta classificação foi seguida por COOVERT \& COOVERT (1995), que propuseram esta espécie como grupo irmão da subfamília Marginellinae, utilizando caracteres anatômicos como sinapomorfias. No entanto, Myobarbum também se assemelha às espécies do outro gênero de Scaphellinae (Volutidae), presente nas formações, Parafusus Wade, 1918, do qual difere apenas no tamanho da concha e disposição das plicas (plica anterior, quando presente, não se funde com o lábio externo). Portanto, no atual estágio de conhecimento, qualquer decisão quanto à posição taxonômica de Myobarbum deve ser considerada dúbia.

COOVERT \& COOVERT (1995) dividem as tribos recentes em dois ramos, Austroginellini e um ramo com Prunini + Marginellini. Esta topologia não foi confirmada no presente estudo. Aqui a subfamília se divide na tribo Prunini e um ramo com 
Austroginella muscaria, representante da tribo Austroginellini, e a tribo Marginellini. A distribuição dos caracteres indicou que a perda da válvula de Leiblein ocorreu independentemente nos dois grupos. Isso é confirmado pelo fato de ambos os clados apresentarem representantes com estágios vestigiais da válvula (o gênero Marginella e "Eratoidea” watsoni).

Clado 3: A tribo Prunini é sustentada por 11 sinapomorfias. Uma das características mais marcantes desta tribo é que nela a tendência à lateralização se acentua, principalmente nos ramos mais apomóficos. Inicialmente neste clado, as evidências desta maior lateralização se limitam ao alongamento da abertura (caráter 3, estado 2) e a posição posterior do ânus na cavidade palial (caráter 79, estado 1).

COOVERT \& COOVERT (1995) consideraram a presença de ceco esofagiano como diagnóstico de Prunini, isto foi confirmado na presente análise (caráter 72, estado 1). $\mathrm{O}$ odontóforo também possui características próprias, como o $\mathrm{m} 3 \mathrm{em}$ forma de fita (caráter 48, estado 1); a completa fusão do m11a (caráter 56, estado 2); a presença de mg (caráter 57, estado 1). Observando-se a distribuição dos caracteres da parte anterior do oviduto palial (caracteres 89 - 92), observa-se uma extrema plasticidade com, nada menos que, 7 transições homoplásticas. Espera-se que aumentando a densidade taxonômica da amostra deste grupo, caracteres do oviduto palial se tornem mais informativos.

Clado 4: Este clado reúne os Prunini mais avançados e é sustentado por 13 sinapomorfias. Na concha a lateralização se reflete na espira quase involuta (caráter 4, estado 2). Na cavidade palial reflete-se, no septo vertical do nervo osfradiano (caráter 22, estado 2), na conexão subterminal entre a veia ctenidial e a aurícula (caráter 26, estado 1) 
e, provavelmente, na forma mais larga do rim (caráter 29, estado 1). Na hemocele ocorre o posicionamento das glândulas salivares, à esquerda da probóscide (caráter 38, estado 2).

Outras características importantes, observadas neste clado, são a perda da válvula de Leiblein (caráter 70, estado 2), a conexão da glândula de Leiblein logo posterior ao odontóforo (caráter 69, estado 2) e o reforço muscular da conexão do bulbo da glândula de Leiblein com a parede hemocélica (caráter 68, estado 1).

As espécies deste clado estavam classificadas em dois gêneros, Volvarina e Prunum. Aqui esta classificação não foi confirmada, sendo as espécies divididas em dois ramos não concordantes com esta classificação, pois ambos abrigam, separadamente, espécies antes classificadas como Volvarina e Prunum.

Clado 5: Este clado, aqui classificado como Leptegouana Woodring, 1928, é sustentado por 2 sinapomorfias, uma reversão na redução da cavidade renal (caráter 30, estado 0 ), a origem de $\mathrm{m} 8$ mais anterior, afastada de $\mathrm{m} 4$ (caráter 58 , estado 1 ).

Leptegouana foi sinonimizada sob Prunum por COAN (1965) e COOVERT \& COOVERT (1995), baseando-se em caracteres da rádula e concha. Aqui é utilizado como gênero pela primeira vez, pois o clado inclui a espécie-tipo Leptegouana guttata (=Voluta guttata Dillwyn, 1817). COOVERT \& COOVERT (1995) afirmam que este nome e outros, por eles sinonimizados sob Prunum (Egouena Jousseaume, 1875; Microspira Conrad, 1868), poderiam ser utilizados como subgêneros com uma revisão mais completa do gênero. Num contexto cladístico, a decisão de se utilizar os nomes como gênero ou subgêneros é geralmente arbitrária, pois seria igualmente possível se estabelecer o ramo 4 como Prunum, o ramo 5 como subgênero Prunum (Leptegouana) e o ramo 6 como Prunum sensu strictu. 
Clado 6: Este clado, classificado como gênero Prunum, é definido por 4 sinapomorfias, a conexão através de longo tubo do odontóforo com o tubo oral (caráter 41, estado 2), perda do músculo horizontal (caráter 54, estado 2) decorrente da fusão posterior da cartilagem do odontóforo (caráter 60, estado 1) e a anteriorização da bursa copulatrix (caráter 92, estado 2).

Neste clado estão incluídas 2 espécies, até recentemente, classificadas no gênero Volvarina (Prunum brasilianum e Prunum warreni). Uma das questões de difícil resolução na sistemática dos Marginellidae é a separação entre os gêneros Prunum e Volvarina. Historicamente, a diferenciação entre estes era baseada no tamanho e forma da concha, uma vez que a rádula não fornece meios de separação. Então, as espécies com conchas mais robustas e largas eram classificadas como Prunum e as de concha mais esguias e cilíndricas eram classificadas como Volvarina (COOVERT, 1988). Alguns autores (GOFAS, 1989; GOFAS \& FERNANDEZ, 1992; SOUZA, 1992) afirmaram que esta forma de classificação levava a muitas decisões arbitrárias quanto a alocação genérica das espécies, sendo que GOFAS (1989) e GOFAS \& FERNANDEZ, (1992) chegaram a tratar todos espécies em Volvarina por ser este o gênero mais antigo, sem no entanto formalizar a sinonímia. COOVERT \& COOVERT (1995) dissecaram o sistema digestório anterior de algumas espécies de Prunini e chegaram a ilustrar os diferentes tipos de cartilagem odontofóricas (COOVERT \& COOVERT 1995: 62, figs. 38 - 42) e mencionam que sua forma pode ter importância taxonômica. Entretanto, nas diagnoses destes gêneros, a fusão posterior das cartilagens é dada como caráter de Volvarina e que Prunum pode apresentar ambos os tipos de cartilagens odontofóricas. No entanto, na sua filogenia intuitiva, a fusão posterior das cartilagens nem é mencionada, enquanto aqui é uma das sinapomorfias o grupo. Apesar das espécies examinadas no presente estudo formarem um grupo 
monofilético, com uma identidade morfológica bem definida, ainda não é possível tomar uma decisão taxonômica definitiva quanto à designação genérica, pois infelizmente não foi possível obter exemplares da espécie tipo de Volvarina [V. mitrella (Risso, 1826)] para exame.

Clado 7: contém Prunum fulminatum como grupo irmão do clado 8. O clado 7 é embasado por duas sinapomorfias conquiliológicas, a presença de dentes parietais (caráter 9, estado 1) e a presença de sulco na margem dorsal do lábio externo (caráter 11, estado 2), demonstrando que caracteres conquiliológicos são importantes, mas que, como qualquer outro caráter morfológico, devem se analisados num contexto comparativo amplo.

Prunum fulminatum possui a peculiaridade de apresentar a fusão completa das cartilagens do odontóforo acompanhada da perda do m5 (caráter 60, estado 2). O odontóforo desta espécie é bem pequeno para um animal do seu tamanho, portanto, podese especular uma possível tendência para a perda desta estrutura.

Clado 8: Este clado contém $P$. prunum, espécie tipo do gênero, e $P$. rubens e tem como sinapomorfias: plicas columelares ocupando mais da metade do comprimento da parede parietal (caráter 8, estado 2); reversão do posicionamento do ânus na cavidade palial (caráter 79, estado 0); conexão do vestíbulo com a bursa copulatrix, através de tubo (caráter 90, estado 1). Deve-se ressaltar que todas estas sinapomorfias são homplásticas.

Clado 9: Abriga Austroginella muscaria como grupo irmão de Marginellini e é definido por 7 sinapomorfias: arranjo das plicas columelares, ocupando mais da metade da abertura (caráter 8, estado 2); canal anal da abertura (caráter 12, estado1) e o sifão anal 
musculoso (caráter 20, estado 1); comunicação do vestíbulo com a bursa copulatrix, através de tubo, (caracteres 90, estado 1 e 91, estado 1).

Conquiliologicamente, a exceção do calo ventral, A. muscaria é semelhante às Marginella, mas outros representantes do gênero como $A$. formicula (Lamarck, 1822) e $A$. tasmanica (Tenison-Woods, 1876), são ainda mais semelhantes. Estas características, aliadas às sinapomorfias das partes moles, justificam a posição de Austroginella como grupo irmão de Marginellini, no entanto, não significa que Autroginellini como um todo o seja.

Austroginella é o gênero tipo da Tribo Austroginellini, criada por COOVERT \& COOVERT (1995) para abrigar os marginelídeos com válvula de Leiblein com ponte tubular, mas, como foi visto, este caráter é sinapomorfia da subfamília Marginellinae. Observando o estudo de COOVERT \& COOVERT (1995) nota-se que tribo formou um grupo morfologicamente pouco coeso, com alguns grupos muito similares aos Prunini (e.g. Serrata e Hydroginella), tanto na forma da concha como da rádula (COOVERT \& COOVERT, 1995: figs. 6, 54, 56), outros mais semelhantes, na forma da concha, aos Marginellini (e.g. Austroginella e Protoginella; COOVERT \& COOVERT, 1995: figs. 57, 59). Isto, aliado ao fato da tribo ter sido baseada em uma plesiomorfia, sugere a parafilia ou polifilia de Austroginellini.

Clado 10: Compreende a tribo Marginellini, e está embasada por 6 sinapomorfias: calo ventral com microgranulações (caráter 5, estado 3); borda livre do ctenídio truncada (caráter 25, estado 1); glândulas salivares a direita da probóscide e dorsal ao esôfago (caráter 38, estado 1); perda do odontóforo, da rádula e do tubo oral (caracteres: 39 estado 1; 42 estado 2; 62 estado 2). 
Na filogenia intuitiva de COOVERT \& COOVERT (1995) Marginellini é grupo irmão de Prunini, unidos pela perda da válvula de Leiblein e pela abertura da glândula no tubo oral ou próximo a boca, e isso não se confirmou na presente análise. A espécie estudada ("Marginella" ealesae) mais basal da tribo, possui válvula de Leiblein com ponte em tubo, e as espécies do clado 11 (gênero Marginella) apresentam a abertura da glândula de Leiblein longo anterior ao anel nervoso.

Clado 11: Este clado abriga os gêneros Marginella e Eratoidea, e está embasado por 5 sinapomorfias: a presença de dentes no lábio externo (caráter 5, estado 1); a glândula anal anterior ao ânus (caráter 76, estado 1); dutos salivares livres do esôfago (caráter 37, estado 1); válvula de Leiblein vestigial (caráter 70, estado 1); parede da bursa copulatrix muito musculosa (caráter 93, estado 1).

Clados (12(13)): Este clado, classificado como Marginella, está sustentado por 5 caracteres: músculo acessório da probóscide(caráter 33, estado 1); a presença de braçadeiras musculares entorno do bulbo da glândula de Leiblein (caráter 68, estado 1); pregueamento complexo, no revestimento do estômago (caráter 74 , estado 1); vesícula seminal com glândulas na sua parte anterior (caráter 81, estado 1); câmara distinta no vestíbulo (caráter 89 , estado 1$)$.

Neste clado está incluída a espécie tipo de Marginella, M. glabella, formando juntamente com M. sebastiani (clado 12) e M. rosea um grupo monofilético bastante coeso morfologicamente. Além de apresentar o músculo acessório, toda a probóscide e o esôfago deste gênero são muito musculosos, provavelmente como adaptação à perda da rádula. 
Clados (13(14(15))): Este clado inclui os Marginellini de tamanho reduzido, que segundo COOVERT \& COOVERT (1995), pertencem aos gêneros Dentimargo e Eratoidea. Este clado é sustentado por 10 sinapomorfias, destas podemos destacar o sifão anal alongado (caráter 14, estado 2), as glândulas salivares longas e saculiformes localizada dentro da probóscide (caracteres, estado: 33, 2;36, 1), poro genital masculino em papila ejaculatória (caráter 83, estado 2) e duto peniano com câmara ejaculatória. PONDER (1970) estudou a anatomia de Volvarinella cairoma (Brookes, 1924) (Volvarinella $=$ Dentimargo ver introdução), que mostrou a morfologia da probóscide e do pênis exatamente como a das espécies aqui estudadas, indicando que esta espécies também pertence a este clado. Outra característica deste gênero é o grande número de reversões, são 7, contando com o clado basal e sub-clados, provavelmente reflexo da miniaturização de suas espécies.

SOUZA (1997) discutiu a utilização dos gêneros, com base em caracteres conquiliológicos, e concluiu que no Recente apenas Eratoidea seria aplicável, por não haver diferenças conquiliológicas para a separação de grupos, o que foi confirmado pela morfologia das partes moles. SOUZA (1997) também discute que Dentimargo deveria se apenas utilizado para as espécies do Eoceno, por ser a espécie tipo do gênero deste período. Se por um lado, o monofiletismo destes Marginellini miniaturizados é confirmada pelo presente estudo, por outro, a espécie tipo de Eratoidea (E. margarita) não foi estudada morfologicamente e até este estudo seja feito, essa classificação deve ser considerada provisória. 


\section{Conclusões}

- Marginellidae é um grupo monofilético sustentado por 17 sinapomorfias

- Marginellidae é distinto de Cystiscidae, que tem uma posição mais basal dentro dos Muricoidea mas com muitos caracteres homoplásticos em relação à Marginellidae.

- Volutidae é o grupo irmão de Marginellidae.

- Austroginellini foi definido por COOVERT \& COOVERT (1995) a partir de uma plesiomorfia interna, sugerindo que não é uma grupo monofilético .

- A perda da válvula de Leiblein ocorreu independentemente em Prunini e Marginellini.

- Prunini é um grupo monofilético definido pelo ceco esofágico e por diversas modificações coquiliológicas e anatômicas decorrentes da lateralização.

- Prunum é um grupo monofilético definido pela fusão posterior da cartilagem odontofórica.

- Leptegouana é um grupo monofilético definido pelo encurtamento do m8 e redução da cavidade renal,

- Marginellini é um grupo monofilético definido pelas perdas do odontóforo e do tubo oral.

- Marginella é um gênero monofilético diagnosticável pela abertura da glândula de Leiblein logo a frente do anel nervoso, válvula de Leiblein vestigial e pela probóscide muito musculosa.

- Eratoidea é um gênero monofilético diagnosticável pelas seguintes características: sifão anal delgado; pênis com papila ejaculatória; abertura da glândula de Laiblein próxima a boca; e glândulas salivares tubulares localizadas dentro da probóscide. 


\section{Referências Bibliográficas}

AMORIM, D.S., 1997. Elementos básicos de sistemática filogenética, segunda edição. Holos Editora. Sociedade Brasileira de Entomologia. Ribeirão Preto. 276 pp.

BARNARD, K. H., 1962. A new genus in the family Marginellidae. Proc. Malacol. Soc. Lond., London, 35 (1): 14-15.

BIELER, R. \& MIKKELSEN,P.M.. 1992. Preliminary phylogenetic analysis of the bivalve family Galeommatidae. Amer. Malac. Bull., Indiana, 9(2): 157-164.

BOSS, K.J. 1982. Mollusca. In PARKER, S.P., Synopsis and Classification of Living Organisms, vol. 1. McGraw-Hill, New York. pp. 945-1166.

BOUCHET, P., 1989. A Marginellid Gastropod Parasites Sleeping Fishes. Bull. Mar. Sci., Coral Gables, 45 (1): 76-84.

BOUVIER, E. L. 1889. Sur le siphon esophagien des marginelles. Bull. Soc. Philom. Par., Paris 1 (1): 13-14.

BOYER, F., 2004. Description of a new Cystiscus (Gastropoda: Cystiscidae) from the Mascarene Islands. Journ. Conch. London; 38 (4): 355-361.

CARPENTER, J, M., 1988. Choosing among equally parsimonious cladograms. Cladistics, New York, 4:291-296

CARRIKER, M. R., 1943. On the structure and function of the proboscis in the common oyster drill, Urosalpinx cinerea Say. Journ. Morph. 73 (3): 441-506.

CHISTIKOV, S. D., 1984. Phylogenetic relationships of the Scaphopoda. Malacol. Rev. Ann Arbor 17 (1-2) 114-115

CLARKE, H. A., Jr., 1992. Annotated list and bibliography of the abyssal marine Mollusca of the world. Bull. Natl. Mus. Can., Ottawa, 181: 1-114.

CLENCH, W.J., \& TURNER R. D.,1964. The subfamilies Volutinae, Zidoninae, Odontocymbiolinae, and Calliotectinae in the Western Atlantic. Johnsonia, Harvard, 4 (43): 129-80 
COAN, E. V., 1965. A proposed reclassification of the family Marginellidae. Veliger, Berkeley, 7 (3): 184-194.

COAN, E. V. \& ROTH, B., 1976. Status of the genus Hyalina Schumacher, 1817 (Mollusca: Gastropoda). Journ. Moll. Stud., London, 42 (2): 217-222.

COOVERT, G. A., 1986a. Type species list. Marginella Marginalia, Dayton, 1 (1): 1-3.

COOVERT, G. A., 1986b. Generic group names. Marginella Marginalia, Dayton, 1 (2): $5-7$.

COOVERT, G. A., 1986c. Two previously unfigured species from Dall. Marginella Marginalia, Dayton, 1 (3): 8-12.

COOVERT, G. A., 1986d. A review of marginellid egg capsule. Marginella Marginalia, Dayton, 1 (4): 13-19.

COOVERT, G. A., 1986e. Notes on the genus Cystiscus and its type species. Marginella Marginalia, Dayton, 1 (5): 20-24.

COOVERT, G. A., 1986f. Notes on the genus Crithe and its type species. Marginella Marginalia, Dayton, 1 (1): 1-3.

COOVERT, G. A., 1987a. The genus Afrivoluta and a review of the type species Afrivoluta pringlei Tomlin, 1947. Marginella Marginalia, Dayton, 2 (1): 1-8.

COOVERT, G. A., 1987b. The Persicula cornea group. Marginella Marginalia, Dayton, $2(2 / 3): 10-19$.

COOVERT, G. A., 1987c. Additional notes on the genus Crithe. Marginella Marginalia, Dayton, 2 (5): 28-35.

COOVERT, G. A., 1987d. Extra extra: read all about it. Marginella Marginalia, Dayton, $2(6): 36-41$.

COOVERT, G. A., 1987e. Proper usage of the generic names Haloginella, Hyalina and Volvarina with a diagnosis of the genus Haloginella. Marginella Marginalia, Dayton, 3 (1): 1-7.

COOVERT, G. A., 1987f. A literature review and summary of marginellid external anatomy. Marginella Marginalia, Dayton, 3 (2/3): 8-23. 
COOVERT, G. A., 1987g. Notes on the genus Granulina and its type species. Marginella Marginalia, Dayton, 3 (4): 26-32.

COOVERT, G. A., 1987h. The external anatomy of two species of Caribbean Marginellidae. Marginella Marginalia, Dayton, 3 (5): 33-37.

COOVERT, G. A., 1987i. Taxonomy: how and why we do what we do. Marginella Marginalia, Dayton, 3 (6): 38-42.

COOVERT, G. A., 1988a. Marginellidae of Florida, Part I: Granulina hadria. Marginella Marginalia, Dayton, 4 (1): 1-8.

COOVERT, G. A., 1988b. Type species of the genus Austroginella and Mesoginella and their synonyms. Marginella Marginalia, Dayton, 4 (2/3): 9-26.

COOVERT, G. A., 1988c. Marginellas from sunwatch, a prehistoric indian village in SW Ohio. Marginella Marginalia, Dayton, 4 (4): 27-34.

COOVERT, G. A., 1988d. Marginellidae of Florida, Part II: Prunum succinea with a Discussion of Prunum and Volvarina. Marginella Marginalia, Dayton, 4 (5): 3542.

COOVERT, G. A., 1988e. Taxonomic characters in the family Marginellidae: conchological characters. Marginella Marginalia, Dayton, 4 (68): 43-47.

COOVERT, G. A., 1988f. A bibliography of the recent Marginellidae. Marginella Marginalia, Dayton, 5 (1-5): 1-43.

COOVERT, G. A., 1989a. The Marginella musica - diacocus group. Marginella Marginalia, Dayton, 6 (3-5): 16-29.

COOVERT, G. A., 1989b. A literature review and summary of plublished marginellid radulae. Marginella Marginalia, Dayton, 7 (1-6): 1-37.

COOVERT, G. A. \& COOVERT, H. K., 1990. A Study of marginellid radullae part I: type 6 radula, "Prunum / Volvarina" Type. Marginella Marginalia, Dayton, 8-9 (16): $1-68$.

COOVERT, G. A. \& COOVERT, H. K., 1995. Revision of the supraspecific classificartion of marginelliform gastropods. Nautilus, Silver Springs, 109 (2-3): 43 -110 . 
COSSIGNANI, T., 2001. Descrizione di dieci nuove marginelle (Gastropoda: Prosobranchia, Marginellidae e Cystiscidae) della provincia Indo-Pacifica. Malacologia Mostra Mondiale, Cupra Marittima 35: 3-11.

COSSIGNANI, T., 2006. Marginellidae and Cystiscidae of the World. Mostra Mondiale Malacologia, Cupra Marittima. 408 pp.

COSSMANN, A. E. M., 1899. Essais de Paléoconchologie Comparé. Vol. 3. Cossmann, Paris. 201 pp., 8 pr.

D'ASARO, C. N., 1970. Egg capsules of prosobranch mollusks from the South Florida and the Bahamas and notes on spawning in the laboratory. Bull. Mar. Sci., Coral Gables, 20 (2): 414-440.

D'ASARO, C. N., 1986. Egg capsules of eleven marine prosobranch from the northwest Florida. Bull. Mar. Sci., Coral Gables, 39 (1): 76-91.

D’ASARO, C. N., 1986a. Laboratory spawning, egg membranes and egg capsules of 14 small marine prosobranchs from Florida and Bimini, Bahamas. Amer. Malac. Bull., Indiana, 4 (2): 185-199; 5 fig. 3tbl.

DAVIS, G. M. CHEN, C. E., ZHENG, X. P., YU, S. H. \& LI, L., 1994. Molecular, genetic and anatomical relationships among pomatiopsid (Gastropoda : Prosobranchia) genera from southern China. Proc. Acad. Nat. Sci. Philad., Philadelphia, 145: 191 - 107

EAMES, F. E. 1952. A contribution to the study of the Eocene in Western Pakistan and Western India. C. The description of the Scaphopoda and gastropoda from standard sections in the Rakhi Nala and Zinda Pir areas of the Western Punjab and in the Koahat District. Phil. Trans. R. Soc. London, Londres, ser. B, 236 (631): 1-168.

ESPINOSA, J. \& ORTEA, J. 2000. Descripcion de un genero y once especies nuevas de Cystiscidae y Marginellidae (Mollusca: Neogastropoda) del Caribe de Costa Rica. Avicennia, Havana, 12-13: 95-114

FARRIS, J. S., 1969. A successive approximations approach to character weighting. Syst. Zoology 18:374-385. 
FISCHER, P. H., 1887. Manuel de Conchyliologie et Paléontologie Conchyliologique ou Histoire Naturelle des Mollusques Vivantes et Fossiles. Vol.2. 608 pp. Librarie F. Savy, Paris.

FLEMING, J., 1828. A History of British Animals, Exhibiting the Descriptive Characters ans Systematical Arrangement of the Genera and Species of Quadrupeds, Birds, Reptiles, Fishes, Mollusca and Radiata of the United Kingdom. Edinburg and London.

FRETTER, V., 1976. The Anatomy and Feeding of the Volutacean Prosobranch Volvarina taeniolata Mörch. Journ. Moll. Stud., London, 42 (2): 327-336.

GARDNER, J. A., 1937. The molluscan fauna of the Alum Bluff group Florida. Prof. Pap. U.S. geol. Surv., Washington, 142-F: 251-435.

GRAHAM, A., 1966. The R/V Pillsbury Deep-Sea Biological Expedition to the Gulf of Guinea, 1964-65.Pt. 8 : The fore-gut of some marginellid and cancellarid prosobranchs. Stud. Trop. Ocean., Coral Gables, 4 (1): 134-151.

GOFAS, S., 1989. Le genre Volvarina (Marginellidae) dans la Méditerranée et 1'Atlantique du Nord Est. Boll. Malac., Milano, 25 (5-6): 1-25.

GOFAS, S. \& FERNANDES, F., 1988. The Marginellids of São Tomé, West Africa. $J$. Conch., Lond., London, 33 (1): 1-30.

GOFAS, S. \& FERNANDES, F., 1992. The Marginellidae of Angola: the genus Volvarina. J. Conch., Lond., London, 34 (4): 187-198.

GOFAS, S. \& FERNANDES, F., 1992. The Marginellidae of Angola: the genus Marginella. J. Conch., Lond., London, 35 (2): 103-119.

GÖTING, K. J., 1974. Malakozoologie. Gustav Fischer Verlag, Stuttugart. 320 pp.

GRAY, J. E., 1847. A list of the genera of Recent Molluscs, their synonyma and types. Proc. Zool. Soc. Lond., London, 17: 129-219.

GRAY, J. E., 1857. Guide to the systematic distribution of Mollusca in the British Museum. Vol. Xii. London. 230 pp. 
HARASEWYCH, M. G., 1984. Comparative anatomy of four primitive muricacean gastropods: implication for trophonine phylogeny. Amer. Malac. Bull., Mississippi, 3 (1): $11-26$.

HENNIG, W. 1950. Gunddzüge einer Theorie der phylogenetischen Systematik. Deutscher Zentralverlag, Berlin. 370 pp.

HENNIG, W., 1966. Phylogenetic Systematics. University of Illinois Press, Urbana.

HERSHLER, R. 1994. A review of North American freshwater snail genus Pyrgulopsis (Hydrobiidae). Smithson. Contr. Zool., Washington, 554: 1-115

HINDS, R. B., 1844. Descriptions of Marginellidae Collected during the Voyage of H. M. S. Sulphur, and from the Collection of Mr. Cuming. Proc. Zool. Soc. Lond., London, 12 (134): 72-77.

ICNZ, 1985. International Code of Zoological Nomenclature, 3rd. Ed. International Trust for Zoological Nomenclature, British Museum (Natural History), London \& University of California Press, Berkeley, Los Angeles. xx +338 pp.

IVANOV, D. L. \& PLAVINOV, I. Y., 1991. Analysis of Morphological characteristics of Caudofoveata (Mollusca, Aplacophora) by means of cladistics. Zh. Obshch. Biol., Moscou, 52 (1): 27-35.

JOUSSEAUME, J. P., 1875. Coquilles de la Famille des Marginelles. Monographie. Rev. Mag. Zool., Paris, 3: 164-271.

KIENER, L. C., 1834-1841. Le Genre Marginelle in Spécies Général et Iconographie des Coquilles Vivants.Vol. 3: 1 - 30 (1834), 31 - 44pp (1841). J. B. Baillière et fils, Paris.

LAMARCK, J. B. P. A. DE M. DE, 1799. Prodome d'une Nouvelle Classification des Coquilles. Mém. Soc. Hist. Nat. Paris, Paris, 1: 63-91.

LAMARCK, J. B. P. A. de M. de, 1822. Histoire Narturalle des Animaux sans Vertbres. Vol. 6. Paris. 711 pp.

LASERON, C. F., 1957. A New Classification of the Australian Marginellidae (Mollusca), with a Review of Species from the Solanderian and Damperian 
Zoogeographical Provinces. Records of the Australian Museum, Sidney, 8 (3): 274311.

LINDBERG, D. R. \& PONDER, W. F., 2001. Influence of classification on the evolutionary interpretation of structure a re-evaluation of the evolution of the pallial cavity of gastropod molluscs. Org. Divers. Evol., Munique, 1(4):273-299.

LINNAEUS, C., 1758. Systema Naturae per Regna tria Naturae. Editio decima, reformata. 1 "Regnum Animale”. Holmiae. 824 pp.

MADDISON, W. P., DONOGHUE \& MADDISON, D. R., 1984. Outgroup analysis and parsimony. Syst. Zool., London, 33: 83-103.

MARCUS, E. \& MARCUS, E., 1968. On the prosobranch Ancilla dimidiata and Marginella fraterculus. Proc. Malacl. Soc. Lond., Londres, 38 (1): 55-69.

MURRAY, F. V., 1970. The Reproduction and Life Cicle of Microginella minutissima (Tenison-Woods, 1876) (Gastropoda: Marginellidae). Mem. Nat. Mus. Victoria, Victoria, 31: 31-35.

NEHM, R., 2001. Calibrating sapatial and temporal species richness in Tropical American marginellid gastropods. J. Paleont. Iowa, 75(3): 680 - 696.

NEHM, R., 2001b. The developmental basis of morphological disarmament in Prunum (Neogastropoda; Marginellidae). Pp. 1-26 (Chapter 1) In: M.L. Zelditch, Ed. Beyond Heterochrony. John Wiley and Sons, New York .

NELSON, G. \& PLATNIK, N., 1981. Systematics and Biogeography. Cladistics and Vicariance. Columbia University Press, New York.

NIXON, K. C. 2002. WinClada ver. 1.00.08. Publicado pelo autor, Ithaca.

NIXON, K. C. \& CARPENTER, J. M., 1993. On outgroups. Cladistics, New York, 9: 413-426.

PENCHASZADEH, P. E. \& RINCON, A., 1996. Egg Capsules and Development of Prunum prunum (Gmelin, 1791) (Prosobranchia: Marginellidae) from the Venezuela Caribbean. Veliger, Berkeley, 39 (1): 83-86.

PETIT, S., 1851. Description de Coquilles Nouvelles. J. Conch., Paris 2 (3): 259-269. 
PINNA, M. C. C., 1991. Concepts and tests of homology in cladistic paradigm. Cladistics, New York, 7: 367-394.

PONDER, W. F., 1970. Some aspects of the morphology of four species of the neogastropod family Marginellidae with a discussion on the evolution of the toxoglossan poison gland. J. Malac. Soc. Austral. 2 (1): 55-81.

PONDER, W. F., 1973. The origin and evolution of the Neogastropoda. Malacologia 12(2): $295-338$.

PONDER, W. F., 1998. Family Marginellidae.in Beesley, P. L., Ross, G. J. B. \& Wells, A. Mollusca: The Southern Synthesis. Fauna of Australia. Vol 5. Part B, CSIRO Publishing, Melbourne. pp.: $838-841$.

PONDER, W. F. \& LINDBERG, D. R., 1997. Towards a phylogeny of gastropod molluscs - a preliminary analysis using morphological characters. Linn. Soc. Journ. (Zool.), Londres, 119: 83-265.

PONDER, W. F. \& LINDBERG, D. R., 1996. Gastropod phylogeny - challenges for the 90s. In TAYLOR., J. (ed.), Origin and evolutionary radiation of the Mollusca. Oxford. pp. 135-154.

PONDER, W. F. \& TAYLOR, J. D., 1992. Predatory shell drilling by two species of Austroginella (Gastropoda: Marginellidae). J. Zool. 228: 317 - 328.

REDFIELD, J. H., 1870. Catalogue of the Known Species, Recent and Fossil, of the Family Marginellidae. Am. J. Conch., Philadelphia, 6 (2): 215-269.

RIPPEL, O. C., 1988. Fundamentals of comparative biology. Birkhauser Verlag, Basel, Boston \& Berlin. 202pp.

RIOS, E. C., 1985. Seashells of Brazil. 329 pp., 102 pls.. Museu Oceanográfico da Fundação Universidade do Rio Grande, Rio Grande.

ROSENBERG, G. 2006. Malacolog 4.1.0: A database of Western Atlantic marine Mollusca. [WWW database (version 4.1.0)] URL http://data.acnatsci.org/wasp; The academy of Natural Sciences, Philadelphia. 
SACCO, F., 1890. I Molluschi dei Terreni Terziarii del Piemonte e della Liguria Descritti da Luigi Bellardii. Part 6 (Volutidae, Marginellidae, Columbellidae). Mem. Real. Accad. Sci. Torino ser. 2, Torino, 40: 295-368.

SCHELTEMA, R. S., 1971. Larval Dispersal as a Mean of Genetic Exchange between Geographically Separated Populations of Shallow Water Benthic Marine Gastropods. Biol. Bull. Ma. Biol. Lab., Woods Hole, 140: 284-322.

SCHELTEMA, R. S., 1978. On the Relation between Dispersal of Pelagic Veliger Larvae and the Evolution of Marine Prosobranch Gastropods. In BATTAGLIA, B. \& BEARDMORE, J. A. (ed.). Marine Organisms, pp. 303-322. Plenum Publishing co., New York.

SCHUMACHER, C. F., 1817. Essais d'un Nouveau Systeme de Habitation des vers Testacés. Schultz, Copenhagen. iv +287 pp., 22 pr.

SIMONE, L.R.L., 1997. Morphology of the Western Atlantic Haliotidae (Gastropoda, Vetigastropoda) with description of a new species from Brazil. Malacologia, Chicago, 39 (1-2): 59-75.

SIMONE, L. R. L., 1999. Comparative morphology and systematics of Brazilian Terebridae (Mollusca, Gastropoda, Conoidea), with descriptions of three new species. Zoosystema, Paris, 21(2): 199-248.

SIMONE, L. R. L., 2001. Phylogenetic analyses of Cerithioidea (Mollusca, Caenogastropoda) based on comparative morphology. Arq. Zool., São Paulo, 36 (2): 147-263.

SIMONE, L. R. L., 2002. Comparative morphological study and phylogeny of representatives of the Superfamily Calyptraeoidea (including Hipponicoidea) (Mollusca, Caenogastropoda). Biota Neotropica, Campinas, 2 (2): 1-137.

SMITH, E. A., 1915. Mollusca. Part I - Gastropoda Prosobranchia, Scaphopoda and Pelecypoda. Nat. Hist. Rep. Br. Antarct. Terra Nova Exped.., London, 2 (4): 61112.

SOHL, N. F. 1963. New gastropod genera from the late Upper Cretaceous of the the east Gulf Coastal Plain. J. Paleo. 37(4): 747 - 757. 
SOUZA, P. J. S., 1992. A new species of Marginellid (Gatropoda: Prosobranchia) from the North coast of Brazil. J. conch, Lond., London, 34: 237-242.

SOUZA, P. J. S., 1997. A Tribo Marginellini Fleming, 1828 na Costa do Brasil (Mollusca, Gartropoda, Marginellidae). Tese de Mestrado, Museu Nacional, UFRJ, Rio de Janeiro, xiii+79 p.

SOUZA, P. J. S. \& COOVERT, G. A. 2001. Revision of the Recent Bullata Jousseaume, 1875 (Gastropoda: Marginellidae) with the description of two new species. Nautilus, Sanibel, 115 (1): 1-14.

SOWERBY, G. B., II, 1846. Monograph on the Genus Marginella. In Thesaurus Conchyliorum or Figures and Descriptions of Recent Shells. Vol. 1. 239-406 pp.. Sowerby, London.

STEINER, G. 1992. Phylogeny and Classifiction of Scaphopoda. J. Moll. Stud., London, 58: $385-400$.

STIMPSON, W., 1865. On Certain Genera and Families of Zoophagous Gasteropods. Am. J. Conch., Philadelphia, 1 (1): 55-64.

SWAINSON, W., 1840. A Treatise on Malacology, or Shells and Shellfish. vii, 419 pp., 130 figs. Longman, Orme, Brown, Green, and Longmans and John Taylor, London.

SWOFFORD, D. L., 2002. PAUP*: Phylogenetic Analysis Using Parsimony (and Other Methods). Versão 4.0 Beta. CD-ROM. Florida State University, Tallahassee.

SWOFFORD, D. L. \& MADDISON, W. P., 1987. Reconstructing ancestral character states under Wagner parsimony. Math. Biosci. 87:199-229.

THIELE, J., 1929-1931. Handbuch der Systematischen Weichtierkunde. 778 pp. Gustav Fischer, Jena.

TILliER, S., MASSELOT, M., GUERDOUX, J., TILLIER, A., 1994. Monophyly of major gastropod taxa tested from partial 28S rRNA sequences, with emphasis on Euthyneura and hot-vent limpets Peltospiroidea. Nautilus, Sanibel, suppl. 2: 122140. 
TILliER, S., MASSElOT, M., PHILIPPE, H., J., TILlIER, A., 1992. Phylogénie Moléculaire des Gastropoda (Mollusca) fondée sur le séquençage partiel de l'ARN ribosomique 28S. C. r. hebd. Séanc. Acad. Sci., Ser. 3, Paris, 134: 79-85.

TOMLIN, J. R., 1917. A Systematic List of the Marginellidae. Proc. Malac. Soc. Lond., London, 12 (5): 242-306.

TOMLIN, J. R., 1918. A Systematic List of the Fossil Marginellidae. Proc. Malac. Soc. Lond, London, . 13 (3): 41-65.

TRACEY, S., TODD, J. A. \& ERWIN, D. H., 1993. Chapter 8: Mollusca: Gastropoda. In: Benton, M. J. Ed. The Fossil Record. Pp.: 131 - 167. Chapman \& Hall, Londres.

TRYON, G. W., Jr., 1882-1883. Manual of Conchology: Structural and Systematics Vol. 5. 276 pp.,. 32 pls. Tryon, Philadelphia.

VOIGHT, J. R., 1993. A cladistic reassessment of ocotopodid classification. Malacologia, Chicago, 35(2): 343-349.

WAGNER, P. J., 2001. Gastropod phylogenetics: progress, problems, and implications. $J$. Paleont., Iowa, 75(6):1128-1140

WATROUS, L. E. \& WHEELER, Q. D., 1981. The out-group comparison method of character analysis. Syst. Zool., London, 30: 1-11.

WEINKAUFF, H. C., 1879. Die Gattungen Marginella und Erato. In MARTINI \& CHEMINITZ Systematisches Conchylien-Cabinet von Martini und Chemnitz. 2 ed. Vol. 5, pt. 4.. Bauer und Raspe, Nurenberg. 166 pp., 26 pr.

WENZ, W., 1938-1943. Gastropoda, Allgemeiner Teil und Prosobranchia. in O. H. SCHIENDEWOLF, ed., 1938-1944, Handbuch der Palozoologie 6: (1-3) (1938): 1480; (4-5) (1939): 481-720; (6) (1940): 721-960; (7) (1941): 961-1200; (8) (1943): 1201-1506; (9) (1944): 1507-1639, i-xii. Verlag von Gerbrüder Borntraeger, Berlin.

WINNER, B. E., 1983. The Direct Development of Marginella (Prunum) apicinum. Of Sea and Shore, Washington, 13 (1): 37-38.

WILEY, E. O., 1981. Phylogenetics: The Theory and Pratice of Phylogenetic Systematics. John Wiley \& sons, New York. xiii +439 pp. 
WILEY, E. O., SIEGEL - CAUSEY, D., BROOKS, D. R. \& FUNK, V.A., 1991. The Compleat Cladist: A Primer of Phylogenetic Procedures. The University of Kansas Museum of Natural History, Lawrence. (Special Publication No. 19). x + 158 pp.

WILKINSON, M., 1992. Ordered versus unordered Characters. Cladistics, New York, 8: 375-385.

WINNPENNINCKX, B.; BACKELJAU, T. \& DE WACHTER, R., 1994. Small ribosomal subunit RNA and the phylogeny of the Mollusca. Nautilus, Sanibel, suppl. 2: 98-110.

WINNPENNINCKX, B.; BACKELJAU, T. \& DE WACHTER, R., 1996. Investigation of Mollusca phylogeny on the basis of $18 \mathrm{~S}$ rRNA sequences. Molec. Biol. Evol., Halifax, 13: 1306-1317.

WOODRING, W. P., 1970. Geology and Paleontology of Canal Zone and Adjoining Parts of Panama: Description of Tertiary Mollusks (Gastropods: Eulimidae, Marginellidae to Helminthoglyptidae). Prof. Pap. U.S. geol. Surv., Washington, 306-D: 299-452. 